\title{
Envejecimiento demográfico y actividad agraria en el Valle de Gistaín
}

\author{
M. ${ }^{\text {a }}$ TeREsa Rubio Benito
}

\section{APROXIMACIÓN METODOLÓGICA Y FUENTES}

Para la realización del estudio demográfico del Valle de Gistaín hemos consultado los Censos Generales, Padrones Municipales, Rectificaciones de los Padrones de Población, Boletines Estadísticos de Parto y de Defunciones publicados por el I.N.E. y las Estadísticas de paro registrado por municipios recogidas por el INEM, además de los datos recogidos en las visitas efectuadas a los Ayuntamientos de la zona.

Hasta 1987 figuran únicamente los municipios de Plan y de San Juan de Plan, y será a partir de esta fecha cuando aparece también Gistaín como municipio independiente de Plan, en los datos referidos a población. No así en los relativos a las actividades agrarias donde todavia permanecen unidos.

Dado que nos movemos con unos efectivos globales de población del valle muy por debajo del millar de habitantes, expresaremos los resultados generalmente en cifras absolutas, salvo en aquellos índices en los que el dato porcentual sea lo suficientemente expresivo, procurando explicar la evolución demográfica del Valle de Gistain en el contexto comarcal del que forma parte:

Despoblamiento continuado desde comienzos del siglo actual hasta nuestros días, aceleración del proceso desde 1960, envejecimiento de sus habitantes y desigual proporción de hombres y mujeres, hechos ambos que dificultan no sólo el crecimiento y la renovación de la población, sino también, la introducción de innovaciones en su actividad económica.

\section{INTRODUCCIÓN}

Situado al Este de la comarca de Sobrarbe en el Alto Aragón, al Norte de la provincia de Huesca, Gistaín es un valle fronterizo de alta montaña 
típicamente pirenaico tanto por el espacio natural donde está enclavado (Pirineo Central), como por la mayoría de las actividades que han desarrollado sus gentes a lo largo de la historia. Caracterizado por su elevada altitud, ofrece al visitante un paisaje de montañas rotundas, como moles, que sobrepasan los 3.000 metros de altura, dominando la vertiente $W$. del río Cinqueta.

En la actualidad el valle está integrado por tres núcleos principales muy próximos entre sí, Gistaín, Plan y $\mathrm{S}$. Juan de Plan y otras entidades menores como Señés, Serveto, Saravillo y S. Mamés que dependen de Plan, lo mismo que ocurría con Gistaín hasta el año 1987 en que se segregó, constituyendo un nuevo municipio con ayuntamiento propio.

Todos los núcleos poblados están situados a más de 1.000 metros de altura, destacando sobre todo el emplazamiento de Gistaín a 1.378 metros. La altitud, el clima, las fuertes pendientes y la dificultad de las comunicaciones han condicionado desde antiguo el poblamiento, la actividad de sus habitantes y la evolución del valle, dentro de la comarca a la que haremos continua referencia.

La población total del Valle, estabilizada desde la década de los 80 en torno a los 700 habitantes, va perdiendo efectivos de forma natural e inexorable debido al gran envejecimiento que padece, característica común, por otra parte, de las áreas de alta montaña y de otros espacios hostiles al poblamiento donde el proceso migratorio del siglo $x x$ ha desvertebrado de tal forma la estructura demográfica, que sus comunidades carecen irremediablemente de generación de reemplazo.

RECTIFICACIONES PADRONALES DE LA POBLACIÓN DE DERECHO DEL VALLE DE GISTAÍN, 1981 A 1986

\begin{tabular}{|c|c|c|c|c|c|c|c|}
\hline \multirow{2}{*}{ MUNICIPIO } & \multirow{2}{*}{$\begin{array}{c}\text { CENSO } \\
1981\end{array}$} & \multicolumn{5}{|c|}{ RECTIFICACIONES PADRONALES } & \multirow{2}{*}{$\begin{array}{c}\text { PADRÓN } \\
1986\end{array}$} \\
\hline & & 1982 & 1983 & 1984 & 1985 & 1987 & \\
\hline Plan & 569 & 563 & 569 & 551 & 543 & 545 & 544 \\
\hline $\begin{array}{l}\text { S. Juan } \\
\text { de Plan }\end{array}$ & 177 & 178 & 176 & 173 & 175 & 174 & 171 \\
\hline $\begin{array}{l}\text { Tot. va. } \\
\text { Gistaín }\end{array}$ & 746 & 741 & 745 & 724 & 718 & 719 & 715 \\
\hline $\begin{array}{l}\text { Tot. Pr. } \\
\text { Huesca }\end{array}$ & 214.907 & 215.834 & 216.382 & 216.532 & 216.413 & 210.257 & 210.094 \\
\hline
\end{tabular}

Fuente: Censos y Padrones de Población. INE. Elaboración propia. 
POBLACIÓN DE DERECHO. VALLE DE GISTAÍN

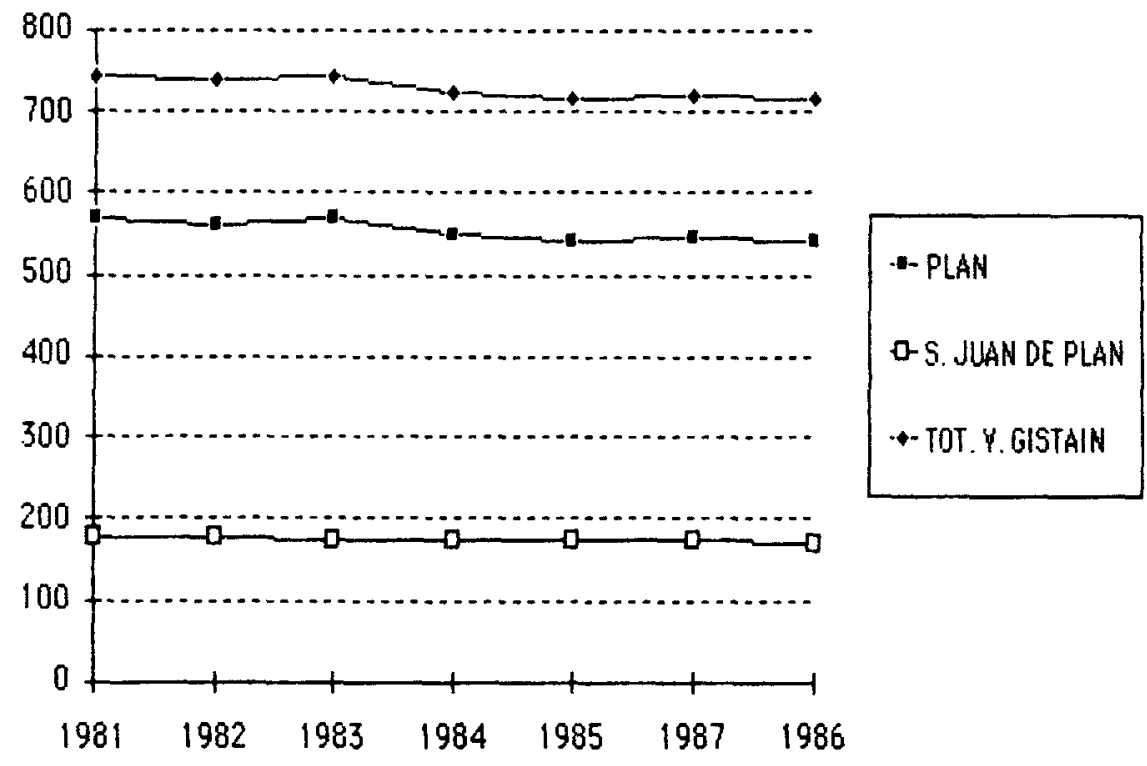

Fuente: Censos y Padrones de Población. INE. Elaboración propia.

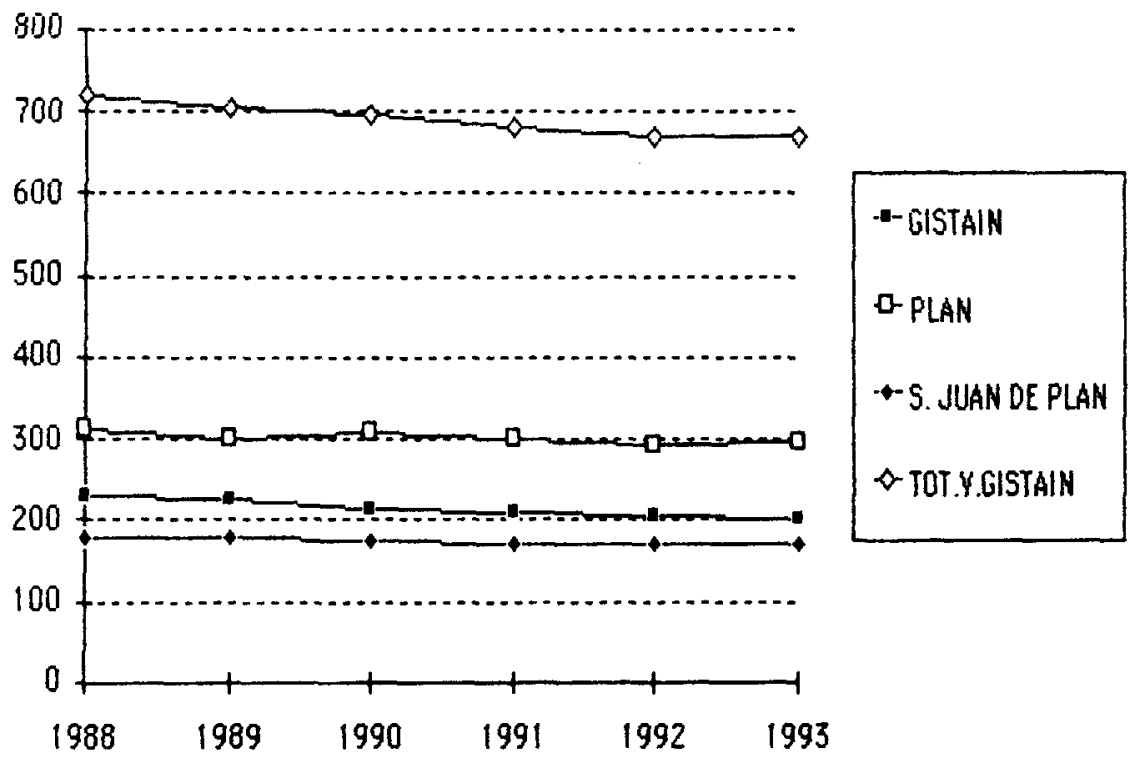


RECTIFICACIÓN DEL PADRÓN MUNICIPAL DE HABITANTES. AÑOS 1988, 1989, 1990, 1992 Y 1993. CENSO DE 1991

\begin{tabular}{|c|c|c|c|c|c|c|}
\hline AÑOS & POBLACIÓN & GISTAIIN & PLAN & $\begin{array}{l}\text { S. JUAN } \\
\text { DE PLAN }\end{array}$ & $\begin{array}{l}\text { TOTAL V. } \\
\text { DE GISTAIN }\end{array}$ & $\begin{array}{c}\text { TOTAL } \\
\text { PROVINCIAL }\end{array}$ \\
\hline \multirow{3}{*}{1988} & Varones & 130 & 171 & 104 & 405 & 106.314 \\
\hline & Mujeres & 100 & 142 & 75 & 317 & 104.608 \\
\hline & Total & 230 & 313 & 179 & 722 & 210.922 \\
\hline \multirow{3}{*}{1989} & Varones & 128 & 165 & 105 & 398 & 106.285 \\
\hline & Mujeres & 96 & 137 & 75 & 308 & 104.462 \\
\hline & Total & 224 & 302 & 180 & 706 & 210.747 \\
\hline \multirow{3}{*}{1990} & Varones & 122 & 165 & 102 & 389 & 106.289 \\
\hline & Mujeres & 92 & 142 & 74 & 308 & 104.430 \\
\hline & Total & 214 & 307 & 176 & 697 & 210.719 \\
\hline \multirow{3}{*}{1991} & Varones & 118 & 164 & 97 & 379 & 104.684 \\
\hline & Mujeres & 92 & 137 & 73 & 302 & 103.126 \\
\hline & Total & 210 & 301 & 170 & 681 & 207.810 \\
\hline \multirow{3}{*}{1992} & Varones & 117 & 163 & 97 & 377 & 104.990 \\
\hline & Mujeres & 89 & 132 & 72 & 293 & 103.400 \\
\hline & Total & 206 & 295 & 169 & 670 & 208.390 \\
\hline \multirow{3}{*}{1993} & Varones & 116 & 166 & 96 & 378 & 105.583 \\
\hline & Mujeres & 87 & 131 & 74 & 292 & 103.982 \\
\hline & Total & 203 & 297 & 170 & 670 & 209.565 \\
\hline
\end{tabular}

Fuente: Rectificación Padrones de Población y Censo INE. Elaboración propia.

El imponente anfiteatro montañoso que conforma Sobrarbe con los valles dispuestos en abrupto abanico convergiendo en un punto, impide todo recorrido transversal de cauce a cauce, de manera que resulta obligado el tránsito longitudinal de los ríos hasta ese punto de encuentro en donde se establece Aínsa, la cabecera de comarca, y muy próxima, Boltaña, sede de los servicios administrativos del área que reúnen las concentraciones humanas más importantes de Sobrarbe.

Esta accidentada topografía que condiciona a la vez una gran parte de las actividades de sus gentes, se suaviza a medida que se avanza hacia el Sur, ya que las sierras van perdiendo altura con la presencia de amplios valles transversales, en donde los ríos Ara, Ena, Nata y Cinca han forma- 
do una cubeta topográfica que abre el paso a las tierras cultivables donde se asientan los núcleos de población, la industria y las principales vias de comunicación.

\section{MÁXIMOS Y MINIMOS DE POBLACIÓN}

En una población cuyos efectivos demográficos decrecen de manera continuada desde hace un siglo, es dificil fijar con precisión unos mínimos que alcanzan hoy su máxima expresión y que, por otra parte, avanzan en cada año intercensal. Por el contrario, es más fácil destacar los momentos de máxima y algunas de las causas que los hicieron posibles.

La comarca del Sobrarbe alcanzó su máximo poblacional en 1920 con 19.519 habitantes, bajando diez años más tarde a 17.704 habitantes y estabilizándose en torno a ese número (ver cuadro 5 ) en los años correspondientes a la guerra civil y en el período de postguerra gracias a las obras de ingeniería civil que se abordaron que repercutieron especialmente en la cabecera de comarca de los altos valles.

Efectivamente, la construcción en 1918 del tramo final de la carretera Aínsa-Bielsa y también de la presa Pineta en esa misma época, supuso un crecimiento extraordinario de Bielsa que pasó de contar con 861 habitantes en 1910 a 1.856 habitantes en 1920 . Esta cifra trascendía el ámbito local repercutiendo en el comarcal, ya que en ese año Sobrarbe, como hemos comentado, alcanzó su nivel más alto de población.

Hay que tener en cuenta que toda obra de infraestructura acometida en la montaña ha supuesto siempre la revitalización demográfica porque la contratación temporal de mano de obra adicional a la del valle, se traducia en la llegada de centenares de personas jóvenes, muchos de los cuales se quedaban a vivir allí definitivamente.

Las obras hidroeléctricas acometidas en los ríos Cinca y Cinqueta, así como las actividades madereras y derivadas, consiguieron retener a la población, al menos temporalmente. Es el caso de los municipios que integran el valle de Chistau: Gistaín, Plan y S. Juan de Plan. Lo mismo podemos decir del vecino municipio de Tella-Sin, en el valle de Sin, cuyo número de habitantes aumentó tras la apertura de la central eléctrica de Lafortunada con la creación de puestos de trabajo que en la actualidad mantienen ocupada a buena parte de la población activa en la empresa Iberduero.

En 1930 los municipios más vitales: Aínsa, Bielsa, Boltaña, Broto y Fiscal superaban el millar de habitantes y La Fueva los 2.200 habitantes. 
Por aquel entonces, la construcción de las presas del Barranco y Collado de Urdiceto contribuyeron a mantener un nivel de población semejante al de 1900. Años después, la guerra civil española y la crisis económica y social que sufrió el campo en los años cincuenta marcarían definitivamente el desarrollo comarcal.

El aumento del número de nacimientos diferidos por el conflicto béli$\mathrm{co}$, inició una breve recuperación demográfica que se puso de manifiesto en el censo de 1950 donde se alcanzan los 16.581 habitantes. Esta recuperación fue muy breve, ya que coincidió con el inicio del proceso de despoblación del campo que sacudiría a nuestro país en los próximos decenios.

A partir de entonces, Sobrarbe se vacía de forma inexorable, de forma que hoy es la comarca del Alto Aragón más castigada por la emigración, sobre todo en las zonas altas del interfluvio Ara-Cinca (Puértolas, Fanlo, Valle de Solana), donde el índice de pérdida poblacional se aproxima al $90 \%$ del total de habitantes.

En cualquier caso, aparte de estas zonas extraordinariamente deprimidas convertidas en un auténtico desierto demográfico, el índice de variación en la evolución intercensal de la población del Sobrarbe entre 1960 y 1986 indica que han desaparecido más de la mitad de sus habitantes, arrojando un saldo negativo próximo al 55\% $(-54,82 \%)$.

Situación parecida encontramos en las franjas limítrofes de Sobrarbe por el Oeste y el Sudeste. Estas zonas han sufrido una despoblación brutal, superior al $65 \%$ que ha conducido a que municipios enteros, incluso valles enteros, estén vacios de tal forma que la población de hecho de la comarca, 6.008 habitantes según el censo de 1991, arroja una densidad de 2,88 habitantes por kilómetro cuadrado con un índice de dispersión superior al $107 \%$.

\section{DENSIDAD DE POBLACIÓN}

El número de habitantes por kilómetro cuadrado que expresa la densidad de población enmascara muchas veces la realidad, ya que, como en esta comarca, hay que contar con las posibilidades del medio natural que cuenta con la presencia de poderosas moles pirenáicas que limitan por su altitud y condiciones fisioclimáticas, la posibilidad de asentamientos humanos. No obstante, y a pesar de contar con estas circunstancias, quedan patentes grandes espacios vacíos de población que se van degradando progresivamente por la ausencia de gestores «in situ». 
La comarca del Sobrarbe, al igual que las de alta montaña, ha mantenido desde antaño una densidad de población débil, muy por debajo de la media provincial, aunque sin llegar a los extremos que se ponen de manifiesto en la evolución intercensal del período más crítico, considerado a partir del año 1960, plasmado en el siguiente cuadro:

\section{EVOLUCIÓN INTERCENSAL DE LA POBLACIÓN DE DERECHO Y DENSIDAD DE POBLACIÓN DE LA COMARCA DEL SOBRARBE} (HUESCA)

\begin{tabular}{|c|c|c|c|c|c|c|c|c|c|c|c|c|}
\hline \multirow{2}{*}{ COMARCA } & \multirow{2}{*}{$\begin{array}{c}\text { SUPER } \\
K M^{i}\end{array}$} & \multicolumn{2}{|c|}{1960} & \multicolumn{2}{|c|}{1970} & \multicolumn{2}{|c|}{1981} & \multicolumn{2}{|c|}{1986} & \multirow{2}{*}{$\begin{array}{l}\% \text { VAR. } \\
\text { POBL. } \\
1986 / 60\end{array}$} & \multicolumn{2}{|c|}{1991} \\
\hline & & HAB. & DEN. & HAB. & DEN. & HAB. & DEN. & HAB. & DEN. & & HAB. & DEN. \\
\hline Sobrarbe & $2.077,7$ & 14.603 & 7,03 & 9.039 & 4,35 & 6.847 & 3,30 & 6.598 & 3,18 & $-54,82$ & 6.389 & 3,08 \\
\hline Total prov. & $15.612,8$ & 234.014 & 14,99 & 221.761 & 14,20 & 214.907 & 13,76 & 210.094 & 13,46 & $-10,22$ & 207.810 & 13,31 \\
\hline
\end{tabular}

Fuente: Censos de Población INE. Elaboración propia.

La densidad de la comarca del Sobrarbe al principio del período se situaba en $(7,03)$, la mitad de la correspondiente al total provincial $(14,99)$, mantenido hasta entonces dentro del margen que arrojaba la densidad nacional media. Será a partir de los años 70 cuando toda la provincia de Huesca acuse un descenso de población que afectará de lleno a la estructura de la misma, aunque en las cifras de densidad el resultado no sea $\tan$ grave, ya que el descenso es moderadamente progresivo: 13,76 en 1981 y 13,23 en 1993.

No sucede así en el caso de Sobrarbe, donde el efecto es fulminante en tan sólo veinte años, ya que, de 1960 a 1981, la densidad de población se rebajó en más de un $50 \%$, situándose en 3,30 habitantes por kilómetro cuadrado. A partir de entonces el proceso de despoblamiento continúa, como puede apreciarse claramente en el siguiente gráfico, pero se hace más lento y se ajusta en la actualidad a la pérdida de efectivos por defunción, correspondiente al movimiento natural de una población fuertemente envejecida.

La distribución de estos habitantes en los $2.084 \mathrm{~km}$. de Sobrarbe no es homogénea, dándose núcleos y las densidades más altas cerca de las principales vías de comunicación, que salvo la que cruza la Fueva, paralela a Sierra Ferrera y Peña Montañesa, siguen el curso de los ríos. 
DENSIDAD DE POBLACIÓN. SOBRARBE

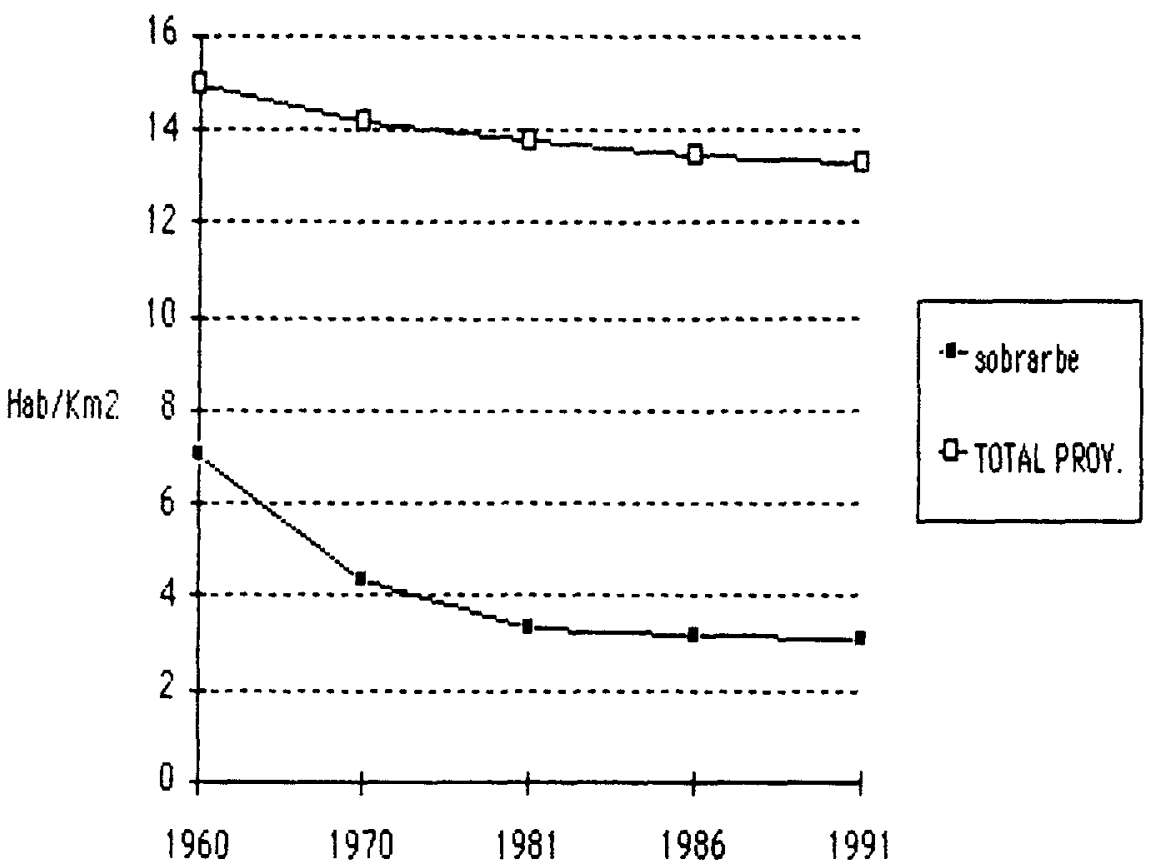

Fuente: Censos de Población INE. Elaboración propia.

Efectivamente, los 6.369 habitantes del Sobrarbe en 1993 viven en pardinas, aldeas, pueblos y villas agrupados en municipios y repartidos a lo largo de los dos valles fluviales definidores de este espacio: El Ara y el Cinca, donde se asientan Aínsa y Boltaña, los núcleos más poblados y con mejores infraestructuras.

El Valle de Gistain en su conjunto, ha seguido una evolución parecida a la comarcal, con una caída brusca de población entre los años 19601970 y una pérdida sostenida a partir de los años 80, llegando a estabilizarse en 1992 y 1993 en una densidad de 3,05 habitantes por kilómetro cuadrado, cifra semejante a la de Sobrarbe, aunque en 1960 arrancase con 5,63 , punto y medio por debajo de la comarca $(7,03)$.

Hasta el año 1987 la población del núcleo de Gistaín aparece censada en el municipio de Plan al que pertenecia, por lo cual la densidad de Plan en 1960, con 5,93 habitantes para un territorio de $92,1 \mathrm{~km}^{2}$ está por encima de la realidad. 
EVOLUCIÓN DE LA DENSIDAD DE POBLACIÓN. VALLE DE GISTAÍN

\begin{tabular}{|c|c|c|c|c|c|}
\hline \multirow{2}{*}{ AÑOS } & GISTAIN & PLAN & $\begin{array}{c}\text { S. JUAN DE } \\
\text { PLAN }\end{array}$ & $\begin{array}{c}\text { TOTAL } \\
\text { VALLE }\end{array}$ & $\begin{array}{c}\text { TOTAL } \\
\text { PROVINCIA }\end{array}$ \\
\cline { 2 - 6 } & $76,4 \mathrm{~km}^{2}$ & $92,1 \mathrm{~km}^{2}$ & $51,2 \mathrm{~km}^{2}$ & $219,7 \mathrm{~km}^{2}$ & $15.612,8 \mathrm{~km}^{2}$ \\
\hline 1960 & (en Plan) & 5,93 & 4,61 & 5,63 & 14,99 \\
\hline 1970 & Ídem & 4,98 & 4,00 & 4,75 & 14,20 \\
\hline 1975 & Ídem & 4,06 & 3,73 & 3,98 & 13,71 \\
\hline 1981 & Ídem & 3,38 & 3,46 & 3,40 & 13,76 \\
\hline 1986 & Ídem & 3,23 & 3,34 & 3,25 & 13,46 \\
\hline 1987 & Ídem & 3,23 & 3,40 & 3,27 & 13,47 \\
\hline 1988 & 3,01 & 3,40 & 3,50 & 3,29 & 13,51 \\
\hline 1989 & 2,93 & 3,28 & 3,52 & 3,21 & 13,50 \\
\hline 1990 & 2,80 & 3,33 & 3,44 & 3,17 & 13,50 \\
\hline 1991 & 2,75 & 3,27 & 3,32 & 3,10 & 13,31 \\
\hline 1992 & 2,70 & 3,20 & 3,30 & 3,05 & 13,35 \\
\hline 1993 & 2,66 & 3,22 & 3,32 & 3,05 & 13,23 \\
\hline
\end{tabular}

Fuente: Censos 1960, 1970, 1981 y 1991, Padrones 1975 y 1986. Rectificaciones del Padrón 1987 a 1993. INE y elaboración propia.

No obstante, como hemos señalado, el fuerte descenso se aprecia en los primeros censos, manteniéndose después más o menos constante desde 1981 entre valores de 3,30 y 3,40 en Plan y S. Juan de Plan, con algunas pulsaciones positivas, de recuperación, sobre todo si comparamos las cifras del último sexenio en los tres pueblos. Gistaín aparece en 1988 con una densidad de 3,01 , cifra ésta en continuo descenso, situándose en 1993 en 2,66 habitantes por kilómetro cuadrado.

\section{DISTRIBUCIÓN DEL HÁBITAT}

Es sabido que la disposición altitudinal del hábitat refleja simultáneamente condiciones de relieve, clima y ocupación del suelo. Las viviendas de estos montañeses, agricultores y ganaderos, cuyas técnicas de producción apenas sí han podido beneficiarse de los avances y mejoras de las últimas décadas, se emplazan en lugares próximos a los campos de cultivo, actividad principal de la población, tal y como se viene haciendo tradicionalmente.

Dado que la mayor parte de los cereales no soporta alturas superiores a los 1.200 y 1.300 metros, es a partir de esta altitud cuando los 
establecimientos humanos tienden a desaparecer, aunque la exposición supone variaciones importantes. Una cuarta parte de la población del Sobrarbe vive por encima de los 1.000 metros, soportando condiciones climáticas duras; sin embargo, éste es un porcentaje corriente en el Pirineo, actualmente y en épocas pasadas, cuando el despoblamiento no había vaciado por completo algunos pueblos.

Al relacionar el número de entidades de población y la superficie del término municipal, se aprecia que los grandes municipios del Norte, de accidentado y elevado relieve, cuentan en términos relativos con el menor número de núcleos. Desde este punto de vista el agricola valle de La Fueva, El Pueyo de Araguás y Aínsa-Sobrarbe serían con diferencia los tres municipios con mayor densidad de núcleos de población.

La población de Sobrarbe vive diseminada en un buen número de minúsculos asentamientos. El más pequeño es el denominado "pardina", explotación agrícola-ganadera familiar aislada en el monte y rodeada de sus campos de cultivo, semejante a sus homólogos, las «masías» catalanas y los "baserriak" vascos. En el nomenclátor del Censo de Población de 1981, se considera que "edificación diseminada» es la constituida por menos de 10 edificaciones contiguas. En 1981 un alto porcentaje de población vivía en este tipo de construcciones.

Los municipios pueden tipificarse según engloben uno o varios núcleos de población dentro del término, y según el tamaño o importancia relativa de estos últimos. Palo y $\mathrm{S}$. Juan de Plan, por ejemplo, son mononucleares; el primero por su reducido tamaño, y el segundo, por ser lo suficientemente importante como para dotarse de una organización autónoma.

En el mismo caso que el de $\mathrm{S}$. Juan podemos incluir a Gistaín desde 1987, sin embargo Plan, el tercero de los municipios del valle de Gistaín, acoge a dos entidades menores, Serveto y Saravillo y pasa a formar parte con los restantes municipios de la comarca del tipo polinuclear o mixto.

Se denominan así, porque en ellos coexisten pardinas, aldeas y pueblos en una amplia gama de situaciones. Con frecuencia los núcleos de población gravitan en torno a una localidad mayor que es la capital y da nombre al término, como Bielsa o Broto; otras veces, la importancia del pueblo es similar o mayor que la de la propia capital y da nombre al término, como Puértolas (Escalona) o Tella-Sin (Lafortunada).

La distribución de los municipios de la comarca según su número de habitantes ha ido evolucionando a través de distintos años censales. Consideramos importante arrancar desde 1960 hasta nuestros días para 
seguir de cerca la atomización producida en la práctica totalidad de los municipios de la comarca.

El número de núcleos permanece invariable en 17, aunque sus habitantes no lleguen en 1991 ni al 50\% de los existentes hace treinta años. Lo que si ha cambiado de forma radical ha sido su distribución. Ha aumentado el número de municipios en los intervalos más bajos, esto es, los comprendidos entre los 100 o menos, y de 100 a 500 habitantes y ha disminuido a partir del umbral de 501 a 1.000 habitantes.

DISTRIBUCIÓN DE LOS MUNICIPIOS POR EL NÚMERO DE HABITANTES DE DERECHO. COMARCA DEL SOBRARBE (HUESCA)

\begin{tabular}{|c|c|c|c|c|c|c|c|c|c|c|c|c|}
\hline \multirow{2}{*}{ CENSO } & \multicolumn{2}{|c|}{$<100$} & \multicolumn{2}{|c|}{$100-500$} & \multicolumn{2}{c|}{$501-1.000$} & \multicolumn{2}{c|}{$1.001-2.000$} & $2.001-5.000$ & \multirow{2}{*}{ TOT. } & TOT \\
\cline { 2 - 14 } & MUN. & HAB. & MUN. & HAB. & MUN. & HAB. & MUN. & HAB. & MUN. & HAB. & MUN. & HAB. \\
\hline 1960 & 0 & 0 & 5 & 1.454 & 7 & 4.641 & 4 & 5.947 & 1 & 2.561 & 17 & 14.603 \\
\hline 1970 & 1 & 58 & 10 & 3.291 & 4 & 2.873 & 2 & 2.817 & 0 & 0 & 17 & 9.039 \\
\hline 1981 & 2 & 113 & 11 & 3.239 & 3 & 2.258 & 1 & 1.237 & 0 & 0 & 17 & 6.847 \\
\hline 1986 & 2 & 84 & 12 & 3.561 & 2 & 1.615 & 1 & 1.338 & 0 & 0 & 17 & 6.598 \\
\hline 1991 & 2 & 83 & 12 & 3.369 & 2 & 1.510 & 1 & 1.427 & 0 & 0 & 17 & 6.389 \\
\hline
\end{tabular}

Fuente: Censos de Población INE. Elaboración propia.

En 1960, ningún municipio tenía menos de 100 habitantes y uno superaba los 2.500; diez años después, la comarca ha perdido 5.000 personas, se ha inaugurado el listado de municipios por debajo de los 100 individuos, y va a duplicarse tanto el número de habitantes (de 1.454 a 3.291) como el de municipios, que pasan de 5 a 10 en el intervalo siguiente de 100 a 500 , al tiempo que se reducen a la mitad en los demás intervalos desapareciendo definitivamente el umbral de 2.001 a 5.000 habitantes.

Analizando el Padrón de habitantes de 1986 observamos que el municipio con mayor número de entidades es La Fueva con 22 y el menor es Palo y S. Juan de Plan con sólo una. Aínsa es la entidad de población mayor con 887 habitantes y Lacort la menor, con tan sólo dos vecinos.

El porcentaje de entidades según el número de habitantes censados es:

- El 55\% tienen 25 vecinos y menos.

- El 76,52\% tienen 50 vecinos y menos.

- El $88,69 \%$ tienen 100 vecinos y menos.

Sólo existen dos entidades de cierta importancia: Aínsa y Boltaña, claramente distanciadas de las demás, aunque no superan los 900 habitantes. 
Se trata de un paisaje rural moteado por diminutas localidades, muchas con menos de 50 vecinos. Un elevado número de núcleos habitados en 1950 han quedado vacíos en la actualidad, tendiendo la población a concentrarse en los fondos de valle.

Solamente tres municipios de los 17 que conforman actualmente la comarca de Sobrarbe superan los 500 habitantes. Ainsa-Sobrarbe (1.387 hab.), Boltaña (777 hab.) y La Fueva (658 hab.). A partir del censo de 1981 Sobrarbe se mueve con una población total superior a las 6.000 personas, cifra que va disminuyendo alcanzándose 6.389 en 1991. Probablemente en el próximo Padrón se habrá descendido a los 5.000 habitantes.

El reducido tamaño de los asentamientos y la dispersión de los mismos son notas dominantes en la geografía humana del Sobrarbe y conllevan añadidas las dificultades de los vecinos para acceder a las dotaciones e infraestructura urbanas con una aportación municipal escasísima.

De hecho, trazar una nueva carretera, ampliar o reparar la existente, acometer el servicio de alumbrado eléctrico, de la línea telefónica o del alcantarillado, supone un esfuerzo económico superior al que el municipio puede soportar. Asi, muchas de estas mejoras se han llevado a cabo en fechas relativamente recientes, ya que la mayoría de ellas datan de los años 70 .

\section{EL PROCESO MIGRATORIO}

Desde antiguo, los altos valles pirenaicos (como toda montaña de latitudes medias con economía agraria, complementada con un aprovechamiento silvopastoril), han mantenido una densidad de población extremadamente débil y prácticamente estacionaria hasta la década de los años cincuenta.

En esa época, los factores de cambio derivados de la introducción de relaciones de producción capitalista en estas áreas, provocaron un flujo compacto de emigración que ocasionó la reducción del tamaño absoluto de la población rural. Posiblemente se deba considerar que es la montaña la que expulsa una carga humana excesiva para las posibilidades que ofrece, una vez producido el cambio económico. Esta corriente migratoria se aceleró decididamente hasta convertirse en un proceso irreversible de desertización y envejecimiento, a partir de 1960.

Dentro del éxodo migratorio desatado en Sobrarbe durante el siglo actual, pueden distinguirse, entre otros, dos tipos claramente diferenciados. El primero arranca a finales del XIX hasta 1915, tiene carácter temporal y no afecta a toda la población. En efecto, son los "tiones» o «tionas", hermanos solteros del "hereu» quienes únicamente salen del pueblo a pasar 
el invierno trabajando en alguna industria francesa, regresando a casa durante el verano para ayudar en las labores del campo.

El segundo tipo de corriente migratoria tiene carácter definitivo y pueden señalarse dos fases: Una entre 1915 y la Guerra Civil Española, en que el destino no sólo de los montañeses segundones, sino también el de familias enteras de la comarca y del valle de Gistaín fue América o Cataluña.

La última fase arranca desde la guerra civil hasta nuestros días y contempla el desmembramiento del sistema productivo tradicional y el vaciamiento casi total de la población de Sobrarbe; fenómeno este último que puede seguirse en su período más crítico a través de la evolución censal de la comarca desde 1930 hasta la década de los setenta, considerada por los demógrafos como etapa final del proceso migratorio.

EVOLUCIÓN DE LA POBLACIÓN DE SOBRARBE: 1930-1970

\begin{tabular}{|l|r|r|r|r|r|}
\hline \multicolumn{1}{|c|}{ MUNICIPIOS } & \multicolumn{1}{c|}{1930} & \multicolumn{1}{c|}{1940} & \multicolumn{1}{c|}{1950} & \multicolumn{1}{c|}{1960} & \multicolumn{1}{c|}{1970} \\
\hline Aínsa & 1.888 & 1.721 & 1.889 & 1.482 & 1.261 \\
\hline Albella, Jánovas & 846 & 831 & 743 & 594 & 214 \\
\hline Bielsa & 1.232 & 781 & 900 & 711 & 621 \\
\hline Boltaña & 1.601 & 1.503 & 1.997 & 1.460 & 1.076 \\
\hline Broto & 1.361 & 1.148 & 1.242 & 1.013 & 674 \\
\hline Fanlo & 628 & 535 & 578 & 524 & 154 \\
\hline Fiscal & 1.056 & 943 & 905 & 743 & 270 \\
\hline Forad. del Toscar & 562 & 503 & 510 & 421 & 353 \\
\hline La Fueva & 2.247 & 2.160 & 2.131 & 1.672 & 1.008 \\
\hline Gistaín & 739 & 518 & 585 & 565 & 363 \\
\hline La Buerda & 389 & 387 & 327 & 297 & 245 \\
\hline Laspuña & 554 & 461 & 468 & 529 & 379 \\
\hline Liñás de Broto & 360 & 335 & 308 & 222 & 139 \\
\hline Mediano & 321 & 358 & 586 & 179 & 93 \\
\hline Palo & 262 & 254 & 225 & 147 & 58 \\
\hline Plan & 615 & 500 & 477 & 425 & 452 \\
\hline Puértolas & 826 & 690 & 724 & 640 & 298 \\
\hline Pueyo d. Araguás & 490 & 470 & 445 & 378 & 244 \\
\hline San Juan de Plan & 265 & 265 & 257 & 236 & 204 \\
\hline Tella-Sin & 931 & 642 & 823 & 595 & 436 \\
\hline Torla & 531 & 397 & 461 & 374 & 287 \\
\hline TOTALES & 17.704 & 15.402 & 16.581 & 13.207 & 8.829 \\
\hline
\end{tabular}

Fuente: Censos de Población I.N.E. Elaboración propia. 
Comenzó con la salida de los primeros vecinos que poco a poco fueron llamando primero a la familia, y más tarde a los amigos, de manera que en los pueblos quedó una población vieja, desarticulada social y funcionalmente.

En el censo de 1950 la comarca todavía cuenta con 16.851 habitantes, pero es a partir de esta segunda mitad de siglo cuando las cifras de población se disparan, de forma que en 1960 el territorio estaba habitado por 13.207 habitantes y el Censo de 1970 con 8.829 habitantes. La población de Sobrarbe había reducido en un $50 \%$ sus efectivos respecto a los años cincuenta. El descenso continuaba imparable.

La reducción de los efectivos demográficos de la Ribera de Fiscal repercutió a su vez en la disminución de la clientela del comercio y servicios de Boltaña, Broto y Aínsa. Dada la escasa población existente, se cuestionó el mantenimiento de algunos servicios clave para la vida de la Comunidad: maestro, médico, secretario de Ayuntamiento, cuya desaparición supuso para el municipio un deterioro tal en la calidad de vida de sus habitantes, que aceleró la emigración de los que todavía quedaban.

En 1960 Bielsa ha descendido a 711 habitantes, aunque las pérdidas más espectaculares se aprecian en los núcleos más poblados. Es el caso de Aínsa que pasa de 1.889 habitantes en el decenio anterior a 1.482 habitantes, y La Fueva de 2.131 a 1.672 habitantes, o el de Boltaña, que pierde 500 habitantes en el mismo período.

Este proceso de despoblamiento fue aprovechado en algunos casos por los organismos públicos para la ampliación del Patrimonio Forestal del Estado, que adquirió $6.800 \mathrm{Has}$. del paraje conocido por La Solana ocupado por 13 aldeas y 53 hogares entre los años 50 y 60 . En esta misma década se gestó la compra de los campos de labor situados junto a los ríos Ara y Cinca para hacer los embalses de Mediano y Jánovas (este último inexistente todavía).

Los problemas territoriales se acusan cuando la comunidad pierde tal número de activos de población joven, que su capacidad productiva queda gravemente dañada. El ritmo de envejecimiento ya sea lento o rápido, va expulsando a los elementos jóvenes que todavía se resisten a dejar el pueblo, y que, finalmente, ceden.

La demanda de una agricultura moderna e industrializada supuso un fuerte reto difícilmente alcanzable para los altos valles pirenáicos, con economía agropastoril, graves carencias de equipamientos y explotaciones familiares, cuya organización social y económica se basa en la institución de «la casa». La renta agro-ganadera fue mermando a la par que 
las perspectivas patrimoniales del "hereu", que pronto dejó de ser un aliciente casadero. A partir de entonces, la emigración fue indiscriminada.

\section{EVOLUCIÓN DE LA POBLACIÓN DE DERECHO. VALLE DE GISTAÍN.} CENSOS: 1960, 1970 Y 1981. PADRÓN DE 1975 Y 1986

\begin{tabular}{|l|r|r|r|r|r|}
\hline \multicolumn{1}{|c|}{ MUNICIPIO } & $\begin{array}{c}\text { CENSO } \\
1960\end{array}$ & $\begin{array}{c}\text { CENSO } \\
1970\end{array}$ & $\begin{array}{c}\text { PADRÓN } \\
1975\end{array}$ & $\begin{array}{c}\text { CENSO } \\
1981\end{array}$ & $\begin{array}{c}\text { PADRÓN } \\
1986\end{array}$ \\
\hline Plan & 1.000 & 839 & 684 & 569 & 544 \\
\hline S. Juan de Plan & 236 & 205 & 191 & 177 & 171 \\
\hline Total Valle Gistaín & 1.226 & 1.020 & 875 & 746 & 715 \\
\hline Total Prov. Huesca & 234.014 & 221.761 & 214.013 & 214.907 & 210.094 \\
\hline
\end{tabular}

Fuente: Censos y Padrones de Población I.N.E. Elaboración propia.

En 1960 el Valle de Gistaín todavía contaba con 1.236 habitantes, residentes en su mayoría en Plan y Gistaín, municipios que han perdido más habitantes que $S$. Juan de Plan a lo largo de las décadas siguientes como reflejan los Censos consultados.

La reforma económica iniciada con el Plan de Estabilización en 1959 potenció la industrialización y el crecimiento del sector terciario en España. La creación de polígonos industriales en las grandes ciudades y el espectacular crecimiento de las mismas, favoreció la gran demanda de mano de obra joven y el éxodo de la población del campo que, en el caso del Valle de Gistaín y la comarca de Sobrarbe, se dirigieron principalmente a Zaragoza y Barcelona.

En muchos casos, previamente al salto definitivo a otras provincias desarrolladas (Cataluña, preferentemente), se produjo la instalación de la población activa rural en Monzón o en Huesca, que absorbió gran cantidad de mano de obra de las zonas próximas.

En algunos pueblos se abandonaron cultivos que requerían mano de obra al igual que las tierras, el ganado se redujo, o incluso desapareció; se rompió la cadena de oficios y talleres que garantizaban en buena medida los servicios, el pequeño comercio suprimió mercancía y no pudo asegurar el abastecimiento de muchos artículos. Quedaba una sociedad envejecida que vive en buena medida de las pensiones de jubilación, con escasa capacidad de respuesta y de iniciativas.

Si el territorio ofrecía un bonito paisaje como el de Sobrarbe, comunicaciones mejorables y la posibilidad de practicar en las proximidades alguna actividad deportiva como caza, pesca, montañismo, senderismo, 
descenso de barrancos, ski acuático o alpino..., etc., comenzaba entonces el proceso de colonización del campo a través de la ciudad: las parcelas yermas se convertirán en suelo urbano, se vende paisaje, proliferan las urbanizaciones, retornan antiguos emigrantes, se abren locales de diversión $y$ tiendas de abastecimiento y de souvenirs.

En 1970 las estadísticas ponían de manifiesto no sólo una pérdida enorme de población, sino lo que es más grave, una desarticulación del sistema de relaciones que había regido hasta entonces la sociedad del Sobrarbe.

Los reajustes administrativos con la fusión de dos o más municipios en uno sólo y la agregación de otro a los ya existentes, han sido continuos a lo largo del proceso de despoblación. De hecho, en el citado Censo de 1970 todavía eran 21 los municipios consignados a pesar de las numerosas anexiones llevadas a cabo hasta entonces desde principios de siglo.

Las pésimas comunicaciones existentes en esa época, la carencia de industria y de ciudades intermedias y la gran distancia que separaba sus núcleos de la población de Huesca, capital de la provincia, y de otros centros industrializados, acentuaron por una parte el proceso de despoblación pero, por otra, todo este cúmulo de circunstancias provocó un freno natural a la colonización urbana acelerada en los últimos decenios consiguiéndose así, de forma indirecta, una defensa del paisaje.

\section{ESTRUCTURA DE LA POBLACIÓN}

El número de personas existentes en cada edad y en cada sexo constituye un factor importante de cara a la organización y funcionamiento de cualquier grupo social, y está determinada por la intervención de tres variables demográficas: la migración, la mortalidad y la fecundidad, que inciden de forma distinta en la creación de desigualdades entre ambos sexos.

El Padrón de habitantes de 1986 permite apreciar en la comarca y en el Valle de Gistaín la incidencia del éxodo rural en la estructura demográfica. En primer lugar, observaremos que los efectivos masculinos rebasan a los femeninos. Por cada 10 mujeres de 15 a 55 años hay casi 12 hombres de la misma edad. La tasa de masculinidad o "sex ratio" en la comarca es de 1,16 puntos, similar a la obtenida en los Padrones municipales de 1975, mientras la del Valle de Gistain asciende a 1,41.

Una población asi estructurada conlleva consecuencias de indole socioeconómica. Una de ellas es la dificultad de matrimoniar cuando los efectivos masculinos en estas edades superan con creces a los femeninos. En 
estos municipios un $55 \%$ de los varones están solteros. Para toda la comarca el porcentaje es de un $38 \%$ de solteras frente a un $45 \%$ de hombres. Así, en números absolutos hay más personas solteras que casadas.

DISTRIBUCIÓN DE LA POBLACIÓN DE DERECHO POR SEXO Y GRUPOS DE EDAD. PADRÓN, 1986. VALLE DE GISTAÍN

\begin{tabular}{|c|c|c|c|c|}
\hline \multicolumn{2}{|c|}{ GRUPOS DE EDAD } & \multirow{2}{*}{ PLAN } & \multirow{2}{*}{$\begin{array}{l}\text { SAN JUAN } \\
\text { DE PLAN }\end{array}$} & \multirow{2}{*}{$\begin{array}{l}\text { COMARCA } \\
\text { SOBRARBE }\end{array}$} \\
\hline (AÑOS) & (SEXO) & & & \\
\hline \multirow{2}{*}{$0-4$} & V & 8 & 2 & 196 \\
\hline & $M$ & 9 & 1 & 146 \\
\hline \multirow{2}{*}{$5-9$} & V & 12 & 7 & 204 \\
\hline & $M$ & 9 & 4 & 153 \\
\hline \multirow{2}{*}{$10-14$} & V & 8 & 12 & 175 \\
\hline & $M$ & 16 & 0 & 187 \\
\hline \multirow{2}{*}{$15-19$} & V & 10 & 8 & 281 \\
\hline & $M$ & 11 & 4 & 244 \\
\hline \multirow{2}{*}{$20-24$} & $\mathrm{~V}$ & 24 & 7 & 329 \\
\hline & $M$ & 11 & 7 & 231 \\
\hline \multirow{2}{*}{$25-29$} & V & 26 & 6 & 276 \\
\hline & $M$ & 11 & 3 & 215 \\
\hline \multirow{2}{*}{$30-34$} & $\mathrm{~V}$ & 23 & 6 & 212 \\
\hline & M & 10 & 3 & 152 \\
\hline \multirow{2}{*}{$35-39$} & V & 18 & 4 & 182 \\
\hline & $M$ & 16 & 3 & 139 \\
\hline \multirow{2}{*}{$40-44$} & $\mathrm{~V}$ & 13 & 6 & 162 \\
\hline & $M$ & 15 & 7 & 145 \\
\hline \multirow{2}{*}{$45-49$} & V & 13 & 7 & 259 \\
\hline & $M$ & 8 & 6 & 214 \\
\hline \multirow{2}{*}{$50-54$} & V & 27 & 7 & 279 \\
\hline & $M$ & 22 & 7 & 242 \\
\hline \multirow{2}{*}{$55-59$} & V & 32 & 6 & 262 \\
\hline & $M$ & 16 & 5 & 252 \\
\hline \multirow{2}{*}{$60-64$} & $V$ & 22 & 4 & 205 \\
\hline & $M$ & 23 & 4 & 198 \\
\hline \multirow{2}{*}{$65-69$} & V & 14 & 8 & 193 \\
\hline & $M$ & 19 & 5 & 232 \\
\hline
\end{tabular}


DISTRIBUCIÓN DE LA POBLACIÓN DE DERECHO POR SEXO Y GRUPOS DE EDAD. PADRÓN, 1986. VALLE DE GISTAÍN (continuación)

\begin{tabular}{|c|c|c|c|c|}
\hline \multicolumn{2}{|c|}{ GRUPOS DE EDAD } & \multirow{2}{*}{ PLAN } & \multirow{2}{*}{$\begin{array}{l}\text { SAN JUAN } \\
\text { DE PLAN }\end{array}$} & \multirow{2}{*}{$\begin{array}{l}\text { COMARCA } \\
\text { SOBRARBE }\end{array}$} \\
\hline (AÑOS) & (SEXO) & & & \\
\hline \multirow{2}{*}{$70-74$} & V & 24 & 3 & 246 \\
\hline & M & 14 & 3 & 202 \\
\hline \multirow{2}{*}{$75-79$} & V & 12 & 4 & 156 \\
\hline & M & 15 & 5 & 124 \\
\hline \multirow{2}{*}{$80-84$} & $\mathrm{~V}$ & 11 & 2 & 54 \\
\hline & $M$ & 10 & 4 & 72 \\
\hline \multirow{2}{*}{$85-89$} & $\mathrm{~V}$ & 3 & 1 & 26 \\
\hline & $M$ & 5 & 1 & 38 \\
\hline \multirow{2}{*}{$90-94$} & V & 1 & 0 & 17 \\
\hline & $M$ & 5 & 1 & 17 \\
\hline \multirow{2}{*}{95 y más } & V & 0 & 0 & - \\
\hline & $M$ & 0 & 0 & - \\
\hline \multirow{2}{*}{ Suman } & V & 311 & 100 & 3.654 \\
\hline & $M$ & 245 & 73 & 3.200 \\
\hline No clasificados & & 0 & 1 & - \\
\hline TOTAL & & 546 & 174 & 6.854 \\
\hline
\end{tabular}

Fuente: Padrón de Población, 1986. INE. Elaboración propia.

Aquí se reproduce la tendencia general a la reducción de la natalidad, pues los efectivos menores de 15 años en la comarca son menores que los de otras épocas: de cada 100 vecinos, sólo $15(15,38 \%)$ son niños. En la mayoría de los casos son hijos de guardia civiles o de funcionarios destinados en la comarca de forma temporal. En el Valle de Gistaín, todavía es más baja la proporción: Tan sólo el $10 \%$ del total de la población, corresponde a menores de 15 años.

En 1986 había municipios enteros sin niños pequeños. Su escolarización, tanto si se hace en la escuela unitaria de la capital del término como si se desplazan a la de Aínsa o se quedan internos en Boltaña, presenta problemas.

Los grupos de edad comprendidos entre los 15 y los 30 años son relativamente numerosos. Dado que en estos grupos la población femenina de 
Sobrarbe supone un $44 \%$ del total, se deduce que las chicas salen a estudiar o a trabajar fuera con más frecuencia que los chicos.

En el Valle de Gistaín esta proporción asciende al 58\%. Estos jóvenes que se quedan son los que no han conocido el éxodo rural, sino la crisis económica de los años 70 . En conjunto representan un interesante $23 \%$ de la población de la comarca y un $18 \%$ de la de Chistau.

Por el contrario, se aprecia un fuerte descenso más acusado en la comarca (14\%) que en el Valle (17\%), de los grupos que oscilan entre los 30 y los 45 años de edad, tocados de lleno por el proceso migratorio.

Los tres grupos de edad comprendidos entre los 45 y los 60 años presentan menores recortes y alcanzan un $22 \%$ de la población total tanto en la comarca como en el Valle. La relevancia de estos efectivos puede explicarse porque ellos nacieron entre 1921 y 1936, fueron los niños y jóvenes de la guerra y postguerra.

Anteriormente vimos que en el Sobrarbe aquellos años fueron especialmente duros y que se detuvo la corriente de emigración temporal o definitiva de solteros y familias enteras. Los individuos que en 1986 tenían de 60 a 70 años vivieron de adultos la Guerra Civil. Ésta sería la causa de que ambos grupos sean en la actualidad poco numerosos.

Un $25,6 \%$ en la comarca y un $31 \%$ de estos montañeses en el Valle supera los 60 años de edad, porcentaje alto de longevidad, si tenemos en cuenta que a nivel provincial, autonómico y nacional ronda el $20 \%$. El índice de envejecimiento relaciona esta cifra con la de los menores de 15 años: en nuestro caso se obtiene un ratio de 1,66 puntos, que es elevada.

El hecho de que un elevado porcentaje de la población presente edades avanzadas, supone la existencia de numerosos hogares que viven de la pensión de un cabeza de familia jubilado: oscila entre el $94 \%$ de Palo y el $23 \%$ de Aínsa-Sobrarbe; la media ronda el $40 \%$ de las familias.

\subsection{El proceso de envejecimiento y regresión}

Además de las pérdidas de población absoluta en los valles del Sobrarbe, cabe señalar como un hecho de extraordinaria importancia para comprender la composición por edades de la misma, la caída de las tasas de natalidad y fecundidad consecuencia del proceso de envejecimiento, propiciado por la emigración masiva a las ciudades que hemos señalado, proceso que ha continuado abierto a través de las sucesivas revoluciones industriales que se han producido hasta ahora. 
Como consecuencia del envejecimiento aludido, la edad media de los matrimonios es bastante más elevada que la de la provincia y los nacimientos vienen siendo cada vez más escasos, contabilizándose en los últimos años una tasa de 4.000 nacimientos, mientras que la provincial es de ocho y la global de España se sitúa en 11 por 1.000 .

NACIDOS VIVOS. AÑOS 1987-1992. VALLE DE GISTAÍN

\begin{tabular}{|c|c|c|c|c|}
\hline AÑOS & POBLACIÓN & GISTAIN & PLAN & S. JUAN DE PLAN \\
\hline \multirow{3}{*}{1987} & Varones & 0 & 2 & 1 \\
\hline & Mujeres & 0 & 0 & 2 \\
\hline & Total & 0 & 2 & 3 \\
\hline \multirow{3}{*}{1988} & Varones & 0 & 2 & 0 \\
\hline & Mujeres & 0 & 0 & 0 \\
\hline & Total & 0 & 2 & 0 \\
\hline \multirow{3}{*}{1989} & Varones & 0 & 0 & 0 \\
\hline & Mujeres & 0 & 1 & 0 \\
\hline & Total & 0 & 1 & 0 \\
\hline \multirow{3}{*}{1990} & Varones & 0 & 1 & 0 \\
\hline & Mujeres & 0 & 0 & 0 \\
\hline & Total & 0 & 1 & 0 \\
\hline \multirow{3}{*}{1991} & Varones & 0 & 3 & 0 \\
\hline & Mujeres & 0 & 1 & 0 \\
\hline & Total & 0 & 4 & 0 \\
\hline \multirow{3}{*}{1992} & Varones & 0 & 2 & 0 \\
\hline & Mujeres & 0 & 0 & 1 \\
\hline & Total & 0 & 2 & 1 \\
\hline
\end{tabular}

Fuente: Boletines Estadísticos de Parto. Acuerdo de colaboración INEDGA.

En el Valle de Gistaín las tasas son más bajas que las comarcales y provinciales quedando explícita la situación en el cuadro arriba expuesto que arroja un resultado absolutamente patético para Gistaín, donde no hubo ningún nacimiento en los seis años estudiados, mientras en $\mathrm{S}$. Juan de Plan se produjeron tan sólo cuatro y en Plan, doce, en cifras absolutas. Mucho más baja que la natalidad es, todavia, la tasa de fecundidad.

En efecto, la fecundidad constituye un factor determinante en la forma que adopta la estructura por sexo y edad de una población. Si es elevada 
( 7,1 hijos por mujer) origina una estructura de edad joven, mientras que una fecundidad baja (de 2,1 que equivale a reemplazo exacto), produce una estructura más vieja. Por debajo de este nivel, la regresión. Éste es precisamente el proceso abierto desde hace años en el Valle de Gistaín, como queda de manifiesto en el siguiente cuadro:

INDICES Y TASAS DEMOGRÁFICAS DEL VALLE DE GISTAÍN, 1986

\begin{tabular}{|c|c|c|c|c|c|c|c|c|c|c|c|c|}
\hline \multirow[b]{2}{*}{ MUNICIPIO } & \multirow[b]{2}{*}{$\begin{array}{c}\text { EDAD } \\
\text { MEDIA }\end{array}$} & \multicolumn{4}{|c|}{ GRADO DE UUVENTUD } & \multicolumn{3}{|c|}{ GRADO DE ENVEJECIMIENTO } & \multicolumn{2}{|c|}{ INDICES } & \multicolumn{2}{|c|}{ TASAS } \\
\hline & & $<15$ & $<25$ & $<35$ & $<45$ & $>45$ & $>55$ & $>65$ & $\begin{array}{l}\text { FECUN- } \\
\text { DIDAD }\end{array}$ & $\begin{array}{l}\text { REEM- } \\
\text { PLAZO }\end{array}$ & MASC. & FEM. \\
\hline Plan & & 11,36 & & & 79 & & 39 & 36 & 0,27 & 4 & 86 & 81,40 \\
\hline & 02 & 15,03 & 30,06 & 0,46 & 52,02 & 47,98 & 32,37 & 21,39 & 0,13 & 0,86 & 136,99 & 73,00 \\
\hline & 43,17 & 13,90 & 26,81 & 41,45 & 51,28 & 48,72 & 37,60 & 22,54 & 0,29 & 1,07 & 114,19 & 87,57 \\
\hline
\end{tabular}

Fuente: Padrones de Población, 1986. INE. Elaboración propia.

El valor de los indices de fecundidad: 0,13 para Gistaín y 0,27 para Pan (muy próximo al total comarcal, nos indica un camino sin retorno hacia un total desierto humano. Es difícil la reactivación demográfica cuando el grado de juventud de la población se sitúa en valores del 11 al $15 \%$ y la edad media de la población y el nivel de envejecimiento son tan altos. Esta situación se traduce, como es lógico, en una ausencia de generaciones de reemplazo en el Valle de Gistaín, lo que repercute a su vez en la comarca.

DEFUNCIONES. AÑOS 1987-1992. VALLE DE GISTAÍN

\begin{tabular}{|c|l|c|c|c|}
\hline AÑOS & POBLACION & GISTAIN & PLAN & S. JUAN DE PLAN \\
\hline \multirow{4}{*}{1987} & Varones & 1 & 0 & 0 \\
\cline { 2 - 5 } & Mujeres & 0 & 5 & 1 \\
\cline { 2 - 5 } & Total & 1 & 5 & 1 \\
\hline \multirow{3}{*}{1988} & Varones & 1 & 4 & 0 \\
\cline { 2 - 5 } & Mujeres & 1 & 5 & 0 \\
\cline { 2 - 5 } & Total & 2 & 9 & 0 \\
\hline \multirow{3}{*}{1989} & Varones & 0 & 2 & 0 \\
\cline { 2 - 5 } & Mujeres & 0 & 1 & 2 \\
\cline { 2 - 5 } & Total & 0 & 3 & 2 \\
\hline \multirow{3}{*}{1990} & Varones & 3 & 3 & 0 \\
\cline { 2 - 5 } & Mujeres & 1 & 0 & 1 \\
\cline { 2 - 5 } & Total & 4 & 3 & 1 \\
\hline
\end{tabular}


DEFUNCIONES. AÑOS 1987-1992. VALLE DE GISTAÍN (continuación)

\begin{tabular}{|c|l|c|c|c|}
\hline AÑOS & POBLACIÓN & GISTAIN & PLAN & S. JUAN DE PLAN \\
\hline \multirow{3}{*}{1991} & Varones & 1 & 3 & 1 \\
\cline { 2 - 5 } & Mujeres & 1 & 3 & 1 \\
\cline { 2 - 5 } & Total & 2 & 6 & 2 \\
\hline \multirow{3}{*}{1992} & Varones & 0 & 2 & 1 \\
\cline { 2 - 5 } & Mujeres & 1 & 0 & 0 \\
\cline { 2 - 5 } & Total & 1 & 2 & 1 \\
\hline
\end{tabular}

Fuente: Boletines Estadísticos de Defunciones. Acuerdo de Colaboración INE-DGA.

En este contexto es lógico que la mortalidad arroje también índices más elevados que los de comarcas menos envejecidas y que las cifras absolutas para el periodo considerado, de 1987 a 1992, sean un $65 \%$ más altas que los nacimientos: Gistaín perdió 10 vecinos; Plan, 28, y S. Juan, 7. En conjunto murieron 45 personas en el Valle, la mitad de ellas, aproximadamente (21 habitantes), en los años más cruciales de 1988 y 1991.

CRECIMIENTO NATURAL DE LA POBLACIÓN, 1987-1992. VALLE DE GISTAIN

\begin{tabular}{|c|l|c|c|c|c|}
\hline AÑOS & POBLACIÓN & GISTAIN & PLAN & S. JUAN DE P. & TOTAL VALLE \\
\hline \multirow{4}{*}{1987} & Varones & -1 & +2 & +1 & +2 \\
\cline { 2 - 6 } & Mujeres & 0 & -5 & +1 & -4 \\
\cline { 2 - 6 } & Total & -1 & -3 & +2 & -2 \\
\hline \multirow{4}{*}{1988} & Varones & -1 & -2 & 0 & -3 \\
\cline { 2 - 6 } & Mujeres & -1 & -5 & 0 & -6 \\
\cline { 2 - 6 } & Total & -2 & -7 & 0 & -9 \\
\hline \multirow{3}{*}{1989} & Varones & 0 & -2 & 0 & -2 \\
\cline { 2 - 6 } & Mujeres & 0 & 0 & -2 & -2 \\
\cline { 2 - 6 } & Total & 0 & -2 & -2 & -4 \\
\hline \multirow{3}{*}{1990} & Varones & -3 & -2 & -1 & -6 \\
\cline { 2 - 6 } & Mujeres & -1 & 0 & 0 & -1 \\
\cline { 2 - 6 } & Total & -4 & -2 & -1 & -7 \\
\hline
\end{tabular}


CRECIMIENTO NATURAL DE LA POBLACIÓN, 1987-1992. VALLE DE GISTAÍN (continuación)

\begin{tabular}{|c|l|c|c|c|c|}
\hline AÑOS & POBLACIÓN & GISTAÍN & PLAN & S. JUAN DE P. & TOTAL VALLE \\
\hline \multirow{4}{*}{1991} & Varones & -1 & 0 & -1 & -2 \\
\cline { 2 - 6 } & Mujeres & -1 & -2 & -1 & -4 \\
\cline { 2 - 6 } & Total & -2 & -2 & -2 & -6 \\
\hline \multirow{3}{*}{1992} & Varones & 0 & 0 & -1 & -1 \\
\cline { 2 - 6 } & Mujeres & -1 & 0 & +1 & 0 \\
\cline { 2 - 6 } & Total & -1 & 0 & 0 & -1 \\
\hline
\end{tabular}

Fuente: Elaboración propia a partir de los cuadros anteriores.

Relacionando ambos factores, natalidad y mortalidad, el resultado es un crecimiento natural de la población del Valle absolutamente negativo, en todo el período considerado, tal como queda reflejado en el siguiente gráfico, expresión del cuadro anterior.

CRECIMIENTO NATURAL DE LA POBLACIÓN. V. DE GISTAIN

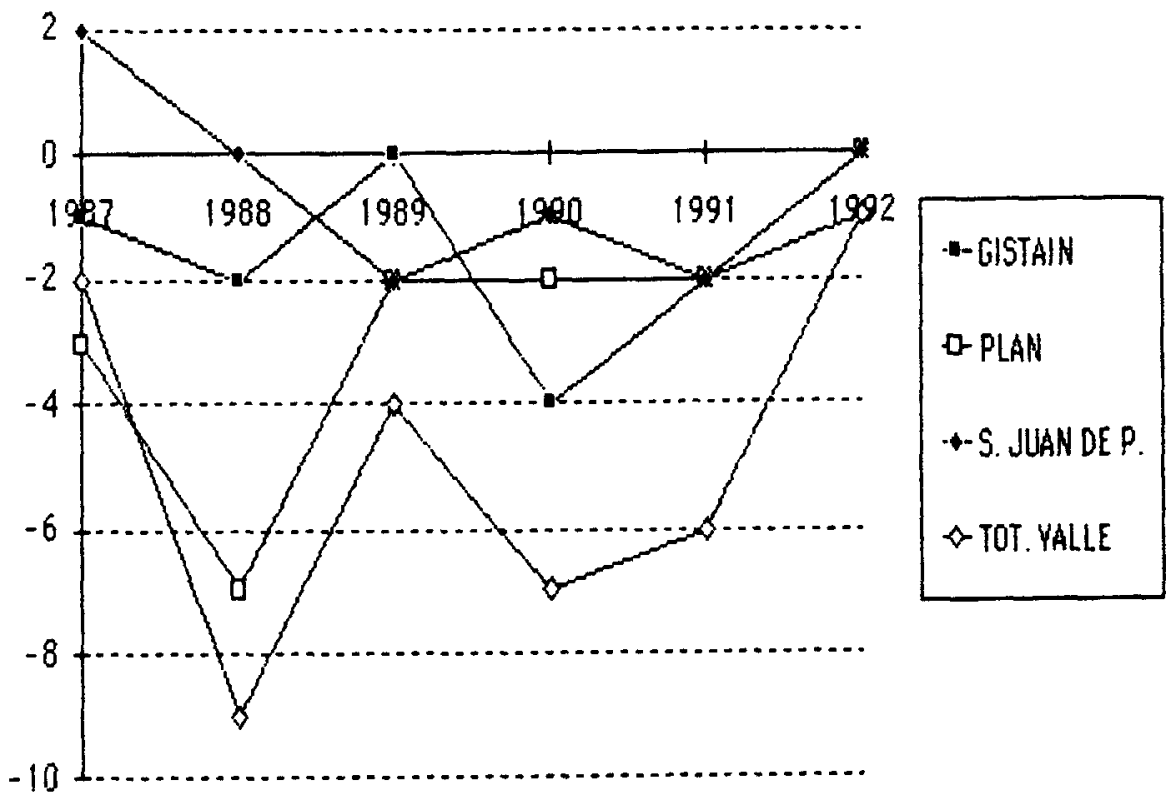

Fuente: Elaboración propia a partir de los cuadros anteriores. 
Los picos más expresivos de la gráfica, por debajo del crecimiento cero, corresponden a 1988 con un crecimiento negativo de 9 personas, y a 1990 , con un crecimiento negativo de siete habitantes.

\section{DISTRIBUCIÓN DE LA POBLACIÓN ACTIVA}

Para el estudio de la población activa se han considerado como fuentes básicas de información el Censo de Población de 1981 y los trabajos: "Renta municipal de Aragón. Año 1981», publicado por la C.A.Z.A.R. complementado con el de: «Renta comarcal de Aragón, 1985», elaborado por el mismo equipo que el anterior y publicado por la D.G.A. y el de "Renta de Aragón», editado por la Fundación Nueva Empresa y la Cámara de Comercio e Industria de Zaragoza.

Los epígrafes utilizados en la siguiente tabla, significan:

1. Población ocupada: La que declara alguna actividad económica en el momento de cumplimentar la encuesta.

2. Población en paro: La que declara esta situación en el momento de la consulta.

3. Población en busca del primer empleo: Las personas que no han desarrollado ninguna actividad productiva debido generalmente a su juventud (no se incluyen en el epígrafe 2).

4. Población activa: Suma de $1+2+3$.

5. Tasa de ocupación: Relación entre la población ocupada (1) y la población de derecho $\times 100$.

6. Tasa de actividad: Relación entre la población activa (4) y la población de derecho x 100 .

La tasa de actividad refleja fielmente la estructura de la población que se puede desagregar a estos efectos en dos grupos:

A) Personas en edad de trabajar.

B) Población preescolar, escolar y jubilados, además de amas de casa dedicadas a "sus labores" o actividades no remuneradas.

La escasa población joven del Sobrarbe y del Valle de Gistaín, hace subir el índice de la tasa de actividad, aunque las más altas se encontrarán, teóricamente, en municipios con un moderado número de niños y ancianos. La actividad agraria como sector principal de ocupación enmascara la realidad, ya que en las explotaciones trabaja gran 
parte de la familia, aunque sólo el titular esté dado de alta en la Seguridad Social y las cifras de paro son muy bajas, como puede apreciarse en el cuadro siguiente:

\section{DISTRIBUCIÓN DE LA POBLACIÓN ACTIVA}

\begin{tabular}{|l|r|r|r|r|r|r|}
\hline & $\begin{array}{r}\text { POBLAC. } \\
\text { OCUPADA }\end{array}$ & PARADOS & $\begin{array}{c}\text { BUSCA 1 } \\
\text { EMPLEO }\end{array}$ & $\begin{array}{c}\text { POBLAC. } \\
\text { ACTIVA }\end{array}$ & $\begin{array}{c}\text { TASA } \\
\text { OCUPAC. }\end{array}$ & $\begin{array}{c}\text { TASA } \\
\text { MUNICIPIO } \\
\text { ACTIVIDAD }\end{array}$ \\
\hline Plan & 195 & 4 & 11 & 210 & 34,88 & 37,57 \\
\hline S. Juan de Plan & 39 & 3 & 17 & 59 & 22,03 & 33,33 \\
\hline Total valle & 18 & 7 & 28 & 269 & 31,36 & 36,05 \\
\hline Total Sobrarbe & 2.250 & 109 & 111 & 2.470 & 32,90 & 36,12 \\
\hline
\end{tabular}

Fuente: «Renta Municipal de Aragón. Año 1981». Elaboración propia.

Hay que tener en cuenta también que la mayor parte de la población joven permanece en la montaña porque no hay trabajo en las ciudades. Otros se colocan durante el verano en algún establecimiento comercial hostelero, o son contratados por el ICONA y por el Servicio de Conservación del Medio Natural de la D.G.A. Todos ayudan a la explotación del negocio familiar.

\subsection{Distribución sectorial de la población ocupada}

El Sobrarbe es una comarca eminentemente agraria, ya que algo más del $50 \%$ de su población ocupada está dedicada al sector primario, mientras que en Huesca baja al $31,51 \%$. Si se desciende a nivel municipal todavía se acentúan más estas diferencias, ya que la mayoría de los términos municipales superan la media comarcal citada como en el caso del valle de Gistaín, un $15 \%$ por encima de dicho valor.

Únicamente Boltaña con un $26,11 \%$ y Labuerda con $30 \%$ rebajan la media provincial y tan sólo Bielsa, Tella-Sin y Aínsa-Sobrarbe, aún superando ésta no alcanzan el $40 \%$. Se trata de municipios grandes más orientados al sector servicios.

La apertura en 1976 del túnel internacional Bielsa-Aragnouet supuso un cambio de rumbo en la orientación económica del municipio, pasando de la actividad ganadera como ocupación principal de la población activa, a las derivadas del turismo y sobre todo, del comercio con los vecinos del 
otro lado de la frontera, lo cual ha proporcionado una cierta estabilidad en los efectivos de la población de Bielsa que no ha trascendido al resto de la zona.

\section{POBLACIÓN OCUPADA POR SECTORES}

\begin{tabular}{|l|r|r|r|r|r|r|r|}
\hline \multirow{2}{*}{ MUNICIPIO } & \multicolumn{2}{|c|}{ AGRARIO } & \multicolumn{2}{|c|}{ INDUSTRIA } & \multicolumn{2}{|c|}{ SERVICIOS } & TOTAL \\
\cline { 2 - 8 } & \multicolumn{1}{|c|}{ № } & $\%$ & \multicolumn{1}{c|}{ № } & $\%$ & \multicolumn{1}{c|}{ № } & $\%$ & \multicolumn{1}{c|}{ № } \\
\hline Plan & 129 & 66 & 38 & 19 & 28 & 14 & 195 \\
\hline S. Juan de P. & 32 & 76 & 5 & 12 & 5 & 12 & 42 \\
\hline Total Valle & 161 & 68 & 43 & 18 & 33 & 14 & 237 \\
\hline Tot. Sobrarbe & 1.187 & 53 & 397 & 18 & 659 & 29 & 2.243 \\
\hline
\end{tabular}

Fuente: «Renta Municipal de Aragón. Año 1981». Elaboración propia.

En el sector industrial las diferencias con la comarca no son tan acusadas, porque las carencias en este sector son manifiestas. En cambio el terciario puede convertirse en un activador de la economía del Valle.

\section{RÉGIMEN DE OCUPACIÓN EN EL SECTOR INDUSTRIAL}

\begin{tabular}{|l|c|c|c|c|c|}
\hline \multirow{2}{*}{ MUNICIPIO } & \multicolumn{2}{|c|}{ NO ASALARIADOS } & \multicolumn{2}{c|}{ ASALARIADOS } & TOTAL \\
\cline { 2 - 6 } & № & $\%$ & № & $\%$ & № \\
\hline Plan & 5 & 13 & 33 & 87 & 38 \\
\hline S. Juan de P. & 2 & 40 & 3 & 60 & 5 \\
\hline Total Valle & 7 & 16 & 36 & 84 & 43 \\
\hline Tot. Sobrarbe & 48 & 12 & 349 & 88 & 397 \\
\hline
\end{tabular}

Fuente: «Renta Municipal de Aragón. Año 1981». Elaboración propia.

Efectivamente, el número total de trabajadores en el sector secundario (43 en todo el Valle) da idea de la atonía del sector. La práctica totalidad de los trabajadores de la industria, lo hacen por cuenta ajena, el $84 \%$, cifra muy próxima a la comarcal, aunque los datos de $\mathrm{S}$. Juan de Plan, tan sumamente bajos, puedan llevar a la confusión si tan sólo se habla de tantos por ciento.

Al sector secundario se dedica una parte muy pequeña de la población comarcal, porque la industria tiene poco peso en esta zona a excepción de algunos pueblos como el de Tella-Sin, en donde el $40 \%$ de su población 
activa trabaja en la central hidroeléctrica de Lafortunada; le siguen con tasas que apenas superan el $20 \%$, Bielsa, Ainsa-Sobrarbe y Boltaña.

Al sector terciario se dedica el $29 \%$ de los trabajadores, cifra mucho más reducida que la media provincial y regional. Los tantos por ciento más elevados corresponden a los dos municipios más poblados. AínsaSobrarbe y Boltaña, que cuentan con el mejor nivel de infraestructura viaria y de alojamiento y también, otros pueblos como Torla y Bielsa con clara orientación turística, se benefician de su proximidad al Parque Nacional de Ordesa y a la frontera con Francia, respectivamente.

RÉGIMEN DE OCUPACIÓN EN EL SECTOR SERVICIOS

\begin{tabular}{|l|c|c|c|c|c|}
\hline \multirow{2}{*}{ MUNICIPIO } & \multicolumn{2}{|c|}{ NO ASALARIADOS } & \multicolumn{2}{|c|}{ ASALARIADOS } & TOTAL \\
\cline { 2 - 6 } & № & $\%$ & № & $\%$ & № \\
\hline Plan & 8 & 28 & 20 & 71 & 28 \\
\hline S. Juan de P. & 1 & 20 & 4 & 80 & 5 \\
\hline Total Valle & 9 & 27 & 24 & 73 & 33 \\
\hline Tot. Sobrarbe & 112 & 17 & 547 & 83 & 659 \\
\hline
\end{tabular}

Fuente: «Renta Municipal de Aragón. Año 1981». Elaboración propia.

En el Valle, el turismo está todavía muy lejos de ser un sector con peso específico en la economía, aunque en los últimos años ha experimentado cierto auge que pudiera convertirse en embrión de un sector terciario por el momento subdesarrollado. La proximidad de Plan, Gistain y S. Juan de Plan hacen posible instalaciones comunes que podrian rentabilizar las inversiones en infraestructuras.

El sector agrario se integra en una sola rama de actividad, mientras que en el secundario la rama de agua, gas y electricidad es la que proporciona la mayoría de empleos con un total de 43 trabajadores, al igual que ocurre en Bielsa y en parte también en Boltaña, donde la población ocupada se reparte mayoritariamente entre esta rama y la de construcción y, en menor parte, en la de alimentación. No figura ningún establecimiento en la producción y primera transformación de metales y papel y artes gráficas.

El sector terciario está representado principalmente por el turismo, el comercio y servicios varios en los dos municipios más importantes que hemos señalado: Aínsa-Sobrarbe y Boltaña. 
Existen algunos movimientos pendulares de población que corresponden a desplazamientos laborales entre municipios de residencia y municipios de trabajo. Se trata de trabajadores del sector de la construcción que se desplazan a L'Aínsa procedentes de S. Juan de Plan, Fiscal, La Fueva, Laspuña, etc., y también de otros que acoge la central hidroeléctrica de Lafortunada en Tella-Sin.

VALOR DE LA PRODUCCIÓN POR SECTORES

\begin{tabular}{|l|c|c|c|c|c|c|c|}
\hline \multirow{2}{*}{ MUNICIPIO } & \multicolumn{2}{|c|}{ AGRARIO } & \multicolumn{2}{c|}{ INDUSTRIA } & \multicolumn{2}{c|}{ SERVICIOS } & TOTAL \\
\cline { 2 - 8 } & PTAS & $\%$ & PTAS. & $\%$ & PTAS. & $\%$ & PTAS. \\
\hline Plan & 142.294 .401 & 41 & 137.786 .960 & 40 & 62.589 .410 & 18 & 342.670 .771 \\
\hline S. J. de Plan & 56.558 .896 & 70 & 11.729 .800 & 14 & 12.659 .640 & 15 & 80.948 .336 \\
\hline Tot. Valle & 70.788 .336 & & 25.508 .496 & & 75.249 .050 & & 423.619 .107 \\
\hline
\end{tabular}

Fuente: «Renta Municipal de Aragón. Año 1981 ». Elaboración propia.

El valor de la producción por sectores refleja el predominio del sector primario sobre el industrial y el de servicios en los tres núcleos del Valle, aunque el contenido de estas cifras sea mucho más expresivo si se traduce su valor a la renta "per cápita».

\begin{tabular}{|l|c|c|}
\hline \multicolumn{1}{|c|}{ MUNICIPIO } & $\begin{array}{c}\text { RENTA } \\
\text { PER CÁPITA }\end{array}$ & $\begin{array}{c}\text { RENTA } \\
\text { MUNICIPAL } \\
\text { DISPONIBLE }\end{array}$ \\
\hline Plan & 336.814 & 191.646 .952 \\
\hline S. Juan de Plan & 354.009 & 62.659 .625 \\
\hline
\end{tabular}

Fuente: «Renta Municipal de Aragón. Año 1981». Elaboración propia.

\subsection{Niveles de paro}

Las cifras de paro de 1981 aparecen desdobladas en el trabajo ya citado de la CAZAR: «Renta Municipal de Aragón, año 1981» en dos apartados: "Parados" y "En busca del primer empleo". La suma de ambos arroja una cifra de 220 personas que suponen el $8,90 \%$ de la población activa comarcal, porcentaje inferior al de la provincia que se sitúa en un $9,41 \%$.

Los porcentajes de paro en cada municipio se obtienen dividiendo la suma de «Parados» y «En busca del primer empleo» entre la población activa. Comparando estos datos con los de noviembre de 1986 se puede 
apreciar que la variación a nivel comarcal ha sido escasa, como corresponde a la baja vitalidad de la comarca, ya que el incremento porcentual de la última fecha es muy reducido, a diferencia de lo ocurido en el resto de Aragón y en España.

A pesar de la ligerísima variación comarcal citada entre 1981 y 1986 (220 y 229 parados, respectivamente), analizando por separado los municipios se aprecian porcentajes más significativos que en muchos casos no implican variaciones absolutas importantes, pues la escasez de población activa induce a que cualquier modificación, por pequeña que sea, suponga fuertes variaciones porcentuales. Tal es el caso de Fanlo, que pasa de un $0 \%$ en 1981 a un $6,25 \%$ en 1986 con la aparición de dos parados.

Las cifras de paro de 1986 pertenecen al mes de noviembre en que los contratos temporales veraniegos dependientes fundamentalmente del Parque Nacional de Ordesa y del sector de hostelería han finalizado. Entre las 18 ramas laborales existe una amplia gama de profesiones declaradas que se repiten y que tienen a veces carácter temporal: peón, palista, electricista, mecánico, maderero y aserrador, conductor, camarero, cocinero, etcétera, y otras como la de profesor de Educación General Básica o la Ayudante de Técnico Sanitario de carácter permanente.

La evolución del paro en la comarca entre 1984 y 1993 pone de manifiesto la estabilidad del número de trabajadores en esa situación, ajena a los altibajos que experimenta la provincia y, sobre todo, la Comunidad Autónoma. En los índices de variación, se registra un paulatino descenso a partir del año 1991, bien porque existan menos habitantes, porque realmente hayan descendido las tasas de paro de la comarca o porque en el año tomado de referente, el indice de paro fuese muy alto.

EVOLUCIÓN DEL PARO EN EL SOBRARBE, 1984-1993

\begin{tabular}{|l|r|r|r|r|r|r|r|r|r|r|}
\hline \multirow{2}{*}{ COMARCA } & \multicolumn{10}{|c|}{ PARO REGISTRADO } \\
\cline { 2 - 11 } & 1984 & 1985 & 1986 & 1987 & 1988 & 1989 & 1990 & 1991 & 1992 & 1993 \\
\hline Sobrarbe & 268 & 321 & 326 & 383 & 439 & 382 & 340 & 212 & 244 & 185 \\
\hline Total prov. & 8.864 & 10.285 & 10.486 & 11.161 & 10.614 & 9.514 & 9.180 & 8.498 & 7.822 & 8.692 \\
\hline Tot. Aragón & 62.516 & 70.973 & 69.431 & 71.306 & 70.615 & 60.699 & 54.959 & 51.177 & 46.265 & 54.482 \\
\hline
\end{tabular}

Fuente: Estadistica de Paro Registrado por municipios. INEM. Elaboración propia. 
EVOLUCIÓN DEL PARO EN EL SOBRARBE: \% VARIACIÓN $1984=100$

\begin{tabular}{|l|c|c|c|c|c|c|c|c|c|c|}
\hline \multirow{2}{*}{ COMARCA } & \multicolumn{10}{|c|}{$\%$ VARIACIÓN $1984=100$} \\
\cline { 2 - 11 } & INDICE & $85 / 84$ & $86 / 84$ & $87 / 84$ & $88 / 84$ & $89 / 84$ & $90 / 84$ & $91 / 84$ & $92 / 84$ & $93 / 84$ \\
\hline Sobrarbe & 100,0 & 119,8 & 121,6 & 142,9 & 163,8 & 142,5 & 126,9 & 79,1 & 91,0 & 69,0 \\
\hline Tot. prov. & 100,0 & 116,0 & 118,3 & 125,9 & 119,7 & 107,3 & 103,6 & 95,9 & 88,2 & 98,1 \\
\hline Total Aragón & 100,0 & 113,5 & 111,1 & 114,1 & 113,0 & 97,1 & 87,9 & 81,9 & 74,0 & 87,1 \\
\hline
\end{tabular}

Fuente: Estadística de Paro Registrado por municipios. INEM. Elaboración propia.

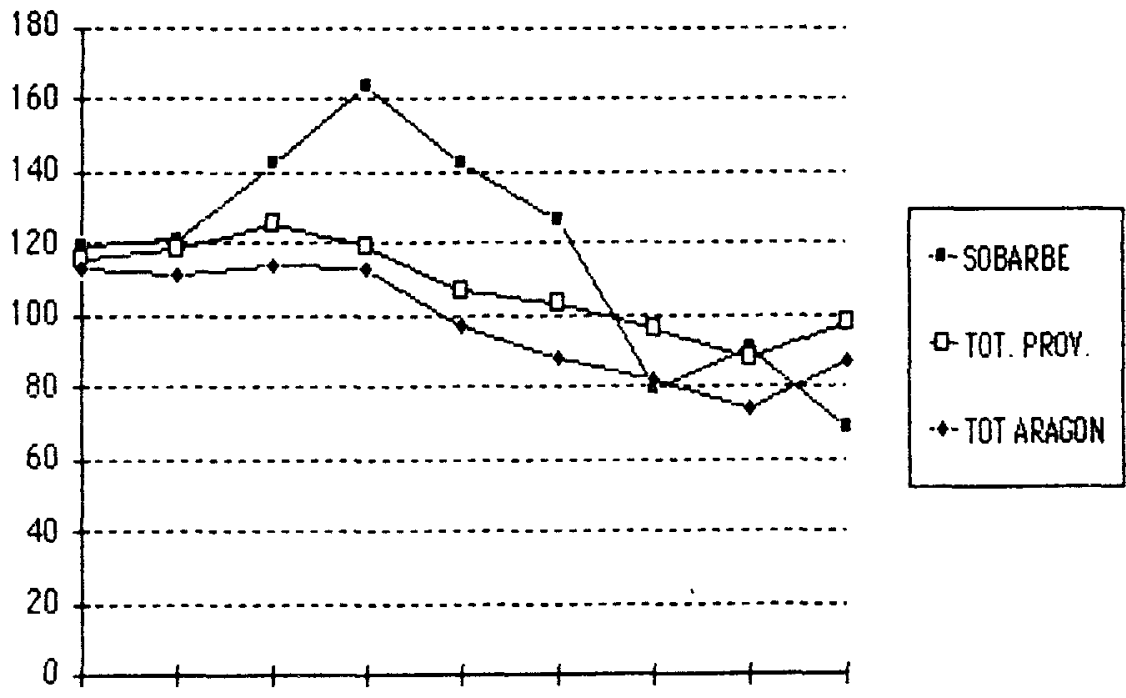

$85 / 8486 / 8487 / 8488 / 8489 / 8490 / 8491 / 8492 / 8493 / 84$

El número mayor de parados se localiza entre los peones agricolas, destacando los municipios de Aínsa-Sobrarbe, Plan y Boltaña. Sin embargo, el terciario en conjunto es el que presenta un número más alto, dado que resulta el sector de empleo más activo, aun contando con que el carácter estacional de los servicios aboque anualmente a incrementar las tasas de paro.

Las cifras de paro en el sector secundario son reducidas, teniendo en cuenta que la industria principal es la hidroeléctrica, si exceptuamos los trabajadores, mujeres en su mayoria, que declaran como actividad profesional su trabajo artesanal de tejido a mano en telar y que pertenecen todas ellas al valle de Gistaín. 
Dentro del Valle las diferencias se acusan fundamentalmente entre Plan, que arroja las menores cifras de paro, y Gistaín, las máximas.

EVOLUCIÓN DEL PARO EN EL VALLE DE GISTAÍN, 1986-1993

\begin{tabular}{|l|r|r|r|r|r|r|r|r|}
\hline \multirow{2}{*}{ MUNICIPIO } & \multicolumn{7}{|c|}{ PARO REGISTRADO (A 31 DE MARZO) } \\
\cline { 2 - 10 } & 1986 & 1987 & 1988 & 1989 & 1990 & 1991 & 1992 & 1993 \\
\hline Gistaín & 14 & 21 & 17 & 28 & 15 & 18 & 29 & 29 \\
\hline Plan & 16 & 17 & 8 & 11 & 4 & 4 & 3 & 0 \\
\hline S. Juan de Plan & - & 25 & 32 & 21 & 13 & 5 & 8 & 10 \\
\hline Total Valle & - & 63 & 57 & 60 & 32 & 27 & 40 & 39 \\
\hline
\end{tabular}

Fuente: Estadística de Paro Registrado por municipios. INEM. Elaboración propia.

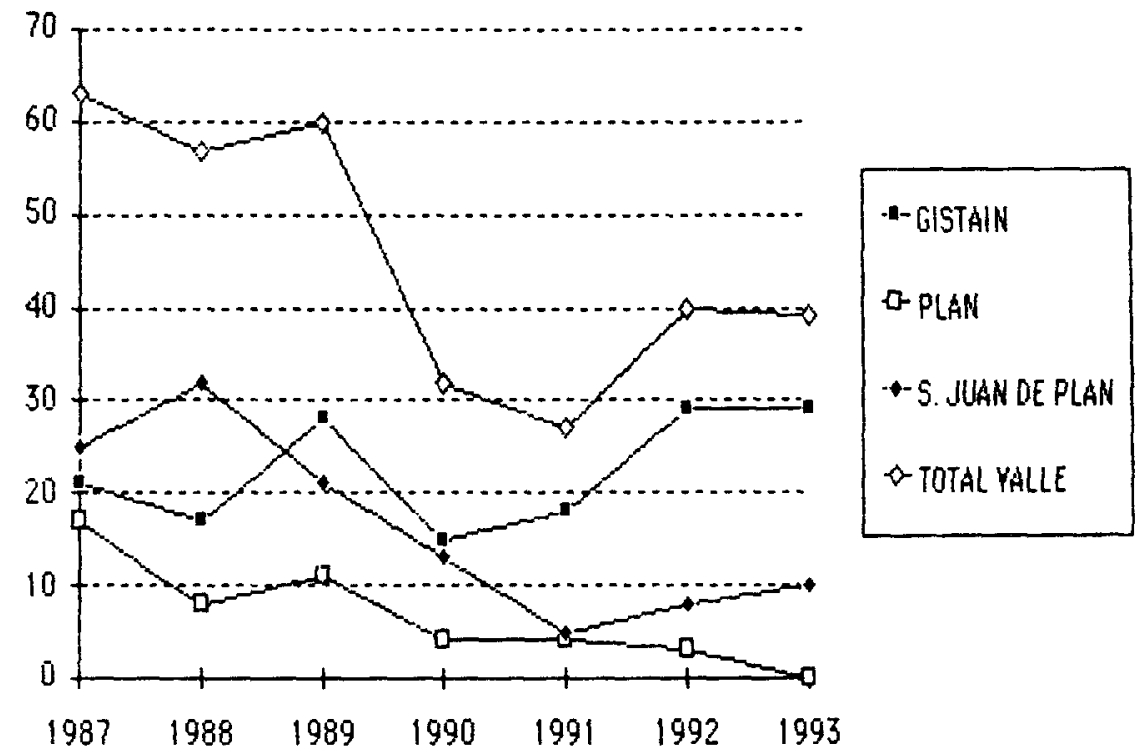

La edad de los parados cuyo número guarda prácticamente la misma proporción de hombres que de mujeres, corresponde significativamente al grupo comprendido entre los 16 y los 35 años, destacando, sobre todo, los situados entre los 21 y los 25 años pertenecientes en su mayoría al sector terciario, donde dominan las mujeres. 
Hecho diferente ocurre en las personas mayores de 40 años, generalmente hombres, vinculadas, por lo general, al sector agrario. Estas cifras reflejan la mayor incidencia del paro entre la población joven y las tendencias profesionales dominantes, situadas mayoritariamente en torno al sector servicios.

\section{CARACTERÍSTICAS DE LA ACTIVIDAD AGRARIA}

Una orografía agresiva y difícil, con un clima poco caluroso en verano y frío a riguroso en invierno, definen la comarca de Sobrarbe en general y el valle de Gistaín en particular, de forma que no resulta demasiado propicio para desarrollar una agricultura extensa y variada. El valor cultivable del suelo y su aprovechamiento, difiere bastante según la altitud en que se encuentre. Por eso al referirnos a la producción agraria es necesario tratar los distintos aspectos que la condicionan.

Las tierras cultivadas propiamente dichas se hallan localizadas al S.W. y al Sur del valle de Gistaín, al lado de los cauces del Ara y del Cinca, principalmente. En realidad comienzan con el laboreo de las tierras en los niveles donde empieza a perderse la dedicación a las plantas forrajeras de pasto directo o para ensilar que son las dominantes en el Valle de Gistaín.

La extensión o número de hectáreas con posibilidad de darles cultivo no es muy grande, estando limitada forzosamente por la propia configuración del terreno, el clima, la posibilidad de regadío y la orientación de los valles. Por el mismo motivo, las parcelas cultivables no suelen tener demasiada extensión: A la altura de Torla y Linás de Broto, las fajas suelen tener media Ha. por término medio, mientras que por Sarvisé y Fiscal alcanzan una y media Has.

Desde las cotas de altitud hacia otras inferiores y guardando estrecha relación con la situación topográfica de las tierras de labor, se observa una mayor diferenciación en la especie de los cultivos y en la época de maduración de las producciones.

El laboreo de las tierras se realiza empleando tractores de ruedas para mover arados de vertedera. El abonado tiene su mayor fuente en el estiércol procedente del ganado vacuno en las tierras altas aunque hay que contar también con los superfosfatos y abonos complejos propios de las explotaciones del Sur de la comarca.

Los cultivos son los tradicionales: vid, olivo, frutales, legumbres, hortalizas y cereales que continúan vigentes desde antiguo. Se inscriben en un 
ángulo con vértice en Mediano y cuyos lados parten de Fiscal y de Escalona, coincidiendo con las riberas de los dos ríos Ara y Cinca.

La más importante zona cerealista es la que se encuentra situada a lo largo de la margen izquierda del rio Cinca, cosechándose el trigo tipo «estrella" blandos. El maíz es otro cereal pienso al que se le presta una atención progresiva, al igual que al de tipo forrajero de gran demanda entre los ganaderos principalmente para vacuno y cerda.

Las patatas constituyen una clase de producción importante con alto rendimiento según las características del suelo. El problema puede surgir cuando la cosecha alcanza gran volumen y se le quiere dar salida ya que la competencia es fuerte con la producción del llano. El cultivo de la vid no es muy extenso y está en regresión sustituído por la cebada; no obstante, cabe señalar una zona formada por los pueblos de Pueyo de Araguás, Guaso, Banastón y Gerbe, donde se mantiene más firme. Suele ser vino de pocos grados, un poco áspero y con buena elaboración.

En los lugares abrigados del frío norte, en terrazas o bancales próximos a las casas o incluso entre ellas, se observan pequeños huertos en los que se plantan hortalizas y legumbres para el gasto de la familia. Estos huertos, $\tan$ característicos de la montaña pirenaica, constituyen en todos los núcleos habitados una heredad que se sigue cultivando hasta edades muy avanzadas, de generación en generación.

El cuidado de la tierra no va únicamente dirigido a la obtención de cosechas de los productos clásicos de la montaña, sino a conservar y acrecentar el valor de su aprovechamiento conservando el suelo y evitando a toda costa su erosión. Este es el principal objetivo del agricultor-ganadero de alta montaña que dedica el principal aprovechamiento de las tierras cultivadas a producir alimento para el ganado.

La base para la alimentación del ganado son los prados naturales a los que se les presta la mayor atención. Al cuidado agrícola debe añadirse el imprescindible parcelamiento para lograr que el pasto sea aprovechado racionalmente en el tiempo, lugar, y por las especies de ganado cuyo correlativo pastoreo beneficie la estabilidad de las praderas. Las pendientes más suaves de las laderas se dedican a prados artificiales, a base de «raigrass", trébol violeta y alguno de otra variedad.

Sólo si la población es estable, y se conjugan adecuadamente todos los recursos, pueden mantenerse las explotaciones con un nivel de beneficios aceptable. Cualquier dejación que se produce es causa de una degradación de la que participa el resto, creándose una huella destructora cuya regeneración es muy difícil. Es por lo que la pérdida de pobla- 
ción en edad joven ocurrida hace treinta años y que hemos comentado en el capítulo de población, causó un impacto decisivo en la actividad agraria.

\subsection{Clasificación agroclimática del Valle de Gistaín}

De acuerdo con la valoración climática de Papadakis, distinguiremos tres zonas correspondientes a otros tantos ambientes agroclimáticos que dominan en el Valle de Gistaín:

La primera zona está situado por encima del piso Submediterráneo que ocupa prácticamente el Sur de la comarca: el bajo Sobrarbe; y corresponde al área de influencia del piso Montano inferior seco que en el Valle de Gistain tiene presencia testimonial ya que se extiende formando pequeños manchones discontínuos sobre la vertiente oriental del río Cinqueta.

Esta zona se caracteriza por tener 7 meses de frio y régimen de lluvias de 900 a $1.100 \mathrm{~mm}$. anuales. La evapotranspiración potencial (ETP), varía mucho por ser una zona de orografía muy accidentada y depende de la pendiente, la orientación al sol y los vientos, pero puede estimarse en menos de $700 \mathrm{~mm}$. Hay zonas con déficit hídrico de 1 a 2 meses (julioagosto) según los años.

Aquí ya no es posible el cultivo del maíz para grano a no ser en enclaves más soleados, y con baja producción debido a problemas de maduración. Lo que sí puede darse es el cultivo de maíz forrajero, lo mismo que el de cereal, trigo o cebada que puede sembrarse incluso en otoño, aunque los agricultoras del Valle de Gistaín prefieren sembrar alfalfa y en menor extensión, trébol y veza para forraje.

Las superficies forrajeras tienen aprovechamientos de primavera y otoño a diente. Las producciones en regadío que ocupan extensiones minúsculas en el Valle, son un $50 \%$ superiores al secano en la baja Ribagorza y garantizan las cosechas en los veranos secos. Se suelen sembrar variedades de cereal de ciclo corto.

La segunda zona, corresponde al área de influencia del piso montano inferior húmedo que en muchos casos se interrelaciona con el nivel altimontano-alpino: Es el dominio de las praderas de siega, Los períodos fríos son largos, superiores a 7 meses, con veranos de escasa termicidad. Las precipitaciones medias son superiores a $1.100 \mathrm{~mm}$. anuales con una ETP de $650 \mathrm{~mm}$. Prácticamente no hay déficit hídrico a no ser algunos años muy secos. 
Las producciones agrícolas están, fundamentalmente, al servicio de la ganadería y son utilizadas en la comarca, a excepción del trigo que sale fuera. El cereal se utiliza para la ganadería intensiva o para la extensiva en épocas de estabulación, mientras que los forrajes recolectados se emplean como apoyo en la ganadería extensiva en época de carestía, sobre todo, para las madres en cria o en las últimas etapas de gestación. Los barbechos y rebastos de forrajeras se consumen a diente durante el invierno, primavera y otoño.

La superficie forrajera se aprovecha a diente en primavera $u$ otoño hasta las primeras nevadas. Tienen que ser variedades criófilas y en ese caso no presentan ningún tipo de problemas. El regadío lo que hace es garantizar el segundo corte los veranos secos y por eso es siempre aconsejable, además de que aumenta ligeramente las cosechas. El cereal, trigo y cebada, sólo es posible cultivarlo sembrándolo en primavera. El trigo tiene problemas de producción.

Las producciones son bajas para lo que se podria extraer ya que la mayoria de la superficie ( $80 \%$ ) se dedica a prados naturales. Estos deberían mejorarse dado que la producción de forraje en estas áreas es uno de los factores limitantes del desarrollo ganadero. Ello se conseguiría haciéndolas artificiales, lo que se traduciría en una mejor composición de los henos y una mayor producción. Además, se tendría que abonar con abonos minerales: existen graves carestías de ello, sobre todo fósforo y potasio. El abonado orgánico es bueno. El nivel de mecanización es muy bajo.

La tercera zona señalada, corresponde a los niveles altimontano y alpino que ocupan la práctica totalidad del Valle de Gistaín. En estos pisos prácticamente no se da el cereal y apenas se localizan tierras labradas más que para cultivos herbáceos como la alfalfa y el trébol para alimento del ganado. Pero sí se dan dentro de la SAU los pastizales de alta montaña, y UGM (unidad de ganado mayor) de vacuno de gran importancia en los sistemas ganaderos locales y provinciales. El aprovechamiento de estos pastizales se limita a 135 días (40\% del año) y están infrautilizados.

El medio donde se producen los pastizales viene condicionado por su situación geográfica donde el clima limita la extensión de los mismos y sus posibilidades de aprovechamiento particularmente en el Valle de Gistaín cuyas montañas delimitan la frontera con el vecino país francés por encima de los 2.500 metros de altura. Es a partir de niveles inferiores cuando el suelo va adquiriendo mejor aptitud para la formación de praderas destinadas a la alimentación del ganado, si bien el tiempo de pastoreo queda reducido a los meses de verano. 
Las áreas con mayor superficie dedicada a pastizales alpinos se encuentran repartidas de forma irregular a partir de alturas por debajo de los 2.500 metros formando una línea de Oeste a Este entre Broto, Gistaín, Plan, y S. Juan de Plan, con algunas ramificaciones hacia el Sur, llegando como limite hasta Foradada de Toscar por debajo de los 1.800 metros de altitud.

Otro grupo de superficies aprovechables para pastos se localiza en las suaves laderas y fondos de valle con más de 1.000 metros de altitud, ya que el pastoreo se efectúa en primavera y otoño en tránsito para los pastos de más altura en los puertos. En estas zonas existe además la posibilidad de crear prados artificiales, conjugando su explotación con la de masas forestales fuertemente desarrolladas entre los 1.000 y los 1.800 metros de altitud.

\subsection{Distribución de la superficie agrícola}

En el Valle de Gistaín, la extensión total de superficie productiva ha sufrido escasas variaciones en los últimos treinta años; no así su distribución y mecanización que han experimentado importantes cambios. Los trazos generales descritos de la agricultura de la comarca, apenas son reconocibles en el Valle de Gistaín. Sólo los huertos y unas pocas has. dedicadas a cereal y forraje para alimento de ganado forman parte de las tierras labradas. La práctica totalidad de la superficie agrícola está integrada por prados, pastizales, bosques y eriales.

DISTRIBUCIÓN DE LA SUPERFICIE AGRICOLA. 1982.

VALLE DE GISTAINN

\begin{tabular}{|l|c|c|c|c|c|c|c|c|c|c|c|}
\hline \multirow{2}{*}{ MUNICIPIO } & \multicolumn{9}{|c|}{ TIERRAS LABRADAS } & \multicolumn{3}{|c|}{ TIERRAS NO LABRADAS } & TOTAL \\
\cline { 2 - 12 } & $\begin{array}{c}\text { Herb. } \\
\text { barb. }\end{array}$ & Olivar & Viña & Frutal & $\begin{array}{c}\text { Resto } \\
\text { t. labr. }\end{array}$ & Total & $\begin{array}{c}\text { Prados } \\
\text { y Past. }\end{array}$ & Forest & $\begin{array}{c}\text { Otras } \\
\text { no Lab. }\end{array}$ & Total & $\begin{array}{c}\text { Explo- } \\
\text { tadas }\end{array}$ \\
\hline PLAN & 4 & 0 & 0 & 0 & 0 & 4 & 1.625 & 12.664 & 2.629 & 16.918 & 16.922 \\
\hline $\begin{array}{l}\text { S.JUAN } \\
\text { DE PLAN }\end{array}$ & 13 & 0 & 0 & 0 & 0 & 13 & 2.068 & 1.547 & 1.681 & 5.296 & 5.309 \\
\hline $\begin{array}{l}\text { TOT. VALLE } \\
\text { GISTAIN }\end{array}$ & 17 & 0 & 0 & 0 & 0 & 17 & 3.693 & 14.211 & 4.210 & 22.214 & 22.231 \\
\hline
\end{tabular}

Fuente: Censo Agrario 1982. $\mathrm{Mt}^{\circ}$. de Agricultura, Pesca y Alimentación. Elaboración propia.

La distribución de la superficie agrícola del Valle en 1982 expresa claramente la situación: Un total de 17 Has. de tierras labradas y 22.214 Has. 
de tierras no labradas de las que 17.904 pertenecen al dominio de prados $y$ bosques.

El municipio de S. Juan de Plan aporta las tres cuartas partes de la superficie cultivada del Valle, con trece Has. mientras Gistaín y Plan en su conjunto no aportan más que cuatro, aunque esta desigualdad ha ido equilibrándose en los últimos años. Por el contrario, el peso de la balanza se inclina a favor del municipio de Plan que engloba también Gistaín en cuanto al volumen y riqueza de recursos del bosque se refiere, con más de 12.000 Has. frente a S. Juan de Plan con 1.547 Has.

En el Censo Agrario de 1989 el total de tierras explotadas en el Valle de Gistaín es de 21.777 Has. lo que representa una disminución respecto al Censo de 1982 de 454 Has. En esos siete años de diferencia aumentaron las extensiones dedicadas a cultivos herbáceos para forraje del ganado pasando de 17 a $45 \mathrm{Has}$. el total de tierras labradas. S. Juan de Plan es el municipio que ha aportado más Has. en este aumento aunque en realidad, los cambios más importantes se han producido en las tierras no labradas.

DISTRIBUCIÓN DE LA SUPERFICIE AGRICOLA. 1989.

VALLE DE GISTAIIN

\begin{tabular}{|l|c|c|c|c|c|c|c|c|c|c|c|}
\hline \multirow{2}{*}{ MUNICIPIO } & \multicolumn{4}{|c|}{ TIERRAS LABRADAS } & \multicolumn{3}{|c|}{ TIERRAS NO LABRADAS } & TOTAL \\
\cline { 2 - 13 } & $\begin{array}{l}\text { Herb. } \\
\text { y barb. }\end{array}$ & Olivar & Viña & Frutal & $\begin{array}{c}\text { Resto } \\
\text { t. labr. }\end{array}$ & Total & $\begin{array}{c}\text { Prados } \\
\text { y Past. }\end{array}$ & Forest & $\begin{array}{c}\text { Otras } \\
\text { no Lab }\end{array}$ & Total & $\begin{array}{l}\text { Explo- } \\
\text { tadas }\end{array}$ \\
\hline GISTAIN & 6 & 0 & 0 & 0 & 0 & 6 & 1.272 & 7.012 & 21 & 8.305 & 8.311 \\
\hline PLAN & 9 & 0 & 0 & 0 & 0 & 9 & 1.256 & 4.768 & 2.884 & 8.907 & 8.916 \\
\hline $\begin{array}{l}\text { S.JUAN } \\
\text { DE PLAN }\end{array}$ & 30 & 0 & 0 & 0 & 0 & 30 & 376 & 3.682 & 463 & 4.520 & 4.550 \\
\hline $\begin{array}{l}\text { TOT. VALLE } \\
\text { GISTAÍN }\end{array}$ & 45 & 0 & 0 & 0 & 0 & 45 & 2.904 & 15.462 & 3.368 & 21.732 & 21.777 \\
\hline
\end{tabular}

Fuente: Censo Agrario 1989. Mtº. de Agricultura, Pesca y Alimentación. Elaboración propia.

En el Censo Agrario de 1989 aparece Gistaín como municipio independiente de Plan con el que mantiene bastante similitud en cuanto a la extensión de tierras no labradas (más de 8.000 Has. cada uno) y de las superficies dedicadas a pasto. Destaca poderosamente en este apartado el espectacular descenso que se observa en el término de $\mathrm{S}$. Juan de Plan que ha pasado de una superficie de 2.068 Has. de prados en 1982 a 376 Has. en 1989, y también se ha quedado en la mitad de superficie forestal en el mismo período de tiempo. 
Evolución de la superficie cultivada (1988-1990)

Para conocer la evolución seguida en el Valle en el último decenio, en cuanto a la distribución de los cultivos vamos a comparar las cifras que arroja el Censo Agrario de 1982 con las Hojas 1.T de las Cámaras Agrarias Locales durante los años 1988-1993, distinguiendo una primera fase de 1988-1990 en donde todavía el municipio de Plan engloba al de Gistaín y una segunda de 1991 a 1993 en el que aparece ya desagregado.

DISTRIBUCIÓN GENERAL DE TIERRAS. 1988-1990. VALLE DE GISTAIIN

\begin{tabular}{|c|c|c|c|c|c|c|c|c|c|c|}
\hline & \multicolumn{3}{|c|}{1988} & \multicolumn{3}{|c|}{1989} & \multicolumn{3}{|c|}{1990} \\
\hline & & Secano & Regad & Total & Secano & Regad. & Total & Secano & Regad. & Total \\
\hline \multirow{4}{*}{$\begin{array}{l}\text { TIERRAS } \\
\text { CULTIVO }\end{array}$} & HERB. & 141 & 45 & 186 & 131 & 43 & 174 & 113 & 37 & 150 \\
\hline & BARB. & 0 & 0 & 0 & 0 & 0 & 0 & 0 & 0 & 0 \\
\hline & LEÑOSO & 0 & 0 & 0 & 0 & 0 & 0 & 0 & 0 & 0 \\
\hline & TOTAL & 141 & 45 & 186 & 131 & 43 & 174 & 113 & 37 & 150 \\
\hline \multirow{3}{*}{$\begin{array}{l}\text { PRADOS } \\
\text { Y } \\
\text { PASTIZAL }\end{array}$} & PRADOS & 1.136 & 131 & 1.267 & 1.150 & 129 & 1.279 & 1.168 & 135 & 1.303 \\
\hline & PASTIZ. & 3.120 & - & 3.120 & 3.121 & - & 3.121 & 3.120 & - & 3.120 \\
\hline & TOTAL & 4.256 & 131 & 4.387 & 4.271 & 129 & 4.400 & 4.288 & 135 & 4.423 \\
\hline \multirow{4}{*}{$\begin{array}{l}\text { TERRENO } \\
\text { FORESTAL }\end{array}$} & Mte. MAD. & 7.995 & 0 & 7.995 & 7.995 & 0 & 7.995 & 7.995 & 0 & 7.995 \\
\hline & Mte. ABIER. & 482 & - & 482 & 482 & - & 482 & 482 & - & 482 \\
\hline & Mte. LEÑO & 1.802 & - & 1.802 & 1.802 & - & 1.802 & 1.802 & - & 1.802 \\
\hline & TOTAL & 10.279 & 0 & 10.279 & 10.279 & 0 & 10.279 & 10.279 & 0 & 10.279 \\
\hline \multirow{5}{*}{$\begin{array}{l}\text { OTRAS } \\
\text { SUPER- } \\
\text { FICIES }\end{array}$} & ERIAL & 6.705 & - & 6.705 & 6.705 & - & 6.705 & 6.705 & - & 6.705 \\
\hline & IMPROD. & 96 & - & 96 & 96 & - & 96 & 96 & - & 96 \\
\hline & NO AGRIC. & 174 & - & 274 & 274 & - & 274 & 274 & - & 274 \\
\hline & RíOS Y L. & 35 & - & 35 & 35 & - & 35 & 35 & - & 35 \\
\hline & TOTAL & 7.110 & - & 7.110 & 7.110 & - & 7.110 & 7.110 & - & 7.110 \\
\hline \multicolumn{2}{|c|}{ TOTAL GENERAL } & 21.786 & 176 & 21.962 & 21.791 & 142 & 21.963 & 21.790 & 172 & 21.962 \\
\hline
\end{tabular}

Fuente: "Superficies Ocupadas por los Cultivos Agrícolas". Hojas 1.T. de las Cámaras Agrarias Locales. Años: 1988, 1989, 1990. Elaboración propia. 


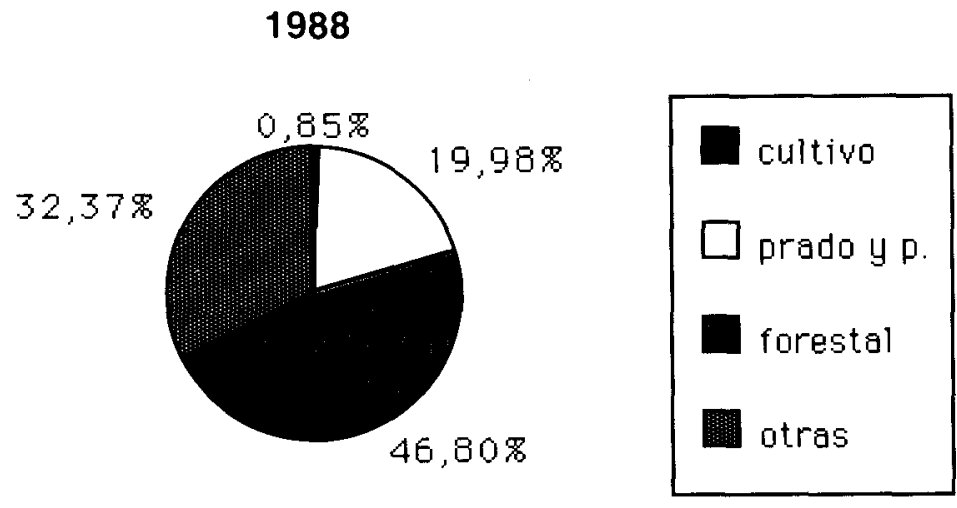

1989

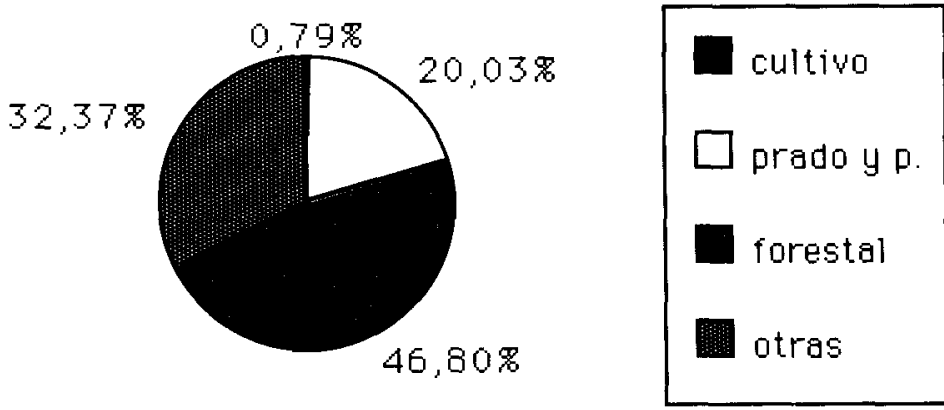

1990
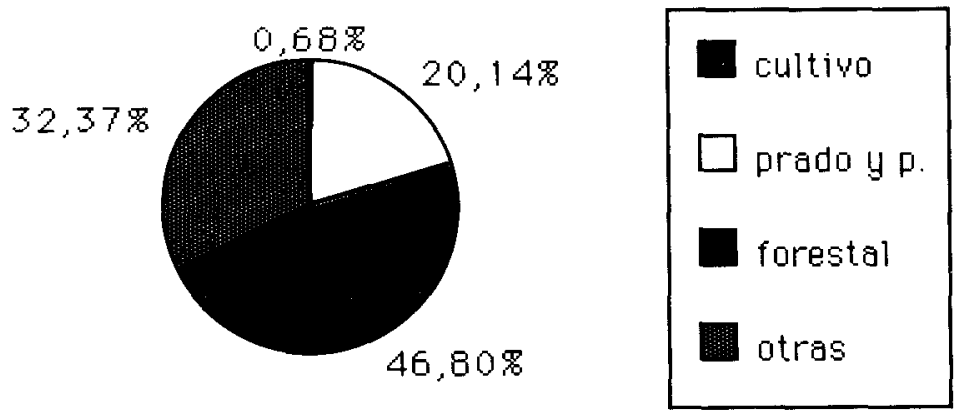
En conjunto, el total de tierras explotadas en el Valle de Gistaín está próximo a las 22.000 Has. en los tres primeros años (1988-90) considerados, lo que supone una superficie semejante a la de 1982 con 22.231 Has. Prácticamente, el terreno forestal y el dedicado a eriales e improductivos parece estabilizado en torno a las 10.000 Has. y 7.000 Has. respectivamente, y lo que más llama la atención es el cambio experimentado en estos dos apartados con respecto a 1982.

En efecto, la superficie forestal ha disminuido en 4.000 Has. mientras que se ha duplicado la superficie improductiva por el abandono de tierras; sin embargo los cultivos herbáceos, tanto en secano como en regadío, han ampliado ocho veces su extensión desde 1982 y también han aumentado los prados y pastizales en 500 Has. Hay que señalar que el retroceso de la superficie forestal en el Valle ha ido, fundamentalmente, en detrimento de los bosques de Gistaín y Plan como puede apreciarse en el siguiente cuadro comparándolo con el Censo Agrario de 1982.

DISTRIBUCIÓN GENERAL DE TIERRAS. 1988-1990.

\section{PLAN Y GISTAIIN}

\begin{tabular}{|c|c|c|c|c|c|c|c|c|c|c|}
\hline & \multicolumn{3}{|c|}{1988} & \multicolumn{3}{|c|}{1989} & \multicolumn{3}{|c|}{1990} \\
\hline & & Secano & Regad. & Total & Secano & Regad. & Total & Secano & Regad & Total \\
\hline \multirow{4}{*}{$\begin{array}{l}\text { TIERRAS } \\
\text { CULTIVO }\end{array}$} & HERB. & 85 & 30 & 115 & 77 & 28 & 105 & 65 & 25 & 90 \\
\hline & BARB. & 0 & 0 & 0 & 0 & 0 & 0 & 0 & 0 & 0 \\
\hline & LEÑOSO & 0 & 0 & 0 & 0 & 0 & 0 & 0 & 0 & 0 \\
\hline & TOTAL & 85 & 30 & 115 & 77 & 28 & 105 & 65 & 25 & 90 \\
\hline \multirow{3}{*}{$\begin{array}{l}\text { PRADOS } \\
Y \\
\text { PASTIZAL }\end{array}$} & PRADOS & 1.012 & 95 & 1.107 & 1.023 & 94 & 1.117 & 1.035 & 97 & 1.132 \\
\hline & PASTIZ. & 3.015 & - & 3.015 & 3.016 & - & 3.016 & 3.015 & - & 3.015 \\
\hline & TOTAL & 4.027 & 95 & 4.122 & 4.039 & 94 & 4.133 & 4.050 & 97 & 4.147 \\
\hline \multirow{4}{*}{$\begin{array}{l}\text { TERRENO } \\
\text { FORESTAL }\end{array}$} & Mte. MAD. & 5.462 & 0 & 5.462 & 5.462 & 0 & 5.462 & 5.462 & 0 & 5.462 \\
\hline & Mte. ABIER. & 461 & - & 461 & 461 & - & 461 & 461 & - & 461 \\
\hline & Mte. LEÑO & 1.569 & - & 1.569 & 1.569 & - & 1.569 & 1.569 & - & 1.569 \\
\hline & TOTAL & 7.492 & 0 & 7.492 & 7.492 & 0 & 7.492 & 7.492 & 0 & 7.492 \\
\hline \multirow{5}{*}{$\begin{array}{l}\text { OTRAS } \\
\text { SUPER- } \\
\text { FICIES }\end{array}$} & ERIAL & 4.776 & - & 4.776 & 4.776 & - & 4.776 & 4.776 & - & 4.776 \\
\hline & IMPROD. & 60 & - & 60 & 60 & - & 60 & 60 & - & 60 \\
\hline & NO AGRIC. & 255 & - & 255 & 255 & - & 255 & 255 & - & 255 \\
\hline & RIOS Y L. & 24 & - & 24 & 24 & - & 24 & 24 & - & 24 \\
\hline & TOTAL & 5.115 & - & 5.115 & 5.115 & - & 5.115 & 5.115 & - & 5.115 \\
\hline \multicolumn{2}{|c|}{ TOTAL GENERAL } & 16.719 & 125 & 16.844 & 16.723 & $\overline{122}$ & 16.845 & 16.722 & 122 & 16.844 \\
\hline
\end{tabular}

Fuente: "Superficies Ocupadas por los Cultivos Agrícolas". Hojas 1.T. de las Cámaras Agrarias Locales. Años: 1988, 1989, 1990. Elaboración propia. 
La superficie dedicada a herbáceos en Plan y Gistaín ha aumentado 20 veces su valor desde 1982 y los improductivos se han duplicado pasando de 2.629 Has. a 5.115 Has. en tanto que los prados y pastizales han bajado de 1.625 Has. a 1.012 en 1988 con ligerísimas recuperaciones poco relevantes en los años siguientes. El monte maderable y el monte leñoso, ambos capitulos importantes en la explotación del bosque, han descendido de 12.664 Has. a 7.492 Has.

\section{RESUMEN DE LOS CULTIVOS (HAS.) AÑOS 1988-1990. PLAN Y GISTAIIN}

\begin{tabular}{|l|c|c|r|r|r|r|r|r|c|}
\hline \multirow{2}{*}{$\begin{array}{l}\text { CULTIVOS } \\
\text { HERBACEOS }\end{array}$} & \multicolumn{3}{|c|}{1988} & \multicolumn{3}{c|}{1989} & \multicolumn{3}{c|}{1990} \\
\cline { 2 - 11 } & Secano & Regad. & Total & Secano & Regad. & Total & Secano & Regad. & Total \\
\hline CEREALES & 4 & - & 4 & 3 & - & 3 & 1 & 1 & 2 \\
\hline $\begin{array}{l}\text { LEGUMIN. } \\
\text { GRANO }\end{array}$ & - & 2 & 2 & - & 2 & 2 & - & 2 & 2 \\
\hline $\begin{array}{l}\text { TUBER. } \\
\text { CONSUMO }\end{array}$ & 27 & 4 & 31 & 23 & 3 & 26 & 18 & 2 & 20 \\
\hline $\begin{array}{l}\text { INDUS- } \\
\text { TRIALES }\end{array}$ & - & - & - & - & - & - & - & - & - \\
\hline $\begin{array}{l}\text { FORRA- } \\
\text { JEROS }\end{array}$ & 54 & 17 & 71 & 51 & 15 & 66 & 46 & 12 & 58 \\
\hline $\begin{array}{l}\text { HORTA- } \\
\text { LIZAS }\end{array}$ & - & 7 & 7 & - & 8 & 8 & - & 8 & 8 \\
\hline TOTAL & 85 & 30 & 115 & 77 & 28 & 105 & 65 & 25 & 90 \\
\hline
\end{tabular}

Fuente: "Superficies Ocupadas por los Cultivos Agrícolas". Hojas 1.T. de las Cámaras Agrarias Locales. Años : 1988, 1989 y 1990. Elaboración propia.

La alfalfa, con más de 40 Has., y la patata tardia (la recolección tiene lugar entre el 30 de septiembre y el 15 de enero) con más de 20 Has.,destacan como ocupación primera o principal en las tierras cultivadas en secano, en Plan y Gistaín, dejando tambien para el regadio algunas Has. de alfalfa y de acelgas (ambas entre 12 y 15 Has.) y en menor extensión judía verde ( $3 \mathrm{Has}$.), col y cebolla ( $1 \mathrm{Ha}$.) y otros productos hortícolas para el gasto de la familia.

En S. Juan de Plan destaca en todos estos años, la reducción a la décima parte de las superficies dedicadas a prados y pastizales. 
DISTRIBUCIÓN GENERAL DE TIERRAS. 1988-1990. SAN JUAN DE PLAN

\begin{tabular}{|c|c|c|c|c|c|c|c|c|c|c|}
\hline & \multicolumn{3}{|c|}{1988} & \multicolumn{3}{|c|}{1989} & \multicolumn{3}{|c|}{1990} \\
\hline & & Secano & Regad. & Total & Secano & Regad. & Total & Secano & Regad. & Total \\
\hline \multirow{4}{*}{$\begin{array}{l}\text { TIERRAS } \\
\text { CULTIVO }\end{array}$} & HERB. & 56 & 15 & 71 & 54 & 15 & 69 & 48 & 12 & 60 \\
\hline & BARB. & 0 & 0 & 0 & 0 & 0 & 0 & 0 & 0 & 0 \\
\hline & LEÑOSO & 0 & 0 & 0 & 0 & 0 & 0 & 0 & 0 & 0 \\
\hline & TOTAL & 56 & 15 & 71 & 54 & 15 & 69 & 48 & 12 & 60 \\
\hline \multirow{3}{*}{$\begin{array}{l}\text { PRADOS } \\
Y \\
\text { PASTIZAL }\end{array}$} & PRADOS & 124 & 36 & 160 & 127 & 35 & 162 & 133 & 38 & 171 \\
\hline & PASTIZ. & 105 & - & 105 & 105 & - & 105 & 105 & - & 105 \\
\hline & TOTAL & 229 & 36 & 265 & 232 & 35 & 257 & 238 & 38 & 276 \\
\hline \multirow{4}{*}{$\begin{array}{l}\text { TERRENO } \\
\text { FORESTAL }\end{array}$} & Mte. MAD. & 2.533 & 0 & 2.533 & 2.533 & 0 & 2.533 & 2.533 & 0 & 2.533 \\
\hline & Mte. ABIER. & 21 & - & 21 & 21 & - & 21 & 21 & - & 21 \\
\hline & Mte. LEÑO & 233 & - & 233 & 233 & - & 233 & 233 & - & 233 \\
\hline & TOTAL & 2.787 & - & 2.787 & 2.787 & 0 & \begin{tabular}{|l|}
2.787 \\
\end{tabular} & 2.787 & - & 2.787 \\
\hline \multirow{5}{*}{$\begin{array}{l}\text { OTRAS } \\
\text { SUPER- } \\
\text { FICIES }\end{array}$} & ERIAL & 1.929 & - & 1.929 & 1.929 & - & 1.929 & 1.929 & - & 1.929 \\
\hline & IMPROD. & 36 & - & 36 & 36 & - & 36 & 36 & - & 36 \\
\hline & NO AGRIC. & 19 & - & 19 & 19 & - & 19 & 19 & - & 19 \\
\hline & RIOS Y L. & 11 & - & 11 & 11 & - & 11 & 11 & - & 11 \\
\hline & TOTAL & 1.995 & - & 1.995 & 1.995 & - & 1.995 & 1.995 & - & 1.995 \\
\hline \multicolumn{2}{|c|}{ TOTAL GENERAL } & 5.067 & 51 & 5.118 & 5.068 & 50 & 5.118 & 5.068 & 50 & 5.118 \\
\hline
\end{tabular}

Fuente: "Superficies Ocupadas por los Cultivos Agrícolas". Hojas 1.T. de las Cámaras Agrarias Locales. Años: 1988, 1989, 1990. Elaboración propia.

\section{RESUMEN DE LOS CULTIVOS (HAS.) AÑOS 1988-1990. SAN JUAN DE PLAN}

\begin{tabular}{|l|c|c|c|c|c|c|c|c|c|}
\hline \multirow{2}{*}{$\begin{array}{l}\text { CULTIVOS } \\
\text { HERBÁCEOS }\end{array}$} & \multicolumn{3}{|c|}{1988} & \multicolumn{3}{c|}{1989} & \multicolumn{3}{c|}{1990} \\
\cline { 2 - 10 } & Secano & Regad. & Total & Secano & Regad. & Total & Secano & Regad & Total \\
\hline CEREALES & 3 & - & 3 & 2 & - & 2 & 1 & - & 1 \\
\hline $\begin{array}{l}\text { LEGUMIN. } \\
\text { GRANO }\end{array}$ & - & 1 & 1 & - & 1 & 1 & - & 0,5 & 0,5 \\
\hline $\begin{array}{l}\text { TUBER. } \\
\text { CONSUMO }\end{array}$ & 10 & 4 & 14 & 10 & 2 & 12 & 8 & 1,5 & 9,5 \\
\hline $\begin{array}{l}\text { INDUS- } \\
\text { TRIALES }\end{array}$ & - & - & - & - & - & - & - & - & - \\
\hline $\begin{array}{l}\text { FORRA- } \\
\text { JEROS }\end{array}$ & 43 & 7 & 50 & 42 & 7 & 49 & 39 & 5,5 & 44,5 \\
\hline $\begin{array}{l}\text { HORTA- } \\
\text { LIZAS }\end{array}$ & - & 3 & 3 & - & 5 & 5 & - & 4,5 & 4,5 \\
\hline TOTAL & 56 & 15 & 71 & 54 & 15 & 69 & 48 & 12 & 60 \\
\hline
\end{tabular}

Fuente: "Superficies Ocupadas por los Cultivos Agricolas". Hojas 1.T. de las Cámaras Agrarias Locales. Años: 1988, 1989 y 1990 . Elaboración propia. 
En cuanto a la especificación de los productos cultivados, hay que señalar al igual que los municipios vecinos, el predominio de la alfalfa (de 35 a 40 Has.) en secano y de 5 a 8 Has. en regadío, complementada para alimento del ganado con menores extensiones ( 2 ó 3 Has.) dedicadas a trébol y veza para forraje. Los cultivos de huerta para consumo humano coinciden tambien con los del resto del Valle: patata tardía y judía verde con 9 Has. y 2 Has., respectivamente.

\section{Evolución de la superficie cultivada (1991-1993)}

Comparando el siguiente cuadro de distribución de las superficies ocupadas por los cultivos agrícolas entre 1991 y 1993 con los anteriores de 1988-1990, se observa la aceleración de algunas tendencias ya apuntadas como la sensible disminución de la superficie de prados y pastizal en general a partir de 1991, y tambien en este mismo año la pérdida en Has. de los cultivos forrajeros tanto en secano como en regadío. En cuanto al terreno forestal, y de otras superficies en las que se incluyen eriales e improductivos, permanece en los niveles de 1988 a 1990 ya comentados, a los que se había reducido desde el Censo Agrario de 1982.

DISTRIBUCIÓN GENERAL DE TIERRAS. 1991-1993. VALLE DE GISTAÍN

\begin{tabular}{|c|c|c|c|c|c|c|c|c|c|c|}
\hline & \multicolumn{3}{|c|}{1991} & \multicolumn{3}{|c|}{1992} & \multicolumn{3}{|c|}{1993} \\
\hline & & Secano & Regad. & Total & Secano & Regad & Total & Secano & Regad & Total \\
\hline \multirow{4}{*}{$\begin{array}{l}\text { TIERRAS } \\
\text { CULTIVO }\end{array}$} & HERB. & 117 & 18 & 135 & 104 & 17 & 121 & 84 & 16 & 100 \\
\hline & BARB. & 0 & 0 & 0 & 0 & 0 & 0 & 0 & 0 & 0 \\
\hline & LEÑOSO & 0 & 0 & 0 & 0 & 0 & 0 & 0 & 0 & 0 \\
\hline & TOTAL & 117 & 18 & 135 & 104 & 17 & 121 & 84 & 16 & 100 \\
\hline \multirow{3}{*}{$\begin{array}{l}\text { PRADOS } \\
Y \\
\text { PASTIZAL }\end{array}$} & PRADOS & 724 & 199 & 923 & 694 & 181 & 875 & 690 & 164 & 854 \\
\hline & PASTIZ. & 2.976 & - & 2.976 & 3.038 & - & 3.038 & 3.080 & - & 3.080 \\
\hline & TOTAL & 3.700 & 199 & 3.899 & 3.732 & 181 & 3.913 & $3 . \overline{770}$ & 164 & 3.934 \\
\hline \multirow{4}{*}{$\begin{array}{l}\text { TERRENO } \\
\text { FORESTAL }\end{array}$} & Mte. MAD. & 7.983 & 0 & 7.983 & 7.983 & 0 & 7.983 & 7.983 & 0 & 7.983 \\
\hline & Mte. ABIER. & 491 & - & 491 & 491 & - & 491 & 491 & - & 491 \\
\hline & Mte. LEÑO & 2.133 & - & 2.133 & 2.133 & - & 2.133 & 2.133 & - & 2.133 \\
\hline & TOTAL & 10.607 & 0 & 10.607 & 10.607 & 0 & 10.607 & 10.607 & 0 & 10.607 \\
\hline \multirow{5}{*}{$\begin{array}{l}\text { OTRAS } \\
\text { SUPER- } \\
\text { FICIES }\end{array}$} & ERIAL & 2.929 & - & 2.929 & 4.919 & - & 4.919 & 4.929 & - & 4.929 \\
\hline & IMPROD. & 4.052 & - & 4.052 & 2.062 & - & 2.062 & 2.052 & - & 2.052 \\
\hline & NO AGRIC. & 300 & - & 300 & 300 & - & 300 & 300 & - & 300 \\
\hline & RÍOS Y L. & 41 & - & 41 & 41 & - & 41 & 41 & - & 41 \\
\hline & TOTAL & 7.322 & - & 7.322 & 7.322 & - & 7.322 & 7.322 & - & 7.322 \\
\hline \multicolumn{2}{|c|}{ TOTAL GENERAL } & 21.746 & 217 & 21.963 & 21.765 & 198 & 21.963 & 21.783 & 180 & 21.963 \\
\hline
\end{tabular}

Fuente: "Superficies Ocupadas por los Cultivos Agricolas". Hojas 1.T. de las Cámaras Agrarias Locales. Años: 1991, 1992, 1993. Elaboración propia. 
DISTRIBUCIÓN GENERAL DE TIERRAS. VALLE DE GISTAÍN 1991
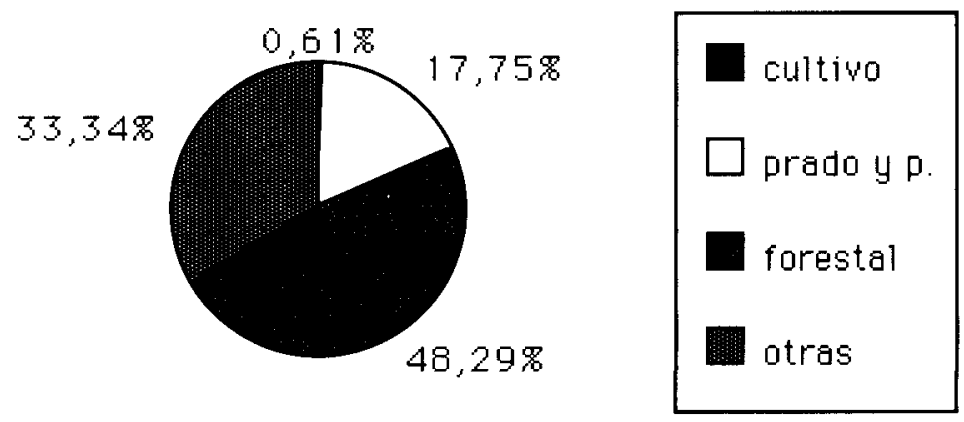

1992

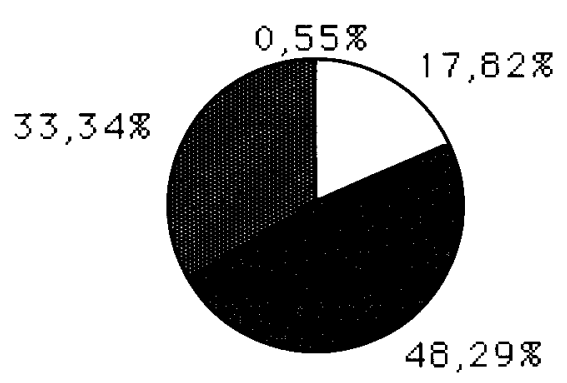

cultivo

$\square$ prado y p.

forestal

otras

1993

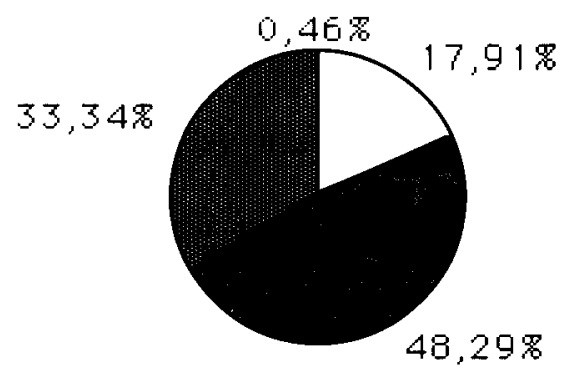

\begin{tabular}{|l}
$\square$ cultivo \\
$\square$ prado y p. \\
$\square$ forestal \\
$\square$ otras
\end{tabular}


Atendiendo a las particularidades que presenta cada pueblo que integra este valle, haremos referencia por vez primera al municipio de Gistaín, desagregado de Plan en 1.987. El total general de la distribución de tierras en ambos términos es bastante equilibrado ya que cada en uno de ellos los cultivos ocupan entre 8.000 y 8.700 Has. de tierra. Claramente decantadas en Gistaín a favor de los improductivos y eriales seguidos de cerca entre 1991 y 1993 , por las superficies de prados y pastizales que ocupan entre 2.500 a 2.600 Has. El monte maderable se sitúa con un valor fijo en 1.500 Has. En el terreno forestal domina Plan, mientras que en en el terreno de pastos, la primacía la ostenta Gistain.

DISTRIBUCIÓN GENERAL DE TIERRAS. 1991-1993. MUNICIPIO DE GISTAIIN

\begin{tabular}{|c|c|c|c|c|c|c|c|c|c|c|}
\hline & \multicolumn{3}{|c|}{1991} & \multicolumn{3}{|c|}{1992} & \multicolumn{3}{|c|}{1993} \\
\hline & & Secano & Regad. & Total & Secano & Regad. & \begin{tabular}{|l|} 
Total \\
\end{tabular} & Secano & Regad. & Total \\
\hline \multirow{4}{*}{$\begin{array}{l}\text { TIERAAS } \\
\text { CULTIVO }\end{array}$} & HERB. & 43 & 6 & 49 & 37 & 5 & 42 & 29 & 6 & 36 \\
\hline & BARB. & 0 & 0 & 0 & 0 & 0 & 0 & 0 & 0 & 0 \\
\hline & LEÑOSO & 0 & 0 & 0 & 0 & 0 & 0 & 0 & 0 & 0 \\
\hline & TOTAL & 43 & 6 & 49 & 37 & 5 & 42 & 29 & 6 & 36 \\
\hline \multirow{3}{*}{$\begin{array}{l}\text { PRADOS } \\
\text { Y } \\
\text { PASTIZAL }\end{array}$} & PRADOS & 436 & 117 & 553 & 410 & 100 & 510 & 410 & 90 & 500 \\
\hline & PASTIZ. & 2.050 & - & 2.050 & 2.100 & - & 2.100 & 2.117 & - & 2.117 \\
\hline & TOTAL & 2.486 & 117 & 2.603 & 2.510 & 100 & 2.610 & 2.527 & 90 & 2.617 \\
\hline \multirow{4}{*}{$\begin{array}{l}\text { TERRENO } \\
\text { FORESTAL }\end{array}$} & Mte. MAD. & 1.500 & 0 & 1.500 & 1.500 & 0 & 1.500 & 1.500 & 0 & 1.500 \\
\hline & Mte. ABIER. & 150 & - & 150 & 150 & - & 150 & 150 & - & 150 \\
\hline & Mte. LEÑO & 350 & - & 350 & 350 & - & 350 & 350 & - & 350 \\
\hline & TOTAL & 2.000 & 0 & 2.000 & 2.000 & 0 & 2.000 & 2.000 & 0 & 2.000 \\
\hline \multirow{5}{*}{$\begin{array}{l}\text { OTRAS } \\
\text { SUPER- } \\
\text { FICIES }\end{array}$} & ERIAL & 0 & - & 0 & 2.000 & - & 2.000 & 2.000 & - & 2.000 \\
\hline & IMPROD. & 3.231 & - & 3.231 & 1.231 & - & 1.231 & 1.231 & - & 1.231 \\
\hline & NO AGRIC. & 208 & - & 208 & 208 & - & 208 & 208 & - & 208 \\
\hline & RIOS YL. & 15 & - & 15 & 15 & - & 15 & 15 & - & 15 \\
\hline & TOTAL & 3.454 & - & 3.454 & 3.454 & - & 3.454 & 3.454 & - & 3.454 \\
\hline \multicolumn{2}{|c|}{ TOTAL GENERAL } & 7.983 & 123 & 8.106 & 8.001 & 105 & 8.106 & 8.010 & 96 & 8.106 \\
\hline
\end{tabular}

Fuente: "Superficies Ocupadas por los Cultivos Agrícolas". Hojas 1.T. de las Cámaras Agrarias Locales. Años: 1991, 1992, 1993. Elaboración propia.

Lo mismo que en los años anteriores unido a Plan, la ocupación principal de la superficie dedicada a los cultivos herbáceos en Gistaín es la alfalfa y el trébol en secano que ocupan de 30 a 35 Has. seguida de la pa- 
tata tardía (4 Has.). El resto de los cultivos, todos ellos de 0,5 Has. de regadío se dedica a judía seca, patata de media estación (recolección entre 15 de junio y 30 de septiembre), y las consabidas hortalizas: col y repollo, lechuga, acelga, cebolla y judía verde.

RESUMEN DE LOS CULTIVOS (HAS.) AÑOS 1991-1993. GISTAIN

\begin{tabular}{|l|c|c|c|c|c|c|c|c|c|}
\hline \multirow{2}{*}{$\begin{array}{c}\text { CULTIVOS } \\
\text { HERBACEOS }\end{array}$} & \multicolumn{3}{|c|}{1991} & \multicolumn{3}{c|}{1992} & \multicolumn{3}{c|}{1993} \\
\cline { 2 - 11 } & Secano & Regad. & Total & Secano & Regad. & Total & Secano & Regad. & Total \\
\hline CEREALES & - & - & - & - & - & - & - & - & - \\
\hline $\begin{array}{l}\text { LEGUMIN. } \\
\text { GRANO }\end{array}$ & - & 1 & 1 & - & 0,5 & 0,5 & - & - & - \\
\hline $\begin{array}{l}\text { TUBER. } \\
\text { CONSUMO }\end{array}$ & 4,5 & 0,5 & 5 & 4 & 0,5 & 4,5 & 3 & - & 3 \\
\hline $\begin{array}{l}\text { INDUS- } \\
\text { TRIALES }\end{array}$ & - & - & - & - & - & - & - & - & - \\
\hline $\begin{array}{l}\text { FORRA- } \\
\text { JEROS }\end{array}$ & 38,5 & - & 38,5 & 33 & - & 33 & 26 & - & 26 \\
\hline $\begin{array}{l}\text { HORTA- } \\
\text { LIZAS }\end{array}$ & - & 4,5 & 4,5 & - & 4 & 4 & - & 3 & 3 \\
\hline TOTAL & 43 & 6 & 49 & 37 & 5 & 42 & 29 & 3 & 32 \\
\hline
\end{tabular}

Fuente: "Superficies Ocupadas por los Cultivos Agrícolas". Hojas 1.T. de las Cámaras Agrarias Locales. Años: 1991, 1992 y 1993. Elaboración propia.

Plan destaca en todo el valle por la masa de montes maderables y leñosos que posee y que mantiene de forma invariable: En conjunto, cerca de 6.000 Has.(3.950 Has. de monte maderable y 1.550 Has de monte leñoso). Las partidas de cultivos herbáceos, prados y pastizal y otras superficies, ofrecen valores semejantes en cuanto a las superficies que ocupan en cada una de ellas a lo largo del último trienio.

La dedicación principal de las tierras cultivadas, como en el resto del valle, es a los cultivos forrajeros, exclusivamente alfalfa, a la que destinan 30 Has. Los demás productos son hortícolas y ocupan superficies muy pequeñas, de 0,2 a 0,5 Has. de col, acelga, lechuga, tomate, judía verde, etc. 
Envejecimiento demográfico y actividad agraria en el Valle de Gistaín

DISTRIBUCIÓN GENERAL DE TIERRAS. 1991-1993.

MUNICIPIO DE PLAN

\begin{tabular}{|c|c|c|c|c|c|c|c|c|c|c|}
\hline & \multicolumn{3}{|c|}{1991} & \multicolumn{3}{|c|}{1992} & \multicolumn{3}{|c|}{1993} \\
\hline & & Secano & Regad. & Total & cano & Regad. & Total & Secano & Regad. & Total \\
\hline \multirow{4}{*}{$\begin{array}{l}\text { TIERRAS } \\
\text { CULTIVO }\end{array}$} & HERB. & 34 & 4 & 38 & 32 & 5 & 37 & 27 & 4 & 31 \\
\hline & BAAB. & 0 & 0 & 0 & 0 & 0 & 0 & 0 & 0 & 0 \\
\hline & LEÑOSO & 0 & 0 & 0 & 0 & 0 & 0 & 0 & 0 & 0 \\
\hline & TOTAL & 34 & 4 & 38 & 32 & 5 & 37 & 27 & 4 & 31 \\
\hline \multirow{3}{*}{$\begin{array}{l}\text { PRADOS } \\
\text { Y } \\
\text { PASTIZAL }\end{array}$} & PRADOS & 146 & 42 & 188 & 144 & 41 & 185 & 140 & 38 & 178 \\
\hline & PASTIZ. & 820 & - & 820 & 824 & - & 824 & 837 & - & 837 \\
\hline & TOTAL & 966 & 42 & 1.008 & 968 & 41 & 1.009 & 977 & 38 & 1.015 \\
\hline \multirow{4}{*}{$\begin{array}{l}\text { TERRENO } \\
\text { FORESTAL }\end{array}$} & Mte. MAD. & 3.950 & 0 & 3.950 & 3.950 & 0 & 3.950 & 3.950 & 0 & 3.950 \\
\hline & Mte. ABIER. & 320 & - & 320 & 20 & - & 320 & 320 & - & 320 \\
\hline & Mte. LEÑO & 1.550 & - & 1.550 & 1.550 & - & 1.550 & 1.550 & - & 1.550 \\
\hline & TOTAL & 5.820 & 0 & 5.820 & 5.820 & 0 & 5.820 & 5.820 & 0 & 5.820 \\
\hline \multirow{5}{*}{$\begin{array}{l}\text { OTRAS } \\
\text { SUPER- } \\
\text { FICIES }\end{array}$} & ERIAL & 1.000 & - & 1.000 & 990 & - & 990 & 1.000 & - & 1.000 \\
\hline & IMPROD. & 785 & - & 785 & 795 & - & 795 & 785 & - & 785 \\
\hline & NO AGRIC. & 73 & - & 73 & 73 & - & 73 & 73 & - & 73 \\
\hline & RIOS Y L. & 15 & - & 15 & 15 & - & 15 & 15 & - & 15 \\
\hline & TOTAL & 1.873 & - & 1.873 & 1.873 & - & 1.873 & 1.873 & - & 1.873 \\
\hline \multicolumn{2}{|c|}{ TOTAL GENERAL } & 8.693 & 46 & 8.739 & 8.693 & 46 & 8.693 & 8.697 & 42 & 8.697 \\
\hline
\end{tabular}

Fuente: "Superficies Ocupadas por los Cultivos Agricolas". Hojas 1.T. de las Cámaras Agrarias Locales. Años: 1991, 1992, 1993. Elaboración propia.

\section{RESUMEN DE LOS CULTIVOS (HAS.) AÑOS 1991-1993. PLAN}

\begin{tabular}{|l|c|c|c|c|c|c|c|c|c|}
\hline \multirow{2}{*}{$\begin{array}{c}\text { CULTIVOS } \\
\text { HERBÁCEOS }\end{array}$} & \multicolumn{3}{|c|}{1991} & \multicolumn{3}{c|}{1992} & \multicolumn{3}{c|}{1993} \\
\hline & Secano & Regad. & Total & Secano & Regad. & Total & Secano & Regad. & Total \\
\hline CEREALES & - & - & - & - & - & - & - & - & - \\
\hline $\begin{array}{l}\text { LEGUMIN. } \\
\text { GRANO }\end{array}$ & - & 0,5 & 0,5 & - & 0,2 & 0,2 & - & - & - \\
\hline $\begin{array}{l}\text { TUBER. } \\
\text { CONSUMO }\end{array}$ & 3,5 & 0,5 & 4 & 3 & 0,6 & 3,6 & 2 & - & 2 \\
\hline $\begin{array}{l}\text { INDUS- } \\
\text { TRIALES }\end{array}$ & - & - & - & - & - & - & - & - & - \\
\hline $\begin{array}{l}\text { FORRA- } \\
\text { JEROS }\end{array}$ & 30,5 & - & 30,5 & 29 & 1,4 & 30,4 & 25 & 1 & 26 \\
\hline $\begin{array}{l}\text { HORTA- } \\
\text { LIZAS }\end{array}$ & - & 3 & 3 & - & 2,8 & 2,8 & - & 2 & 2 \\
\hline TOTAL & 34 & 4 & 38 & 32 & 5 & 37 & 27 & 3 & 30 \\
\hline
\end{tabular}

Fuente: "Superficies Ocupadas por los Cultivos Agrícolas". Hojas 1.T. de las Cámaras Agrarias Locales. Años: 1988, 1989 y 1990 . Elaboración propia. 
Por último, S. Juan de Plan mantiene valores parecidos a Plan en cuanto a la extensión dedicada a cultivos herbáceos (entre 30 y 40 Has.) y a prados (170-180 Has.) y pastizal (115-130 Has.) Al igual que en los demás pueblos del valle, carece de barbechos y de cultivos leñosos que no permite la dureza climática. El monte maderable ocupa 2.533 Has. y el erial, 1.929 Has.

DISTRIBUCIÓN GENERAL DE TIERRAS. 1991-1993.

SAN JUAN DE PLAN

\begin{tabular}{|c|c|c|c|c|c|c|c|c|c|c|}
\hline & \multicolumn{3}{|c|}{1991} & \multicolumn{3}{|c|}{1992} & \multicolumn{3}{|c|}{1993} \\
\hline & & Secano & Regad. & Total & Secano & Regad. & Total & Secano & Regad. & Total \\
\hline \multirow{4}{*}{$\begin{array}{l}\text { TIERRAS } \\
\text { CULTIVO }\end{array}$} & HERB. & 40 & 8 & 48 & 35 & 7 & 42 & 28 & 6 & 34 \\
\hline & BARB. & 0 & 0 & 0 & 0 & 0 & 0 & 0 & 0 & 0 \\
\hline & LEÑOSO & 0 & 0 & 0 & 0 & 0 & 0 & 0 & 0 & 0 \\
\hline & TOTAL & 40 & 8 & 48 & 35 & 7 & 42 & 28 & 6 & 34 \\
\hline \multirow{3}{*}{$\begin{array}{l}\text { PRADOS } \\
\text { Y } \\
\text { PASTIZAL }\end{array}$} & PRADOS & 142 & 40 & 182 & 140 & 40 & 180 & 140 & 36 & 176 \\
\hline & PASTIZ. & 106 & - & 106 & 114 & - & 114 & 126 & - & 126 \\
\hline & TOTAL & 248 & 40 & 288 & 254 & 40 & 294 & 266 & 36 & 302 \\
\hline \multirow{4}{*}{$\begin{array}{l}\text { TERRENO } \\
\text { FORESTAL }\end{array}$} & Mte. MAD. & 2.533 & 0 & 2.533 & 2.533 & 0 & 2.533 & 2.533 & 0 & 2.533 \\
\hline & Mte. ABIER. & 21 & - & 21 & 21 & - & 21 & 21 & - & 21 \\
\hline & Mte. LEÑO & 233 & - & 233 & 233 & - & 233 & 233 & - & 233 \\
\hline & TOTAL & 2.787 & 0 & 2.787 & 2.787 & 0 & 2.787 & 2.787 & - & 2.787 \\
\hline \multirow{5}{*}{$\begin{array}{l}\text { OTRAS } \\
\text { SUPER- } \\
\text { FICIES }\end{array}$} & ERIAL & 1.929 & - & 1.929 & 1.929 & - & 1.929 & 1.929 & - & 1.929 \\
\hline & IMPROD. & 36 & - & 36 & 36 & - & 36 & 36 & - & 36 \\
\hline & NO AGRIC. & 19 & - & 19 & 19 & - & 19 & 19 & - & 19 \\
\hline & RIOS Y L. & 11 & - & 11 & 11 & - & 11 & 11 & - & 11 \\
\hline & TOTAL & 1.995 & - & 1.995 & 1.995 & - & 1.995 & 1.995 & - & 1.995 \\
\hline \multicolumn{2}{|c|}{ TOTAL GENERAL } & 5.070 & 48 & 5.118 & 5.071 & 47 & 5.118 & 5.076 & 42 & 5.118 \\
\hline
\end{tabular}

Fuente: "Superficies Ocupadas por los Cultivos Agrícolas". Hojas 1.T. de las Cámaras Agrarias Locales. Años: 1991, 1992, 1993. Elaboración propia.

No presenta ninguna novedad respecto a los cultivos forrajeros (25 a 30 Has. de alfalfa) y a los hortícolas de regadio para consumo familiar.en los que ocupan en su mayor parte de 0,1 a 0,5 Has. 
RESUMEN DE LOS CULTIVOS (HAS.) AÑOS 1991-1993. SAN JUAN DE PLAN

\begin{tabular}{|l|c|c|c|c|c|c|c|c|c|}
\hline \multirow{2}{*}{$\begin{array}{l}\text { CULTIVOS } \\
\text { HERBÁCEOS }\end{array}$} & \multicolumn{3}{|c|}{1991} & \multicolumn{3}{c|}{1992} & \multicolumn{2}{c|}{1993} \\
\cline { 2 - 11 } & Secano & Regad. & Total & Secano & Regad. & Total & Secano & Regad. & Total \\
\hline CEREALES & - & - & - & - & - & - & - & - & - \\
\hline $\begin{array}{l}\text { LEGUMIN. } \\
\text { GRANO }\end{array}$ & - & 0,5 & 0,5 & - & 0,3 & 0,3 & - & 0,2 & 0,2 \\
\hline $\begin{array}{l}\text { TUBER. } \\
\text { CONSUMO }\end{array}$ & 4,5 & 1 & 5,5 & 4 & 1 & 5 & 3 & 1 & 4 \\
\hline $\begin{array}{l}\text { INDUS- } \\
\text { TRIALES }\end{array}$ & - & - & - & - & - & - & - & - & - \\
\hline $\begin{array}{l}\text { FORRA- } \\
\text { JEROS }\end{array}$ & 35,5 & 2,7 & 38,2 & 31 & 2,7 & 33,7 & 25 & 1,8 & 26,8 \\
\hline $\begin{array}{l}\text { HORTA- } \\
\text { LIZAS }\end{array}$ & - & 3,8 & 3,8 & - & 3 & 3 & - & 3 & 3 \\
\hline TOTAL & 40 & 8 & 48 & 35 & 7 & 42 & 28 & 6 & 34 \\
\hline
\end{tabular}

Fuente: "Superficies Ocupadas por los Cultivos Agricolas". Hojas 1.T. de las Cámaras Agrarias Locales. Años: 1988, 1989 y 1990 . Elaboración propia.

Toda la actividad agrícola del Valle de Gistaín como hemos comprobado a través de los cuadros comentados sobre la distribución de la superficie cultivada, está en función de la cabaña ganadera de cuyos efectivos trataremos seguidamente comentando los últimos Censos y pormenorizando también en las explotaciones ganaderas que han experimentado una fuerte transformación en los últimos años.

\section{DISTRIBUCIÓN DE LA CABAÑA GANADERA}

\subsection{Análisis Censo Ganadero 1986}

Una visión de conjunto de la distribución de la cabaña ganadera del Valle en los Censos de 1986 y 1989, nos lleva a destacar por su pobreza la cabaña equina que se mantiene estacionaria por debajo del centenar de ejemplares. En general, el ganado caballar, mular y asnal ha ido perdiendo bastante importancia en toda la provincia como podemos comprobar en los cuadros siguientes (se ha pasado de un total de 1.581 cabezas en 1986 a 775 cabezas 1989 ) y particularmente en la comarca de Sobrarbe a pesar de ser la tradicional fuente de recursos del ganado montañés.

En el Censo Ganadero de 1986 no existen datos desagregados que especifiquen si se trata de caballar, mular o asnal; no así en el Censo 
Ganadero de 1989 que pone de manifiesto la semejanza existente entre Plan y S. Juan de Plan en cuanto al número de caballos, mulos y asnos, superados los efectivos de estos últimos por Gistaín, que cuenta sin embargo con tan sólo dos caballos.

La paulatina desaparición de estas especies de los pastos se hizo porque muchos de ellos degeneraron perdiendo extensión y calidad, cuando la dentición de los équidos resulta imprescindible para consumir hierbas que ovinos y vacunos no pueden aprovechar. La mecanización de las tareas agrícolas motivó la caída en la demanda de este ganado de labor, cuya necesidad puede volver a sentirse valorando las posibilidades que ofrecen como productores de carne y pieles.

DISTRIBUCIÓN DE LA CABAÑA GANADERA. 1986. VALLE DE GISTAÍN

\begin{tabular}{|c|c|c|c|c|c|}
\hline & & $\begin{array}{l}\text { PLAN Y } \\
\text { GISTAINN }\end{array}$ & $\begin{array}{l}\text { S. JUAN DE } \\
\text { PLAN }\end{array}$ & $\begin{array}{l}\text { TOTAL } \\
\text { VALLE }\end{array}$ & $\begin{array}{c}\text { TOTAL } \\
\text { PROVINCIA }\end{array}$ \\
\hline \multirow{3}{*}{ BOVINO } & TOT. BOVINO & 1.611 & 542 & 2.153 & 77.756 \\
\hline & VACAS ORDEÑO & 0 & 0 & 0 & 18.357 \\
\hline & VAC. NO ORDEÑO & 932 & 312 & 1.244 & 8.330 \\
\hline \multirow{2}{*}{ OVINO } & TOTAL OVINO & 7.050 & 4.450 & 11.500 & 733.483 \\
\hline & HEM. > 12 MESES & 5.200 & 3.220 & 8.420 & 559.041 \\
\hline \multirow{2}{*}{ CAPRINO } & TOTAL CAPRINO & 871 & 347 & 1.218 & 16.407 \\
\hline & HEM. $>12$ MESES & 750 & 265 & 1.015 & 12.592 \\
\hline \multirow{2}{*}{ PORCINO } & TOTAL PORCINO & 0 & 0 & 0 & 875.015 \\
\hline & HEMBRA $>50 \mathrm{KG}$. & 0 & 0 & 0 & 78.271 \\
\hline \multirow{2}{*}{ AVES } & PONED. SELECTAS & 0 & 0 & 0 & 523.605 \\
\hline & GALL. CAMPERA & 0 & 0 & 0 & 49.466 \\
\hline CONEJAS & REPRODUCTORAS & 0 & 0 & 0 & 38.441 \\
\hline \multirow{3}{*}{ EQUINOS } & CABALLAR & * & * & * & * \\
\hline & MULAR-ASNAL & * & * & * & $\ldots$ \\
\hline & TOTAL EQUINOS & 96 & 25 & 121 & 1.581 \\
\hline COLMENA & & 0 & 0 & 0 & 14.900 \\
\hline
\end{tabular}

Fuente: Censo Ganadero 1986. Dpt ํำ de Agricultura, Ganaderia y Montes D.G.A. Elaboración propia.

* Se conoce el total de equinos, sin distinguir entre caballar y mular-asnal.

La explotación del ganado lanar en trashumancia tambien ha decaído de forma acusada en la provincia y en la comarca, máxime si se compara con la preponderancia que antiguamente gozaba. 


\subsection{Análisis Censo Ganadero 1989}

En el valle de Gistaín, entre 1986 y 1989, se redujeron 1.255 ejemplares y en Gistaín y Plan descendió en 200 ejemplares el total de la cabaña ovina, cifra que coincide con el descenso de ovejas madres. Mucho más fuerte ha sido el descenso de 1.640 madres en S.Juan de Plan, que ha pasado de 3.942 cabezas a 2.302 en tan sólo tres años.

DISTRIBUCIÓN DE LA CABAÑA GANADERA. 1989.

VALLE DE GISTAIIN

\begin{tabular}{|l|l|r|r|r|r|r|}
\hline \multicolumn{2}{|c|}{} & GISTAIN & PLAN & $\begin{array}{c}\text { S. JUAN DE } \\
\text { PLAN }\end{array}$ & $\begin{array}{r}\text { TOTAL } \\
\text { VALLE }\end{array}$ & $\begin{array}{c}\text { TOTAL } \\
\text { PROVINC. }\end{array}$ \\
\hline \multirow{3}{*}{ BOVINO } & TOT. BOVINO & 419 & 656 & 605 & 1.680 & 115.367 \\
\cline { 2 - 7 } & VACAS ORDEÑ & 10 & 12 & 0 & 22 & 9.767 \\
\cline { 2 - 7 } & VAC. NO ORDEÑO & 366 & 569 & 488 & 1.423 & 51.121 \\
\hline \multirow{3}{*}{ OVINO } & TOTAL OVINO & 4.585 & 2.279 & 4.034 & 10.898 & 660.260 \\
\cline { 2 - 7 } & HEM. $>12$ MESES & 3.264 & 1.726 & 2.302 & 7.292 & 558.875 \\
\hline \multirow{3}{*}{ CAPRINO } & TOTAL CAPRINO & 358 & 594 & 174 & 1.126 & 19.498 \\
\cline { 2 - 7 } & HEM. $>12$ MESES & 288 & 485 & 140 & 913 & 16.106 \\
\hline \multirow{3}{*}{ PORCINO } & TOTAL PORCINO & 3 & 0 & 3 & 6 & 735.211 \\
\cline { 2 - 7 } & HEMBRA > 5O KG. & 0 & 0 & 0 & 0 & 64.468 \\
\hline \multirow{3}{*}{ AVES } & PONED. SELECTAS & 27 & 6 & 0 & 33 & 279.408 \\
\cline { 2 - 7 } & GALL. CAMPERA & 446 & 272 & 308 & 1.026 & 461.560 \\
\cline { 2 - 7 } & POLLOS CARNE & 32 & 5 & 5 & 42 & 4.582 .462 \\
\cline { 2 - 7 } & OTRAS AVES & 23 & 17 & 20 & 60 & 1.208 .212 \\
\hline CONEJAS & REPRODUCTORAS & 84 & 45 & 64 & 194 & 21.458 \\
\hline \multirow{3}{*}{ EQUINOS } & CABALLAR & 2 & 13 & 14 & 29 & 498 \\
\cline { 2 - 7 } & MULAR-ASNAL & 41 & 13 & 16 & 70 & 277 \\
\cline { 2 - 7 } & TOTAL EQUINOS & 43 & 26 & 30 & 99 & 775 \\
\hline \multirow{2}{*}{ COLMENA } & & 0 & 0 & 4 & 4 & 8.583 \\
\hline
\end{tabular}

Fuente: Censo Ganadero 1989. Dpt ${ }^{\circ}$ de Agricultura, Ganaderia y Montes D.G.A. Elaboración propia.

Esta disminución observada en conjunto perjudica, no sólo a la cabaña, sino también a la conservación de los pastos, que se van degradando conforme el ganado ovino no aprovecha suficientemente los pastizales consumiendo las hierbas más jugosas y dejando la menos tiernas, que por su carácter leñoso invaden poco a poco el terreno sofocando cualquier rebrote de pastizal puro. 
El caprino está en alza en la Provincia y en el Valle; en la primera ha aumentado en 3.000 cabezas en el período intercensal considerado y sigue en esa línea; en el valle el aumento ha sido menor, pero tambien significativo, dadas las magnitudes en que nos movemos. Plan destaca entre los tres municipios con 594 cabezas de las que el $82 \%$ son hembras mayores de 12 meses.

Mejores perspectivas presenta todo lo referente a la cría del ganado vacuno tanto en la zona como en la provincia. De hecho, de todas las especies ganaderas que integran la cabaña provincial, es en la que se han producido el mayor aumento de cabezas (67\%) y de cambio de orientación. En efecto, las 18.357 vacas de ordeño se redujeron a la mitad y continúa el descenso mientras aumenta el ganado para carne, de acuerdo con las orientaciones de la C.E.E.

La raza más abundante en toda la comarca es la cruzada de pardo suizo con pirenaica, alcanzándose con ello un mayor rendimiento de carne. La otra predominante es la frisona, aunque no alcanza el número de cabezas de la anterior. La vaca del país, muy mezclada por numerosos y poco cuidados cruces, va desapareciendo por su escasa calidad.

El vacuno de raza selecta necesita una alimentación muy equilibrada para sacarle el máximo rendimiento, respondiendo ampliamente a las atenciones y cuidados. Unicamente el ganado sin seleccionar no rinde lo suficiente, aunque se le apliquen métodos modernos de explotación de tal modo que resulta antieconómico cualquier tipo de atenciones que se le preste.

Las vacas de ordeño han ido desapareciendo del Valle de Gistaín, especialmente de $\mathrm{S}$. Juan de Plan, teniendo en cuenta que pertenecían a su término las 111 vacas que figuran en el Censo de 1.986, reducidas a cero tres años después. También hay que destacar el descenso total de cabezas de bovino ( 1.020 cabezas en 1.986 y 605 cabezas en 1989), reducido a la mitad en el citado pueblo.

En cuanto al ganado de cerda que se explota en la Comarca del Sobrarbe, es en un $90 \%$ producción destinada a la venta y un $10 \%$ para consumo casero. La mayoría del destinado a la venta es de cerda de cría, es decir, para la producción de lechones. Las mejores granjas de cría se sitúan en La Fueva y Ainsa y algunas en Laspuña, Labuerda, Fiscal, Boltaña y El Pueyo de Araguas.

Las explotaciones dedicadas a la cría del ganado de cerda en el Sobrarbe son en su mayor parte de tipo familiar, y están representadas por explotaciones de cerdas de vientre que son las que acaparan la atención de los ganaderos, no dándose apenas las dedicadas a la recría, manteniendo de 2 a 4 hembras por casa. 
Su mayor densidad se centra en el área situada al sur de L'Ainsa en los municipios de Foradada de Toscar y La Fueva. Los piensos más empleados son los propios que se obtienen de sus propiedades agrícolas. En cuanto a las razas, desaparecida prácticamente de la zona la celta, predomina la Large White cruzada con machos Landrace.

Las instalaciones de aves bajan bastante en relación con la importancia de la ganaderia descrita. Existen pequeñas naves de ponedoras y cría de pollos pero de escaso volumen.

\section{MAQUINARIA AGRICOLA}

Los Censos de maquinaria en uso ponen una vez más de manifiesto la vocación ganadero-forestal del Valle de Gistain, como revelan la ausencia por una parte, y la presencia por otra, de mecanización. Destacan los escasísimos motores para riego existentes y la carencia de los medios de equipo de siembra propiamente dicho (sembradoras y abonadoras), contando, sin embargo, con tractores de ruedas, motocultores, remolques para estiércol, cisternas de purín y motosierras.

CENSOS DE MAQUINARIA EN USO AÑOS 1989 Y 1990. VALLE DE GISTAIIN

\begin{tabular}{|c|c|c|c|c|c|c|c|}
\hline & \multicolumn{3}{|c|}{1989} & \multicolumn{3}{|c|}{1990} \\
\hline & & $\begin{array}{l}\text { PLAN Y } \\
\text { GISTAIN }\end{array}$ & $\begin{array}{l}\text { S. JUAN } \\
\text { DE PLAN }\end{array}$ & $\begin{array}{l}\text { TOTAL } \\
\text { VALLE }\end{array}$ & $\begin{array}{l}\text { PLAN Y } \\
\text { GISTAIN }\end{array}$ & $\begin{array}{l}\text { S. JUAN } \\
\text { DE PLAN }\end{array}$ & $\begin{array}{l}\text { TOTAL } \\
\text { VALIE }\end{array}$ \\
\hline \multirow[t]{3}{*}{ TRACTOR } & CADENAS & $\overline{0}$ & 0 & 0 & 0 & 0 & 0 \\
\hline & RUEDAS & 44 & 21 & 65 & 46 & 23 & 68 \\
\hline & MOTOCUL. & 0 & 39 & 39 & 0 & 40 & 40 \\
\hline \multirow{2}{*}{$\begin{array}{l}\text { MOTORES } \\
\text { RIEGO }\end{array}$} & COMBUST. INT. & 2 & 2 & 4 & 2 & 2 & 2 \\
\hline & ELECTRICOS & 2 & 1 & 3 & 2 & 1 & 3 \\
\hline \multirow{2}{*}{$\begin{array}{l}\text { OTROS } \\
\text { MOTORES }\end{array}$} & COMBUST. INT. & 0 & 0 & 0 & 0 & 0 & 0 \\
\hline & ELECTRICOS & 0 & 2 & 2 & 0 & 2 & 2 \\
\hline \multirow{2}{*}{$\begin{array}{l}\text { EQ. LABOR. } \\
\text { TRACTOR }\end{array}$} & ARADOS & 15 & 2 & 17 & 17 & 0 & 17 \\
\hline & GRADAS & 8 & 4 & 12 & 8 & 0 & 8 \\
\hline \multirow{4}{*}{$\begin{array}{l}\text { EQUIPO } \\
\text { SIEMBRA }\end{array}$} & SEMBRADORAS & 0 & 0 & 0 & 0 & 2 & 2 \\
\hline & ABONADORAS & 0 & 0 & 0 & 0 & 4 & 4 \\
\hline & REMOL. ESTIER. & 4 & 3 & 7 & 4 & 0 & 4 \\
\hline & PULVERIZAD. & 0 & 0 & 0 & 0 & 3 & 3 \\
\hline EQUIPO & EMPACADORAS & 13 & 3 & 16 & 14 & 4 & 18 \\
\hline \multirow{5}{*}{$\begin{array}{l}\text { EQUIPO } \\
\text { AUXILIAR }\end{array}$} & CARGADORES & 2 & 0 & 2 & 3 & 0 & 3 \\
\hline & REMOLQUES & 44 & 21 & 65 & 45 & 23 & 68 \\
\hline & MOLINOS PIENSO & 1 & 2 & 3 & 1 & 2 & 3 \\
\hline & ORDENAAD. PORT. & 1 & 0 & 1 & 1 & 0 & 1 \\
\hline & MOTOSIERRA & 52 & 25 & 77 & 53 & 25 & 78 \\
\hline
\end{tabular}

Fuente: "Censo de Maquinaria en uso". Instituto de Relaciones Agrarias. Cámara Agraria Local. Años: 1989, 1990. Elaboración propia. 
Entre los Censos de 1989 a 1992, se ha producido un cambio a la baja en el número de tractores de ruedas (han pasado de 68 a 48) en favor del aumento de motocultores producido en Plan y Gistaín en 1991, pasando de cero a más de treinta máquina en cada pueblo. En sentido parecido podemos observar en los dos núcleos citados, el aumento de motosierras que prácticamente se duplicaron en dos años.

CENSOS DE MAQUINARIA EN USO AÑOS 1991 Y 1992.

\section{VALLE DE GISTAIIN}

\begin{tabular}{|c|c|c|c|c|c|c|c|c|c|}
\hline & \multicolumn{4}{|c|}{1991} & \multicolumn{4}{|c|}{1992} \\
\hline & & $\begin{array}{l}\text { GIS- } \\
\text { TAIN }\end{array}$ & PLAN & $\begin{array}{l}\text { S. JUAN } \\
\text { DE P. }\end{array}$ & $\begin{array}{l}\text { TOTAL } \\
\text { VALLEE }\end{array}$ & $\begin{array}{l}\text { GIS- } \\
\text { TAIN }\end{array}$ & PLAN & $\begin{array}{c}\text { S. JUAN } \\
\text { DE P. }\end{array}$ & $\begin{array}{l}\text { TOTAL } \\
\text { VALLE }\end{array}$ \\
\hline \multirow[t]{3}{*}{ TRACTOR } & CADENAS & 0 & 35 & 0 & 35 & 0 & 35 & 0 & 35 \\
\hline & RUEDAS & 25 & 0 & 23 & 48 & 25 & 0 & 23 & 48 \\
\hline & MOTOCULTOR & 32 & 35 & 40 & 107 & 30 & 35 & 35 & 100 \\
\hline \multirow{2}{*}{$\begin{array}{l}\text { MOTORES } \\
\text { RIEGO }\end{array}$} & COMB. INT. & 0 & 0 & 2 & 2 & 0 & 0 & 2 & 2 \\
\hline & ELECTRICOS & 0 & 2 & 1 & 3 & 0 & 2 & 1 & 3 \\
\hline \multirow{2}{*}{$\begin{array}{l}\text { OTROS } \\
\text { MOTORES }\end{array}$} & COMB. INT. & 0 & 0 & 0 & 0 & 0 & 0 & 0 & 0 \\
\hline & ELECTRICOS & 0 & 0 & 2 & 2 & 0 & 0 & 2 & 2 \\
\hline \multirow{2}{*}{$\begin{array}{l}\text { EQ. LABOR } \\
\text { TRACTOR }\end{array}$} & ARADOS & 6 & 7 & 2 & 15 & 6 & 7 & 2 & 15 \\
\hline & GRADAS & 0 & 0 & 4 & 4 & 0 & 0 & 4 & 4 \\
\hline \multirow{5}{*}{$\begin{array}{l}\text { EQUIPO } \\
\text { SIEMBRA }\end{array}$} & SEMBRADORA & 0 & 0 & 0 & 0 & 0 & 0 & 0 & 0 \\
\hline & ABONADORA & 0 & 0 & 0 & 0 & 0 & 0 & 0 & 0 \\
\hline & CIS. PURIN & 0 & 3 & 0 & 3 & 0 & 3 & 0 & 3 \\
\hline & REM. EST. & 0 & 0 & 3 & 3 & 0 & 0 & 3 & 3 \\
\hline & PULVER. & 0 & 0 & 0 & 0 & 0 & 0 & 0 & 0 \\
\hline EQ. REC. & EMPACADORA & 6 & 15 & 4 & 25 & 6 & 15 & 4 & 25 \\
\hline \multirow{5}{*}{$\begin{array}{l}\text { EQUIPO } \\
\text { AUXILIAR }\end{array}$} & CARGADORA & 0 & 0 & 0 & 0 & 0 & 0 & 0 & 0 \\
\hline & REMOLQUE. & 25 & 0 & 23 & 48 & 25 & 0 & 23 & 48 \\
\hline & MOL. PIENSO & 0 & 1 & 0 & 1 & 0 & 1 & 0 & 1 \\
\hline & ORDEÑ. POR. & 0 & 0 & 0 & 0 & 0 & 0 & 0 & 0 \\
\hline & MOTOSIERRA & 48 & 38 & 25 & 111 & 48 & 38 & 22 & 108 \\
\hline
\end{tabular}

Fuente: "Censo de Maquinaria en uso".Instituto de Relaciones Agrarias. Cámara Agraria Local. Años: 1991, 1992. Elaboración propia.

\section{ANÁLISIS DE LA EMPRESA AGRARIA}

\subsection{Tamaño y Régimen de Tenencia de las Explotaciones}

En el Valle de Gistaín el grueso de las explotaciones según la superficie en Has. que ocupan, se sitúa en los tres primeros intervalos establecidos por el Ministerio de Agricultura, que acogen desde aquellas cuya superficie no alcanza $1 \mathrm{Ha}$. hasta las que no llegan a $20 \mathrm{Has}$. El resto de los 
intervalos acoge un número de explotaciones muy bajo. Esto nos indica que el grado de parcelación es altísimo, hecho que tiene mayor incidencia en las explotaciones donde domina el ganado vacuno que es en la mayoría del Valle.

Los dos primeros tipos, corresponden a espacios con fuertes pendientes y/o suelos desfavorables, en los que la agricultura intensiva mediterránea de los climas secos o los prados de siega de los climas húmedos, deben concentrarse en los estrechos fondos de valle muy productivos.

Los pequeños tamaños de la S.A.U. se compensan a veces con la utilización de los recursos de alta montaña; en otros, con el trabajo ein alguna central hidroeléctrica o industria próxima en la cabecera de comarca y tambien en pequeños negocios del sector servicios de un terciario incipiente o con escasa entidad.

A través de la información que nos ofrecen los Censos Agrarios de 1982 y 1989, observamos una creciente tendencia en los municipios de Gistaín y Plan al aumento de pequeñas explotaciones, comprendidas en el primer tramo señalado por debajo de las cinco Has., a costa quizá, del descenso de las explotaciones de 50 a más de 100 Has.

SUPERF. Y RÉGIMEN DE TENENCIA EXPLOT. AGRARIAS 1982. VALLE DE GISTAIIN

\begin{tabular}{|c|c|c|c|c|c|c|c|c|c|c|c|c|}
\hline \multirow[b]{2}{*}{ MUNICIPIO } & \multicolumn{7}{|c|}{ № Explotaciones según la superficie $(\mathrm{Ha}$.) } & \multicolumn{4}{|c|}{$\begin{array}{l}\text { Régimen de Tenencia } \\
\text { de las explotaciones ( } \mathrm{Ha} \text { ) }\end{array}$} & \multirow{2}{*}{$\begin{array}{l}\text { № } \\
\text { Total } \\
\text { Par- } \\
\text { celas }\end{array}$} \\
\hline & $\begin{array}{l}\geq 0,1 \\
a<5\end{array}$ & $\begin{array}{l}\geq 5 \\
a<10\end{array}$ & $\begin{array}{l}\geq 10 \\
a<20\end{array}$ & $\begin{array}{l}\geq 20 \\
a<50\end{array}$ & $\begin{array}{l}\geq 50 \\
a<100\end{array}$ & $\geq 100$ & Total & $\begin{array}{c}\text { Propie- } \\
\text { dad }\end{array}$ & $\begin{array}{l}\text { Arren- } \\
\text { dada }\end{array}$ & $\begin{array}{l}\text { Apar- } \\
\text { cero }\end{array}$ & Otro & \\
\hline PLAN & 64 & 30 & 15 & 2 & 0 & 5 & 117 & 16.835 & 87 & 0 & 0 & 787 \\
\hline $\begin{array}{l}\text { S. JUAN } \\
\text { DE PLAN }\end{array}$ & 6 & 20 & 10 & 2 & 1 & 3 & 42 & 5.251 & 8 & 0 & 50 & 399 \\
\hline $\begin{array}{l}\text { TOT. VALLE } \\
\text { GISTAIN }\end{array}$ & 70 & 50 & 25 & 4 & 1 & 8 & 159 & 22.086 & 95 & 0 & 50 & 1.186 \\
\hline
\end{tabular}

Fuente: Censo Agrario 1982. Mtº de Agricultura, Pesca y Alimentación. Elaboración propia.

En S. Juan de Plan, por el contrario, ha descendido el número total de explotaciones pero el planteamiento es semejante en cuanto a la disminución, en este caso supresión, de las cuatro explotaciones mayores del municipio (una de 50 a 100 Has. y tres, de 100 y más Has.), en el período comprendido entre 1982 y 1989 . Hay que señalar además, el descenso de 20 a 11 explotaciones en el segundo tramo (entre 5 y 10 Has.) con un breve aumento de tres explotaciones en el tercero (entre 10 y $20 \mathrm{Has}$.). 
SUPERF. Y RÉGIMEN DE TENENCIA EXPLOT. AGRARIAS 1989. VALLE DE GISTAINN

\begin{tabular}{|c|c|c|c|c|c|c|c|c|c|c|c|c|}
\hline \multirow{2}{*}{ MUNICIPIO } & \multicolumn{7}{|c|}{ № Explotaciones según la superficie ( $\mathrm{Ha}$.) } & \multicolumn{4}{|c|}{$\begin{array}{l}\text { Régimen de Tenencia } \\
\text { de las explotaciones }(\mathrm{Ha})\end{array}$} & \multirow{2}{*}{$\begin{array}{c}N^{0} \\
\text { Total } \\
\text { Par- } \\
\text { celas }\end{array}$} \\
\hline & $\begin{array}{l}\geq 0,1 \\
a<5\end{array}$ & $\begin{array}{c}\geq 5 \\
a<10\end{array}$ & $\begin{array}{l}\geq 10 \\
a<20\end{array}$ & $\begin{array}{l}\geq 20 \\
a<50\end{array}$ & $\begin{array}{l}\geq 50 \\
a<100\end{array}$ & $\geq 100$ & Total & $\begin{array}{c}\text { Propie- } \\
\text { dad }\end{array}$ & $\begin{array}{l}\text { Arren- } \\
\text { dada }\end{array}$ & $\begin{array}{l}\text { Apar- } \\
\text { cero }\end{array}$ & Otro & \\
\hline GISTAIN & 36 & 15 & 14 & 1 & 0 & 1 & 67 & 8.238 & 73 & 0 & 0 & 603 \\
\hline PLAN & 49 & 13 & 13 & 1 & 0 & 1 & 77 & 8.763 & 153 & 0 & 0 & 662 \\
\hline $\begin{array}{l}\text { S. JUAN } \\
\text { DE PLAN }\end{array}$ & 6 & 11 & 13 & 5 & 0 & 0 & 35 & 4.467 & 83 & 0 & 0 & 458 \\
\hline $\begin{array}{l}\text { TOT. VALLE } \\
\text { GISTAÍN }\end{array}$ & 91 & 39 & 40 & 7 & 0 & 0 & 179 & 21.468 & 309 & 0 & 0 & 1.723 \\
\hline
\end{tabular}

Fuente: Censo Agrario 1989. $\mathrm{Mt}^{\circ}$ de Agricultura, Pesca y Alimentación. Elaboración propia.

El régimen de tenencia de las explotaciones es el de propiedad por mayoría absoluta siguiendo la tendencia general de la provincia acentuada en este caso en los valles de alta montaña como el de Gistaín. La superficie en arrendamiento es baja e incluso testimonial, como en el caso de S. Juan de Plan, con 8 Has. en 1982; situación que ha cambiado de signo en los últimos años y aunque las cifras son muy bajas, ha aumentado la superficie arrendada en todo el valle y de forma expresa, el total de parcelas que ha pasado en unos años de 1.186 a 1.723 .

\subsection{Características de los Empresarios Agrarios}

DATOS RELATIVOS A LOS EMPRESARIOS AGRARIOS. 1994

\begin{tabular}{|l|c|c|c|c|c|c|c|}
\hline \multirow{2}{*}{ MUNICIPIO } & \multicolumn{2}{|c|}{ TIPO PERSONA } & \multicolumn{5}{c|}{ EDADES DE LOS EMPRESARIOS } \\
\cline { 2 - 9 } & JURIDICA & FISICA & $<35$ Años & $35-45$ Años & $45-55$ Años & $55-65$ Años & $>65$ Años \\
\hline GISTAIN & 1 & 57 & 0 & 4 & 5 & 15 & 33 \\
\hline PLAN & 1 & 48 & 0 & 3 & 10 & 13 & 22 \\
\hline $\begin{array}{l}\text { S. JUAN DE } \\
\text { PLAN }\end{array}$ & 1 & 34 & 0 & 1 & 4 & 9 & 20 \\
\hline TOT. VALLE & 3 & 139 & 0 & 8 & 19 & 37 & 75 \\
\hline PORCENT. & 2 & 98 & 0 & 6 & 14 & 27 & 54 \\
\hline
\end{tabular}

Fuente: “Directorio de Explotaciones Agrarias". Cámara Agraria Provincial del Alto Aragón. HUESCA. Elaboración propia. 
La condición jurídica dominante en un $98 \%$ entre los empresarios del valle es la de personas físicas, excepto una jurídica en cada uno de los pueblos. En cuanto a la edad de los empresarios, dato que consideramos del máximo interés teniendo en cuenta que la empresa agraria es la principal actividad de la gente del valle, dominan ampliamente los empresarios mayores de 55 años cargando el peso considerablemente entre los mayores de 65 años que alcanzan el $54 \%$, porcentaje mucho más significativo si se tiene en cuenta que la edad de partida es alta (35-45 años).

\subsection{Indemnización compensatoria de montaña}

La indemnización compensatoria de montaña se concede desde al año 1986 a los titulares de explotaciones agrarias que reúnen las condiciones de beneficiarios para percibirla: Estar en activo, dedicar más del $50 \%$ de su actividad (explícita en el régimen de la Seguridad Social) a la explotación y percibir de la misma más del $50 \%$ de los rendimientos netos declarados a Hacienda. Prácticamente, todo empresario del Valle que cumple estas condiciones, solicita la indemnización.

Intervienen en la cuantificación de la misma el no de cabezas de ganado, el de Has. de la explotación dedicado a cultivos pratenses, y la superficie forrajera total excepto barbechos y eriales. Con ellos se establece el primer coeficiente $\left(\operatorname{coef}_{1}\right)$ en el que figura el tipo de ganado mayor (UGM) y el tipo de cultivo (UEC). Ambos apartados dan lugar al segundo coeficiente $\left(\mathrm{coef}_{2}\right)$ que expresa la orientación técnico-económica de la explotación. El tercer coeficiente $\left(\operatorname{coef}_{3}\right)$, resultante de los dos anteriores, refleja los tramos de las unidades liquidables totales (ULT).

El resultado final es un índice que no puede ser superior a 1,4 UGM por $\mathrm{Ha}$. de superficie forrajera equivalente. El máximo de unidades de ganado mayor computables para obtener la indemnización compensatoria de montaña es de 20 , aunque el total de cabezas de la explotación sea muy superior.

Plan y Gistaín figuran de manera conjunta en las solicitudes de indemnización cuyo número ha experimentado en el Valle ciertos altibajos en los últimos años, como puede apreciarse en la tabla siguiente: 
INDEMNIZACIÓN COMPENSATORIA DE MONTAÑA 1990-1993

\begin{tabular}{|l|c|c|c|c|c|}
\hline MUNICIPIO & AÑOS & $\begin{array}{c}\text { NÚMERO } \\
\text { SOLICITUDES }\end{array}$ & $\begin{array}{c}\text { LIQUIDACIÓN } \\
\text { UGM }\end{array}$ & $\begin{array}{c}\text { LIQUIDACIÓN } \\
\text { UEC (Has.) }\end{array}$ & $\begin{array}{c}\text { I.C.M. } \\
\text { PESETAS }\end{array}$ \\
\hline \multirow{4}{*}{ PLAN } & 1990 & 61 & $1.046,900$ & 4,921 & 4.110 .160 \\
\cline { 2 - 6 } & 1991 & 27 & 439,300 & 2,493 & 1.773 .624 \\
\cline { 2 - 6 } & 1992 & 52 & 900,850 & 3,280 & 3.717 .563 \\
\cline { 2 - 6 } & 1993 & 41 & 746,150 & 1,789 & 3.341 .572 \\
\hline \multirow{4}{*}{$\begin{array}{l}\text { SAN JUAN } \\
\text { DE PLAN }\end{array}$} & 1994 & 42 & Sin resolver & Sin resolver & Sin resolver \\
\cline { 2 - 6 } & 1990 & 22 & 424,350 & 1,491 & 1.587 .264 \\
\cline { 2 - 6 } & 1991 & 9 & 171,900 & 0,639 & 645.831 \\
\cline { 2 - 7 } & 1992 & 19 & 356,950 & 1,491 & 1.425 .508 \\
\cline { 2 - 7 } & 1993 & 13 & 239,300 & 1,278 & 1.071 .522 \\
\hline
\end{tabular}

Fuente: Cámara Agraria Provincial del Alto Aragón. Huesca.

\section{TIPOS DE EXPLOTACIONES}

\subsection{En la Comarca}

De acuerdo con la orientación principal de la explotación, se tipifican en ocho categorías según sea su especialización en grandes cultivos, horticolas, cultivos permanentes, ganaderas especializadas, mixtas agrícolaganaderas, etc. Las explotaciones agrarias en la comarca de Ribagorza varían según la situación geográfica de las mismas.

Dentro de las explotaciones de la zona dedicadas a vacuno, la raza que domina es la parda alpina (más del $90 \%$ del total). El resto son frisonas y charolesas. Ha desaparecido la pirenaica, raza autóctona de mayor rusticidad que se conserva sin embargo en otras zonas del Pirineo, y sólo aparece algún híbrido lejano con frisona. En la comarca pueden distinguirse explotaciones:

- De leche: Además de producirla también dan terneros, que se venden como mamones, aunque en proporción inferior a los que se consiguen con las explotaciones de vacas nodrizas. Dan unos 2.500 l. de leche por vaca y año, cifra que está muy alejada de la media europea (6000 I./vaca y año). Este tipo de ganadería es muy escasa en la comarca y se sitúa en Torla y Broto.

- Mixtas: Destinadas conjuntamente a la producción de leche y de terneros. Las características de la producción de terneros son las mismas 
del apartado anterior. En cuanto a la producción de leche, en el valle del Ara la media es $700 \mathrm{I}$. por vaca y año, cantidad que se produce durante 45 meses (desde el parto hasta que suben a puerto). Hace algunos años en el valle del Cinca sobre todo en Gistaín, cuando todavía se vendia leche, las cifras de producción eran muy inferiores: 140 I. por vaca y año.

La Dirección General de la Producción Agraria distingue en las producciones ganaderas las tipologías: 1) de ordeño; 2) de no ordeño y 3) de cebo.

\subsection{En el valle}

\subsubsection{Explotaciones de Vacuno}

Las explotaciones de vacuno predominantes en el valle de Gistaín son fundamentalmente de tipología 2 (de no ordeño) y se han plasmado en el siguiente cuadro. Se centran en las vacas nodrizas exclusivamente para carne. Se trata de ganado destinado a la producción de terneros que con 6 meses de vida, después de bajar los puertos, se venden mamones a recriadores que los engordan en otras explotaciones fuera del Valle.

EXPLOTACIONES CON VACAS NODRIZAS. 1989-1992

\begin{tabular}{|l|c|c|c|c|c|c|c|c|c|}
\hline \multirow{2}{*}{ MUNICIPIO } & \multicolumn{2}{|c|}{1989} & \multicolumn{2}{c|}{1990} & \multicolumn{2}{c|}{1991} & \multicolumn{2}{c|}{1992} & $\begin{array}{c}\text { Media } \\
\text { Periodo } \\
\text { Ceabezas }\end{array}$ \\
\cline { 2 - 12 } & Explot. & Cabezas & Explot. & Cabezas & Explot. & Cabezas & Explot. & Cabezas & Cabín \\
\hline GISTAIN & 31 & 282 & 27 & 247 & 25 & 235 & 21 & 241 & 251 \\
\hline PLAN & 35 & 470 & 34 & 448 & 32 & 433 & 33 & 446 & 449 \\
\hline $\begin{array}{l}\text { SAN JUAN } \\
\text { DE PLAN }\end{array}$ & 23 & 307 & 23 & 309 & 21 & 270 & 21 & 307 & 298 \\
\hline $\begin{array}{l}\text { TOT. VALLE } \\
\text { GISTAÍN }\end{array}$ & 89 & 1.059 & 84 & 1.004 & 78 & 938 & 75 & 994 & 998 \\
\hline
\end{tabular}

Fuente: Directorio de Explotaciones Agrarias. Cámara Agraria Provincial del Alto Aragón. HUESCA. Elaboración propia.

En la actualidad se producen para la venta 0,70 terneros por hembra adulta, esto es, por cada 100 vacas, se venden 70 terneros y se podría llegar a 0,80 terneros por vaca, introduciendo algunas mejoras en el manejo. Esta cifra sólo la consiguen el $30 \%$ de las explotaciones ganaderas. 
En el cuadro anterior que muestra una evolución reciente, observamos que este tipo de explotaciones mantiene una situación estable en todos los municipios del valle. De acuerdo con los últimos datos facilitados por la Sección de Estudios del Servicio Provincial de Agricultura, Ganadería y Montes de Huesca, en 1994 existen:

- En el término de Gistaín, 4 explotaciones de vacuno de ordeño con 12 vacas de no ordeño y 6 cebos y 26 explotaciones específicas de no ordeño, con 297 vacas y 57 cebos. No existe ninguna explotación de la tipología 3 (cebos).

- En el término de Plan, 5 explotaciones de ordeño con trece vacas de carne y 5 plazas de cebo y 32 explotaciones de no ordeño con 510 cabezas y 57 cebos. Como en el caso anterior, no existe ninguna explotación de cebos. Por último,

- En el término de S. Juan de Plan, 3 explotaciones de ordeño con 1 vaca de ordeño, 2 de no ordeño y 5 de cebo y 21 explotaciones de no ordeño, con 328 cabezas y 47 cebos.

\section{Alimentación del ganado vacuno}

Como en toda zona de alta montaña, el ganado sube a puerto en verano para alimentarse de los pastos naturales y se estabula en bordas durante el invierno, donde se alimenta con pienso y forrajes desde diciembre hasta mayo.

- 135 días de "alpage" o subida a puerto, durante el verano.

- 170 días de alimentación estabulada en pesebre durante el invierno.

- El resto se hace a diente en primavera y otoño, en praderas cercanas al pueblo.

Los pastos de altura son excelentes porque su aprovechamiento se produce en un breve espacio de tiempo que favorece su conservación de forma que podrian soportar mayor número de cabezas de ganado en las mismas hectáreas si el pastoreo se realizase de forma ordenada, por parcelas, y sin dejar libre al ganado para que recorra los pastos sin apurarlos.

En los puertos, los prados naturales se están degradando por la ausencia que se observa de algunas especies de ganado, lo que hace que el que pasta vaya seleccionando las hierbas mejores, favoreciendo tomen 
fuerza los pastos de menor calidad, que acaban sofocando y apoderándose del bueno.

Otra forma de mejorar los pastos sería mediante su aprovechamiento por la especie de ganado conveniente, ya sea equina, vacuna u ovina, evitando erosiones del suelo y degeneración del pastizal.

Estos pastos de altura suelen estar compuestos generalmente de trébol blanco y dactilo; los más pobres de festucas. Casi todos ellos suelen ser comunales, excepto los del fondo de los valles que generalmente pertenecen a particulares.

En verano se paga un canon al Ayuntamiento de 400 pesetas por cabeza y pastoreo de temporada. La contratación de un vaquero que permanece con el ganado en puerto, supone un gasto de 1.000 pesetas por vaca. Este pastoreo estival y el heno recolectado en el valle durante el verano constituyen la base fundamental de la alimentación del ganado, completada en otoño y primavera por reducidos periodos de pastoreo en praderas. Los gastos por vaca en puerto se aproximan a las 1.500 pesetas por cabeza y año, a lo que habría que añadir 850 ptas. más, por semental y medicación.

La carga ganadera por ha. de pradera de siega tanto natural como artificial (polifita, alfalfa, trébol, etc.) es de 1,85 vacas. De estas hectáreas se obtiene el alimento invernal ya que como queda expuesto, el alimento adquirido fuera de la explotación se puede considerar como simbólico.

Durante el invierno el ganado es estabulado en pequeñas bordas o establos que van reuniendo en lotes el ganado de la explotación y en las que se guarda el heno recogido en verano. Cuando este se acaba, se lleva el ganado a otra borda. La distribución de las raciones es diaria y en tres o cuatro veces, lo que obliga al ganadero a ir de una a otra borda si tiene un número aceptable de vacas.

Algunas de estas bordas están a una o dos horas de camino desde el pueblo y en época de nieve el recorrido es difícil, de forma que el ganadero se ve forzado en algunos casos a permanecer en la borda como vivienda tal y como sucede en Gistaín y en S. Juan de Plan.

Los gastos de alimentación para el invierno suponen una media de 5.600 ptas por vaca, de las cuales el $74 \%$ se dedica a concentrados y el resto, para alimentos voluminosos y paja. Estos gastos son exiguos, consiguiéndose que el mayor porcentaje de lo consumido por los animales proceda de la propia explotación, con una media de $1.700 \mathrm{Kg}$. por vaca. 
En invierno las raciones diarias no superan como media los $10 \mathrm{Kg}$. variando desde 12-14 hasta $5 \mathrm{Kg}$. y menos aún.

La dificultad de trasladar la hierba desde las praderas de siega, la falta de suelo útil en los pueblos y de recursos económicos hacen dificil la construcción de granjas comunitarias que reunirian el ganado de cada explotación y lo sacarian del pueblo mejorando las condiciones de trabajo y sobre todo, las sanitarias que mantienen un deficiente nivel.

Existen elevados riesgos de infecciones y parasitismos originados por deficiencias nutricionales, pastos contaminados, cambio de pastos en la trashumancia, malos alojamientos..etc. Cualquier medida encaminada a subsanar estas deficiencias choca con las reticencias de los ganaderos.

\subsubsection{Explotaciones de ovino}

La comarca de Sobrarbe ha sido mayoritariamente de producción ovina hasta las últimas décadas, en que ha desaparecido en gran medida. Las razas son las autóctonas: la churra y la rasa. La totalidad de la cabaña ovina se dedica a la producción de ternascos: corderos de $24 \mathrm{Kg}$ y 100 días de edad. No hay ovejas de ordeño.

La ganadería ovina es fundamentalmente trashumante y ha sido la trashumancia larga (la que iba al Valle del Ebro y La Hoya de Huesca) la que más ha disminuido, mientras se mantienen las más cercanas, pasando el invierno gran parte de ella en el bajo Sobrarbe: La Fueva, Ainsa, Boltaña y Fiscal. Quedan algunos ganaderos que aún bajan al Valle del Ebro desde Gistain, Fanlo y Puértolas.

La trashumancia se realiza entre los puertos (pastoreo estival) y el llano o tierra baja (pastoreo invernal). El alimento lo consiguen directamente del medio natural: en verano, pastizal de alta montaña y en invierno los barbechos y montes cercanos a los pueblos (matorrales, pastizales, quejigales, pinares, etc.).

La disminución en más de un $70 \%$ de la ganadería ovina se debe principalmente a la crisis de la trashumancia y al aumento relativo de la cabaña bovina, aunque ambas hayan disminuido en términos generales.

El cuadro siguiente recoge el número de explotaciones y cabezas de ovino del Valle de Gistaín en los últimos años. 
Envejecimiento demográfico y actividad agraria en el Valle de Gistaín

EXPLOTACIONES CON GANADO OVINO. 1989-1992

\begin{tabular}{|c|c|c|c|c|c|c|c|c|c|}
\hline \multirow{2}{*}{ MUNICIPIO } & \multicolumn{2}{|c|}{1989} & \multicolumn{2}{|c|}{1990} & \multicolumn{2}{|c|}{1991} & \multicolumn{2}{|c|}{1992} & \multirow{2}{*}{$\begin{array}{c}\text { Media } \\
\text { Periodo } \\
\text { Cabezas }\end{array}$} \\
\hline & Explot. & Cabezas & Explot. & Cabezas & Explot. & Cabezas & Explot. & Cabezas & \\
\hline GISTAIIN & 30 & 3.287 & 29 & 2.237 & 37 & 3.085 & 35 & 3.549 & 3.039 \\
\hline PLAN & 31 & 1.760 & 29 & 1.676 & 27 & 1.235 & 32 & 2.159 & 1.707 \\
\hline $\begin{array}{l}\text { SAN JUAN } \\
\text { DE PLAN }\end{array}$ & 21 & 810 & 29 & 1.896 & 21 & 966 & 23 & 1.439 & 1.277 \\
\hline $\begin{array}{l}\text { TOT, VALLE } \\
\text { GISTAIIN }\end{array}$ & 82 & 5.857 & 87 & 5.809 & 85 & 5.286 & 90 & 7.147 & 6.024 \\
\hline
\end{tabular}

Fuente: Directorio de Explotaciones Agrarias. Cámara Agraria Provincial del Alto Aragón. HUESCA. Elaboración propia.

El término de Gistaín mantiene una media de 3.039 cabezas de ovino en un número de explotaciones semejante al de Plan que tan sólo alcanza 1.707 cabezas en el período considerado lo que equivale a los efectivos de Plan y S.Juan de Plan (1.277 cabezas) juntos.

En algunos casos las explotaciones específicas de ganado ovino mantienen tambien un reducido número de cabras que consignamos aquí junto con los últimos datos del año 1.994, facilitados por la Sección de Estudios del Servicio Prov. de Agricultura, Ganadería y Montes de Huesca. Existen:

- En el término de Gistaín, 32 explotaciones especificas de ovino con 4.510 ovejas y 229 cabras y 9 explotaciones de cabras con 135 cabezas de esa cabaña y ninguna oveja.

- En el término de Plan, 26 explotaciones de ovino con 2.448 cabezas y 334 cabras y 11 explotaciones de caprino con 431 ejemplares y 141 ovejas.

- En el término de S. Juan de Plan, 26 explotaciones de ovino con 2.991 ovejas y 80 cabras y 2 explotaciones de caprino con 29 cabras y 2 ovejas.

La fecundidad es de 1,1 a 1,5 por oveja; esto es, cada 100 ovejas, se producen de 110 a 150 corderos al año Para reposición se guarda aproximadamente el $15 \%$ de los corderos nacidos, por lo que se venden 0,93 a 1,27 ternascos por hembra madura y año; la media se sitúa en torno a 1,1 ternascos año.

Dentro del conjunto de las explotaciones ganaderas extensivas, los ovinos constituyen el apartado de mayores gastos, sobre todo, los trashumantes de largo recorrido que han de soportar unas fuertes inversiones en el alquiler de los pastos de invierno y en algunos rebaños en la contrata- 
ción de pastor. Los gastos oscilan entre 3.500 Y 4.000 ptas. por oveja y año.

La falta de pastos de invernada donde poder dar cabida al ganado trashumante impone unos límites en su explotación contribuyendo igualmente a que se acelere la reducción de sus efectivos. Este es un proceso muy difícil de modificar si se tiene en cuenta que la evolución de la agricultura y los medios por ella empleados para su explotación favorecen el aumento de las superficies productivas.

Considerando que los pastos cada vez se hacen menos extensos y de calidades herbáceas inferiores y la lana ha decaído en su cotización y demanda ante el empuje de las fibras sintéticas, pocas razones apuestan a favor de estas explotaciones ganaderas donde los pastores escasean y son difíciles de contratar. 


\section{BIBLIOGRAFIA}

Camara AgRaria Local: "Superficies ocupadas por los Cultivos Agrícolas". Hojas 1.T. Años 1988, 1989, 1990.

Cámara Agraria Prov. del alto Aragón. Huesca: "Directorio de Explotaciones Agrarias". Años 1989, 1990, 1991 y 1992.

Cámara Agraria Prov. del alto aragón. Huesca: “Indemnización Compensatoria de Montaña». Años 1990, 1991, 1992 y 1993.

C.A.Z.A.R.: "Renta Municipal de Aragón». Años 1981 y 1985.

Diputación General de Aragón (D.G.A.): “Censo Ganadero». Años 1986 y 1989.

I.N.E.-D.G.A. (Acuerdo de colaboración): «Boletines Estadísticos de Defunciones". Años 1987, 1988, 1989, 1990, 1991 y 1992.

I.N.E.-D.G.A. (Acuerdo de colaboración): «Boletines Estadísticos de Parto». Años 1987, 1988, 1989, 1990, 1991 y 1992.

I.N.E.: "Censo Agrario de España 1982. Tomo IV. Resultados Comarcales y Municipales. Huesca". Madrid, 1984.

I.N.E.: “Censo Agrario de España 1989. Tomo IV. Resultados Comarcales y Municipales. Huesca». Madrid, 1991.

I.N.E.: “Censo de la Población de España». Años 1930, 1940, 1950, 1960, 1970, 1981 y 1991.

I.N.E.: «Padrón Municipal de Habitantes, prov. Huesca». Años 1975 y 1986.

I.N.E.: «Rectificación del Padrón Municipal de Habitantes prov. de Huesca». Años 1982, 1983, 1984, 1985, 1987, 1988, 1989, 1990, 1992 у 1993. 
I.N.E.M.: «Estadística de Paro Registrado por Municipios». Años 1984, 1985, 1986, 1987, 1988, 1989, 1990, 1991, 1992 у 1993.

instituto de Relaciones Agrarias y Cámaras Agrarias locales: "Censo de maquinaria en uso». Años 1989, 1990, 1991 y 1992.

ManRIQUe, E.; RevilLa, R. (1982): “Las técnicas de producción bovina en una zona de montaña. Valle de Gistaín (Huesca)". Anales de la Facultad de Veterinaria, 16-17. Zaragoza.

ManRiQue, E.; Revilla, R. (1983): «Factores condicionantes de la intensificación productiva en la explotación del vacuno en alta montaña". Instituto de Economia y Producciones Ganaderas del Ebro (C.S.I.C.), no 61.

Ministerio de Agricultura, Pesca y Alimentación (1982): "Mapa de Cultivos y Aprovechamientos. Esc. 1/200.000". Provincia de Huesca. Diciembre.

Romano, I. (1993): "Proyecto de I+D a nivel ganadero en el valle de Chistau mediante fórmulas asociativas al servicio de la mujer". Georgica, 2, Huesca.

Rubı, M. ${ }^{a}$ T. (1988): "Problemática actual de la población de Huesca". En Espacio, Tiempo y Forma, oㅜ 3. Geografía. UNED, pp. 195-216. Madrid.

RuBio, M. ${ }^{a}$ T. (1989): “Emigración y Cambio de Actividad en el Pirineo". En Espacio, Tiempo y Forma, Serie VI, Geografía, t. II, UNED, pp. 155168. Madrid.

Rubio, M. $\stackrel{a}{T}$ T. y Munuera GiL, P. (1979): “La propiedad pública, factor condicionante del desarrollo económico de los Altos Vailes pirenáicos oscenses". En Actas del VI Coloquio de Geógrafos españoles. AGE. Palma de Mallorca. 